\title{
Using a Results-Based Organization Design Methodology to Construct the Technology Innovation Management Review
}

by

Christopher Scott McPhee

A thesis submitted to the Faculty of Graduate and Postdoctoral Affairs in partial fulfillment of the requirements for the degree of

\author{
Master of Applied Science \\ in \\ Technology Innovation Management
}

Carleton University

Ottawa, Ontario

(C) 2012

Christopher Scott McPhee 
UMI Number: MR91502

All rights reserved

\section{INFORMATION TO ALL USERS}

The quality of this reproduction is dependent upon the quality of the copy submitted.

In the unlikely event that the author did not send a complete manuscript and there are missing pages, these will be noted. Also, if material had to be removed, a note will indicate the deletion.

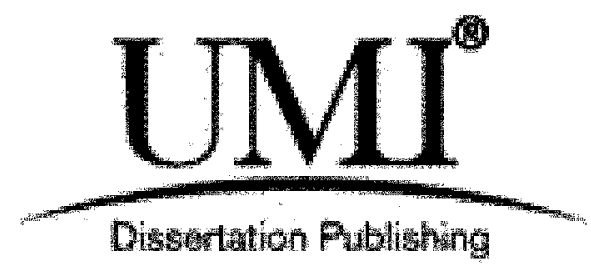

UMI MR91502

Published by ProQuest LLC 2013. Copyright in the Dissertation held by the Author. Microform Edition (C) ProQuest LLC.

All rights reserved. This work is protected against unauthorized copying under Title 17, United States Code.

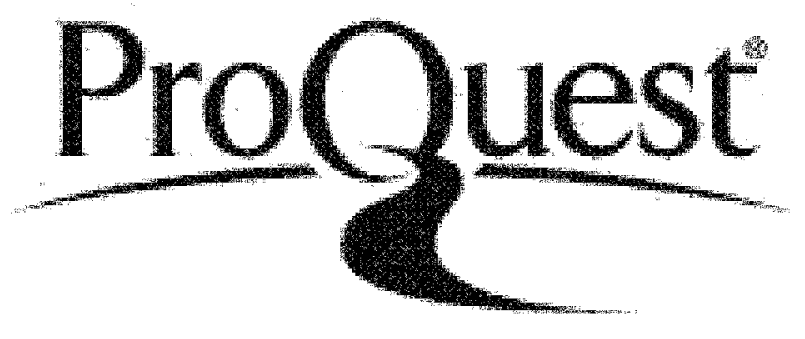

ProQuest LLC

789 East Eisenhower Parkway

P.O. Box 1346

Ann Arbor, MI 48106-1346 


\begin{abstract}
This research used a constructive methodology to design an organization using a combination of organization design and results-based management approaches. Drawing upon the business ecosystems literature and practical experience, design principles were used to guide the design of the organization that produces and disseminates the Technology Innovation Management Review, a journal concerned with the issues relating to launching and growing technology companies. A logic model links the organization's activities to outputs and expected outcomes across multiple time scales. An integrated performance management framework tracks the organization's progress toward those outcomes and provides a mechanism to continuously improve the organization by feeding these results into new cycles of ongoing redesign. The results from the first six months of the organization's operation provide lessons and action items that demonstrate the potential of this approach for broader application.
\end{abstract}




\section{Acknowledgements}

Constructive research of this nature depends on a lot of input from a lot of people. I would first like to thank the readers and authors of the Open Source Business Resource and Technology Innovation Management Review, not only for their contributions to these publications, but also for teaching me how to be a better editor. Thank you to Dru Lavigne for showing me the ropes, for sharing lessons learned, and for telling me the story of the OSBR. I am also very grateful for the advice and input from the Advisory Board and Review Board members of the OSBR and TIM Review.

Nathaniel Hudson, Frank Horsfall, and Ludovico Prattico provided essential development work and technical support for the TIM Review, along with David Ker and his staff at RealWat Inc. Coral CEA provided funding and development work for the prototype platform; special thanks go to Jorge Morales, Gerry Williams, Craik Pyke, Ian Bothwell, and Yu Shen.

This research received valuable support from Carleton University staff, especially in Computing and Communication Services, Media Relations, and the Department of Systems and Computer Engineering; special mentions go to Narendra Mehta for his ongoing help with the OSBR platform and server over many years, to Mike Milne for his timely help in getting the TIM Review website ready to launch, and to Lin Moody for helping promote the launch of the TIM Review. Roseann O'Reilly Runte (President of Carleton University), Rafik Groubran (Dean of the Faculty of Engineering), and Jerry Tomberlin (Dean of the Sprott School of Business) wrote me letters of congratulations on 
the launch of the TIM Review, which were published in its first issue; I am extremely grateful for this public show of support for the journal.

Thank you to Michael Weiss, Steven Muegge, and Jonathan Wells for teaching me how business ecosystems work, in theory and in practice. Thank you to my fellow TIM students for support, feedback, and shared suffering. Thank you to Kevin Goheen, David Hudson, and Tom Duxbury, who provided valuable feedback on this research as members of the TIM Research Council.

None of this would have been possible without Tony Bailetti, whose generosity of spirit is second to none. Tony, thank you for opening doors and making things happen. Thank you also for letting me take care of one of your favourite "children" - the OSBR - and for trusting me to turn it into the TIM Review.

Most of all, I would like to thank my family. Thank you to my wife, Erin, for her immeasurable support throughout a project that has been a tremendous amount of work, for both of us. Thank you also to my children, Fionn, Cormac, and Orla, who kept me laughing and always wondered when this "book" I was working on would be finished. 


\section{Table of Contents}

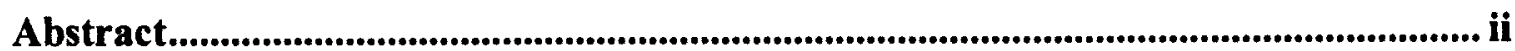

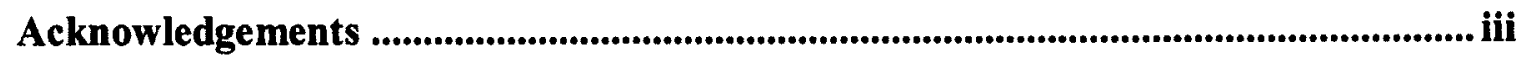

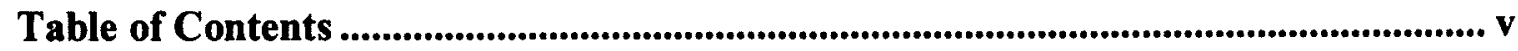

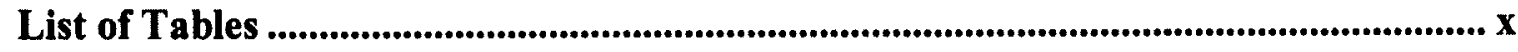

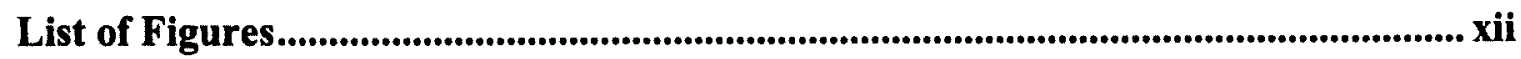

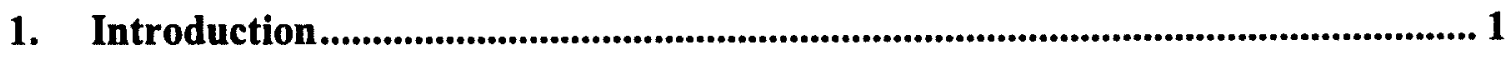

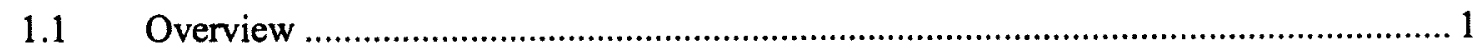

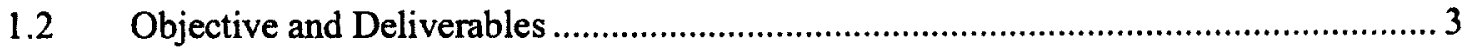

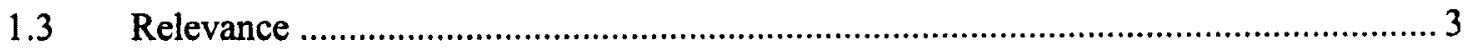

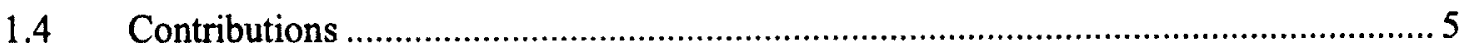

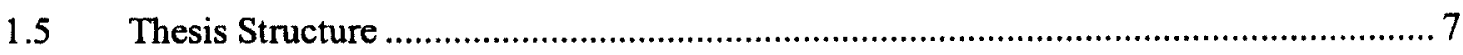

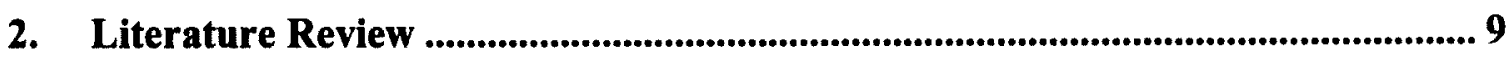

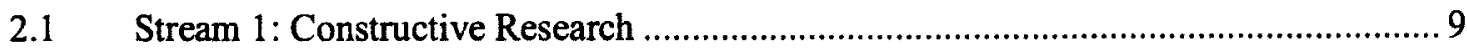

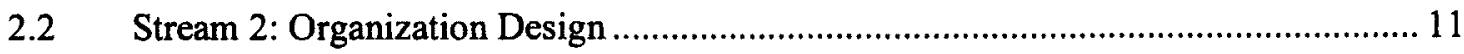

2.3 Stream 3: Results-Based Management ......................................................... 15

2.3.1 CIDA's Approach to Results-Based Management ............................................... 16

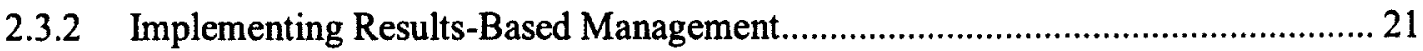

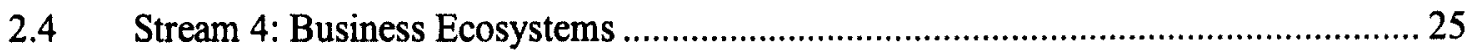

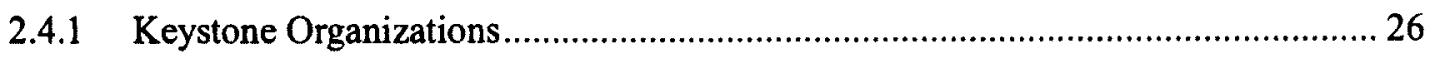

2.4.2 Multi-Sided Platforms and Value Propositions ............................................... 28

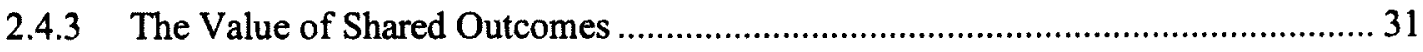

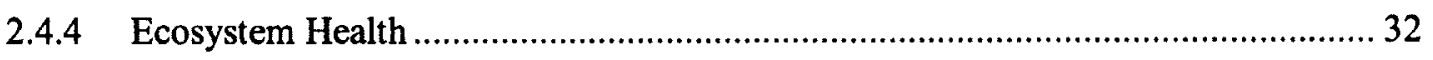

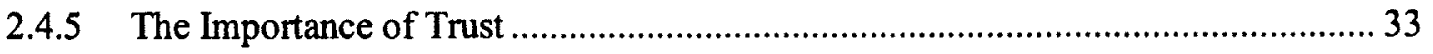

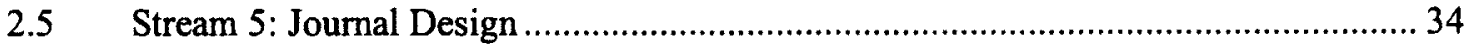




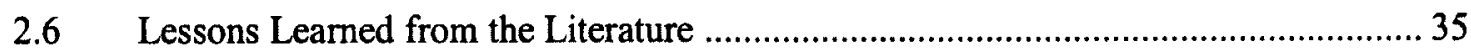

2.6.1 Lessons from Stream 1: Constructive Research............................................. 36

2.6.2 Lessons from Stream 2: Organization Design.................................................. 36

2.6.3 Lessons from Stream 3: Results-Based Management .......................................... 37

2.6.4 Lessons from Stream 4: Business Ecosystems ............................................... 40

2.6.5 Lessons from Stream 5: Journal Design .................................................. 42

3. Background and Lessons Learned from the Open Source Business Resource .. 44

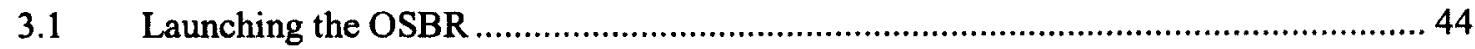

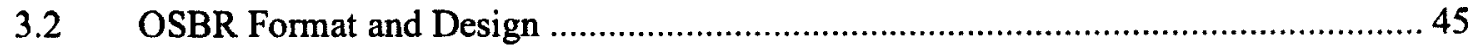

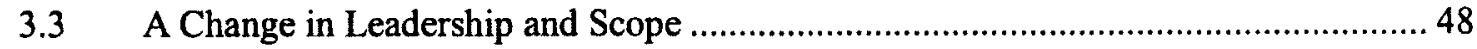

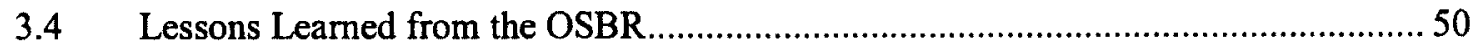

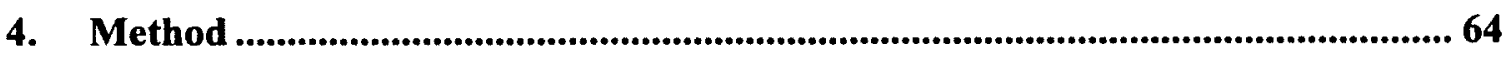

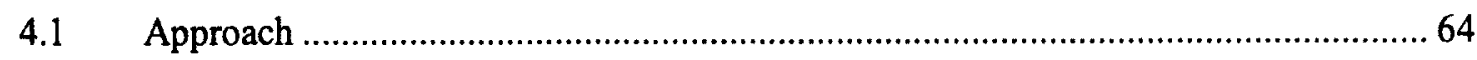

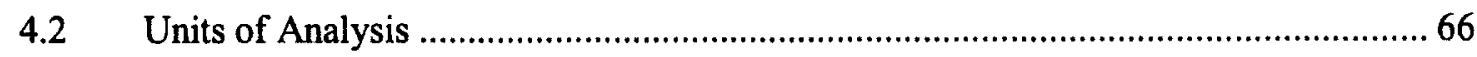

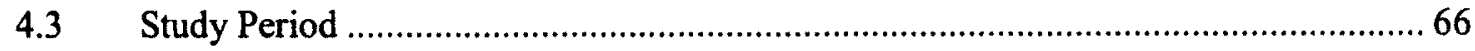

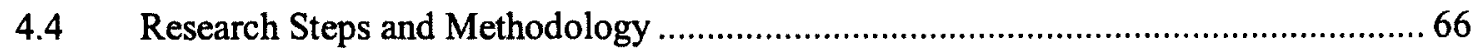

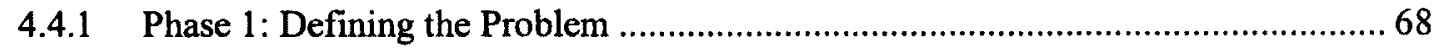

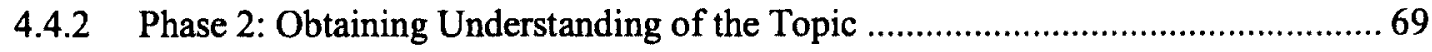

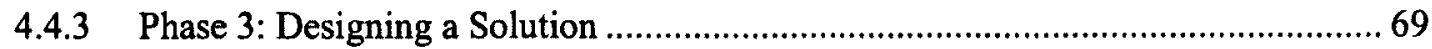

4.4.4 Phase 4: Implementing the Solution and Gathering Data .............................. 73

4.4.5 Phase 5: Showing Theoretical Connections and Research Contributions ............. 74

4.4.6 Phase 6: Examining the Scope of Applicability of the Solution ........................... 75

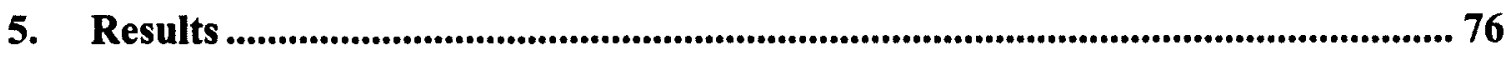

5.1 Design Principles Synthesized from Practice and Research....................................... 77

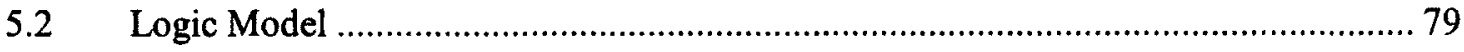




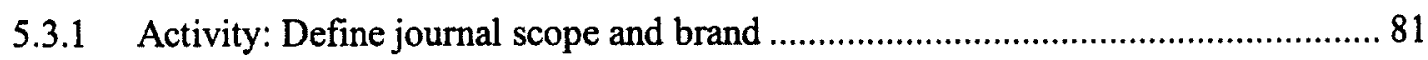

5.3.2 Activity: Gather feedback, define board mandate, recruit diverse board members .83

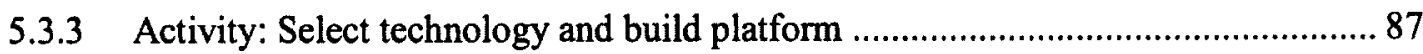

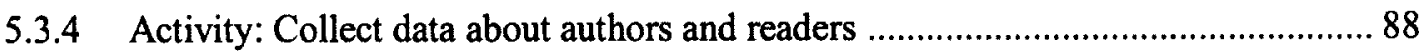

5.3.5 Activity: Engage with readers and authors to refine value propositions, suggest

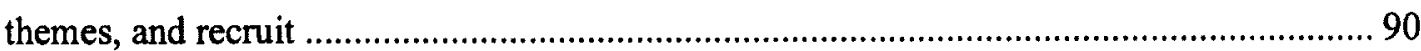

5.3.6 Activity: Recruit authors with expertise in new scope .................................. 91

5.3.7 Activity: Encourage others to recruit on organization's behalf ......................... 91

5.3.8 Activity: Encourage interaction between stakeholders .................................... 91

5.4 Performance Management Framework and Early Performance Data ........................ 92

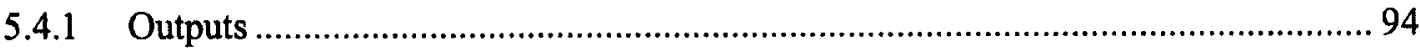

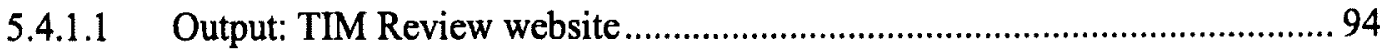

5.4.1.2 Output: Advisory Board composed of salient stakeholders .......................... 95

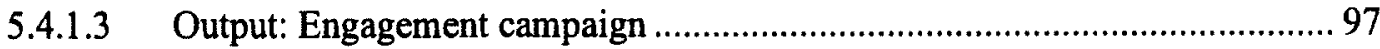

5.4.1.4 Output: Brand, including clearly identifiable niche................................... 98

5.4.1.5 Output: Published issues that match new scope ...................................... 99

5.4.1.6 Output: Author and reader database ................................................. 100

5.4.1.7 Output: Recruitment is a part of all mandates (board members and guest

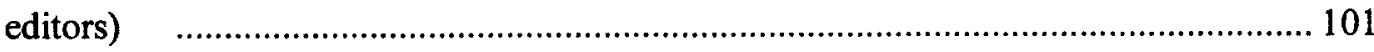

5.4.1.8 Output: Tools to promote engagement …............................................ 102

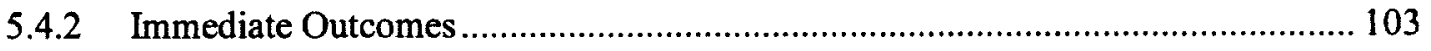

5.4.2.1 Immediate Outcome: Access to articles and awareness of new organization .. 103

5.4.2.2 Immediate Outcome: Greater input into themes, authors, and guest editors .... 107

5.4.2.3 Immediate Outcome: New readers, authors, and sponsors attracted ................ 108 
5.4.2.4 Immediate Outcome: Users attracted to articles that closely fit with new brand.....

5.4.2.5 Immediate Outcome: Increased awareness of diversity of readers and authors .......

5.4.2.6 Immediate Outcome: High levels of contribution and readership.

5.4.3 Intermediate Outcomes

5.4.3.1 Intermediate Outcome: Website referred by others as a destination for knowledge

5.4.3.2 Intermediate Outcome: Diverse authorship and readership in line with scope. 122 5.4.3.3 Intermediate Outcome: Self-sustaining growth of diverse contributions and readership 123

5.4.4 Ultimate Outcome 125

5.5 Lessons Learned From First Six Issues of the TIM Review. 126

5.5.1 Lessons Learned About the TIM Review 126

5.5.2 Lessons Learned About the Research Methodology 129

5.6 Refined Logic Model 133

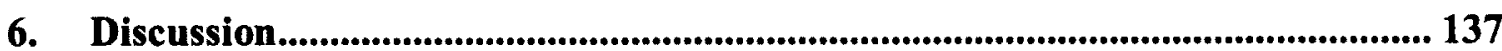

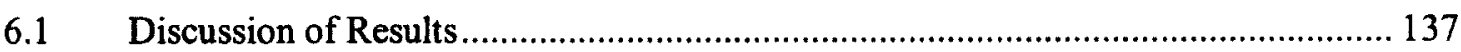

6.1.1 Applying Results-Based Organization Design to the TIM Review ..................... 137

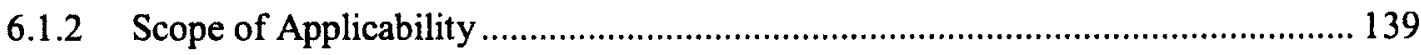

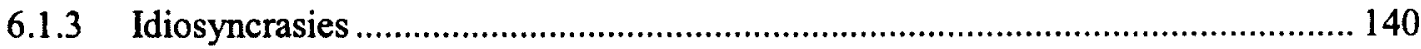

6.2 Theoretical Connections and Research Contribution .......................................... 143

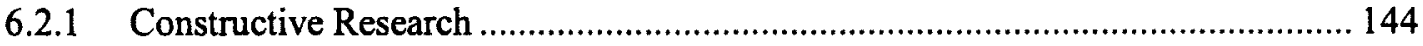

6.2.2 Organization Design and Results-Based Management ................................. 145

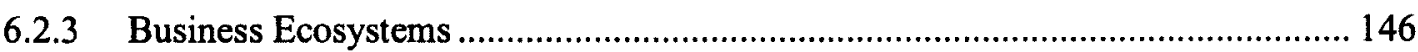

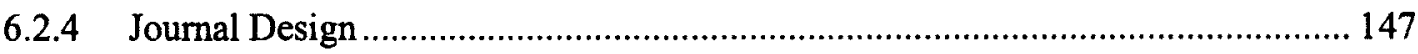


7. Conclusions, Limitations, and Future Research ................................................... 148

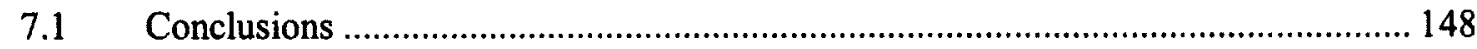

7.2 Limitations

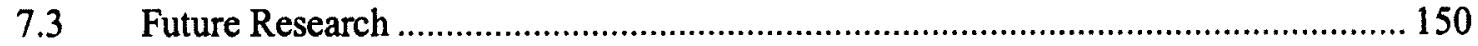

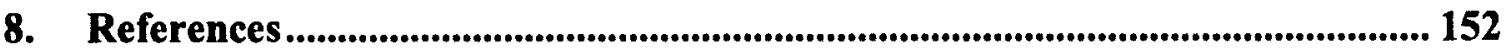




\section{List of Tables}

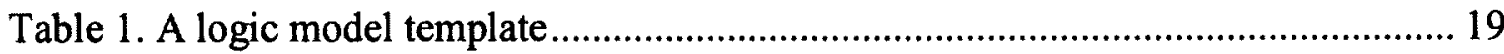

Table 2. A performance management framework template.............................................. 20

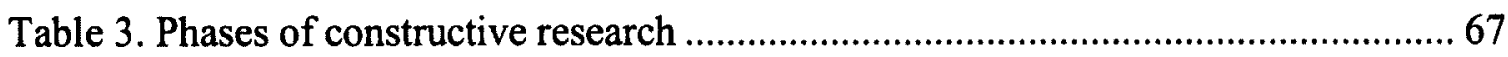

Table 4. Design principles derived from theory and practice ........................................... 78

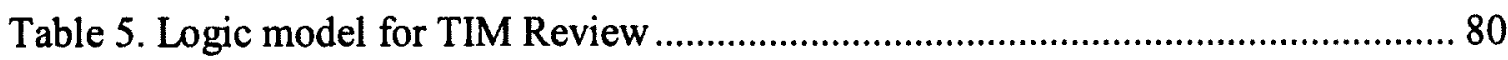

Table 6. Mandates of the TIM Review Advisory Board and Review Board..................... 85

Table 7. Data collected during account creation on TIM Review website ....................... 89

Table 8. PMF for Output: TIM Review website .............................................................. 94

Table 9. PMF for Output: Advisory Board composed of salient stakeholders................. 96

Table 10. PMF for Output: Engagement campaign ......................................................... 97

Table 11. PMF for Output: Brand, including clearly identifiable niche ........................... 98

Table 12. PMF for Output: Published issues that match new scope................................. 99

Table 13. PMF for Output: Author and reader database............................................... 101

Table 14. PMF for Output: Recruitment is a part of all mandates (board members and

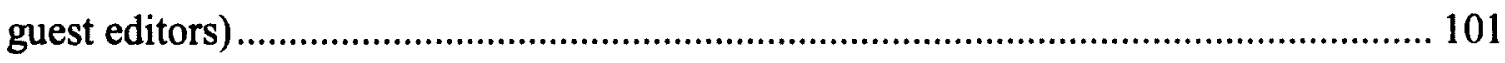

Table 15. PMF for Output: Tools to promote engagement............................................ 102

Table 16. PMF for Immediate Outcome: Access to articles and awareness of new

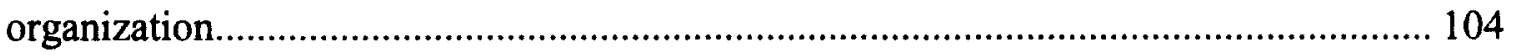

Table 17. PMF for Immediate Outcome: Greater input into themes, authors, and guest

editors. 107

Table 18. PMF for Immediate Outcome: New readers, authors, and sponsors attracted 108 
Table 19. PMF for Immediate Outcome: Users attracted to articles that closely fit with new brand

Table 20. Article popularity by topic based on percentage of views.

Table 21. PMF for Immediate Outcome: Increased awareness of diversity of readers and authors 114

Table 22. PMF for Immediate Outcome: High levels of contribution and readership ... 119 Table 23. PMF for Intermediate Outcome: Website referred by others as a destination for knowledge 121

Table 24. PMF for Intermediate Outcome: Diverse authorship and readership in line with scope 123

Table 25. PMF for Intermediate Outcome: Self-sustaining growth of diverse contributions and readership 124

Table 26. PMF for Ultimate Outcome 125

Table 27. Refined logic model for TIM Review. 135 


\section{List of Figures}

Figure 1. The organization design process .............................................................. 13

Figure 2. Conceptual links in a logic model ............................................................ 17

Figure 3. An architectural arch with its keystone highlighted ......................................... 27

Figure 4. OSBR author perspectives by sector .......................................................... 46

Figure 5. OSBR author perspectives by location........................................................ 47

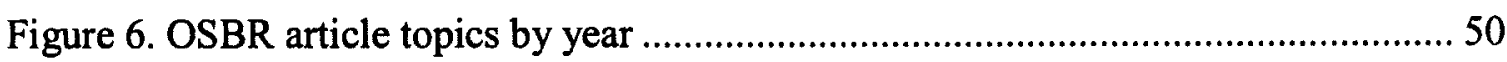

Figure 7. The results-based organization design approach ............................................. 71

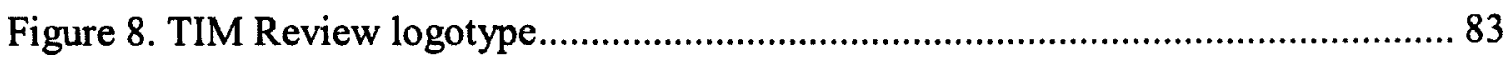

Figure 9. Cover of the first issue of the TIM Review: October 2011 .............................. 83

Figure 10. Unique visitors to TIM Review website, by week ........................................ 105

Figure 11. TIM Review author and reader perspectives by sector ................................ 115

Figure 12. TIM Review author and reader perspectives by role................................... 116

Figure 13. TIM Review author and reader perspectives by location .............................. 117 


\section{Introduction}

Chapter 1 is organized into five sections. Section 1.1 provides an overview of the research. Section 1.2 describes the objective and deliverables. Section 1.3 identifies the groups that will find this research relevant. Section 1.4 describes the contribution made by this research. Section 1.5 outlines the structure of the thesis.

\subsection{Overview}

Organizations may grow organically in response to internal or external demands, but that does not necessarily mean they are finely tuned to achieve particular outcomes. Even when organizations have well-defined objectives, there may not be a logical connection between the organization's structures, processes, and activities and any theoretical or practical understanding about the mechanisms by which the desired outcomes may be achieved. Organizations may be a result of happenstance as much as intention.

In this thesis, an organization design methodology is used to develop design principles based on scholarly knowledge and practice, which are then used to develop and implement the design of an organization following a constructive research approach. A logic model and performance measurement framework from the domain of results-based management are added to this organization design methodology to allow data about the resulting design to be collected and acted upon in a closed loop of continuous feedback and improvement. This new, combined methodology has been developed through the course of this research and I give it the title: "results-based organization design". 
The organization that is designed and implemented in this constructive research is the organization that produces and disseminates the Technology Innovation Management Review (TIM Review; http://timreview.ca). The TIM Review is a monthly journal that focuses on the issues and emerging trends that are relevant to launching and growing technology businesses. From 2007 to 2010, the journal was known as the Open Source Business Resource (OSBR) and focused on the issues relevant to the development and commercialization of open source assets. As a deliverable of this research, the OSBR was re-designed and re-launched as the TIM Review in October 2010. The research benefited from contributions both from theory and from the practical experience gained from four years of the Open Source Business Resource, the last year of which I acted as both researcher and practitioner in my role of Editor-in-Chief of the journal. My role as Editor-in-Chief extends throughout and beyond the timelines of the research described in this thesis.

My combined role of both researcher and practitioner makes this research unique. While it is now not uncommon for researchers to act as both observers and participants, this thesis describes a much closer relationship to the subject of the study. Research findings are not presented to the owner with recommendations; in this instance, the researcher is also the owner. Ownership implies unrestricted access and the ability to fundamentally shape the organization through this research. The result is a research methodology that is embedded into the design and informs the ongoing operation and management of the organization itself. 


\subsection{Objective and Deliverables}

The objective of this research is to design and construct an organization using a methodology that is grounded in both theory and practice, and which enables continuous improvement based on measured progress toward desired outcomes.

This research delivers:

1. An organization. A real-world organization will be constructed to produce and disseminate content about the growth of early-stage technology companies.

2. A closed-loop feedback framework. The research will deliver a system for a) measuring the performance of the organization against defined goals and $b$ ) effecting ongoing change to improve the organization's ability to deliver desired outcomes.

3. Lessons learned. Insights from the perspective of the "owner", which were gained from applying the research methodology to organization design in a specific context will be captured so that they can be shared with other researchers and practitioners, thereby informing future research and the construction of other organizations.

\subsection{Relevance}

This research is relevant to those designing keystone organizations in this domain or in other domains. While much is now known about the responsibilities and strategies of keystone organizations within business ecosystems (e.g., Bailetti, 2010a; Iansiti \& Levien, 2004a), there is little specific guidance available to those wishing to design such 
organizations to achieve specific outcomes. The research methodology and outcomes described here provide a means by which keystone owners can design and continuously improve their organizations to suit their particular contexts and desired outcomes by following principles that draw upon both the theoretical and practical knowledge from relevant domains.

Publishers of content in the knowledge economy will find this research relevant because it describes a novel approach to designing and improving an organization. Publishers seek novel business models, particularly with respect to academic journals, where lower publishing costs (both real and perceived) have paradoxically coincided with increased charges and have led to a "serials crisis" (Clarke \& Kingsley, 2008; Kling \& Callahan, 2003; Moghaddam, 2009). This methodology and lessons learned from this research may stimulate further business-model innovation among publishers.

This research is also relevant to researchers interested in organization design, resultsbased management, or business ecosystems. The resulting framework for designing and improving organizations can be applied to further constructive research or its outputs may stimulate further interesting questions to be answered through positive and grounded research. Researchers will also be interested in the potential for the feedback loop to contribute back to the theoretical body of knowledge in relevant domains.

This research is also relevant to practitioners who can apply a methodology that combines results-based management with a design approach that is based on both theory 
and lessons learned from practice. For the practitioner, this framework becomes a valuable tool to help solve real-world design problems.

This research is of strong practical relevance to the stakeholders of the organization that has been constructed. These stakeholders depend on the organization to deliver the desired outcomes defined through this research. The likelihood of achieving these outcomes is greatly impacted by the practical functioning of the solutions that were designed and implemented through this research.

Finally, this research is of practical relevance to the broader ecosystem that surrounds the Technology Innovation Management program at Carleton University. If this methodology can be shown to be sufficiently useful in its application within the TIM Review organization, there is a strong likelihood that other assets within the broader ecosystem will adopt it. It may become part of the ecosystem culture.

\subsection{Contributions}

This research makes a theoretical contribution to organization design science by demonstrating how the integration of a results-based management approach can help designers bridge the gap between existing knowledge and a new design solution. It adds a model to clarify the logical connections between what the design is meant to achieve, what activities will be undertaken to move toward the desired outcomes of the design solution, and what basis exists for the expectation that these activities can contribute to achieving those outcomes. Furthermore, the integration of a results-based management 
approach provides a clear performance-measurement mechanism for closing the feedback loop advocated by organization design, which increases the likelihood that the ongoing functioning of a design solution will yield useful insights that can be fed back into the theoretical domain from which the design solution arose.

An important practical contribution of this combined approach is that it provides a method for the owner of an organization to act to improve the organization's performance on an ongoing basis, not just measure it.

This combined framework, which I have titled "results-based organization design", can be applied in other real-world constructions and the lessons learned from the application of the framework in this research may stimulate further research questions for others to investigate.

This research also provides a unique example of the application of organization design approach to the construction of a business ecosystem keystone organization. I am not aware of other studies that have taken a similar approach to designing and constructing a keystone organization generally, nor specifically in relation to the context of publishing content. Thus, this research makes a further contribution by beginning to address the gap in the literature relating to designing and improving an organization that produces and delivers content. 
This research makes a practical contribution by combining organization design with results-based management. This combination also makes the methodology appealing as a practical tool that can be used by researchers and practitioners alike. By making organization design methodology more accessible, this research bridges the gap between practice and theory, as well as the gaps between: i) practitioners and theory; ii) theoreticians and practice; and iii) between practitioners and theoreticians.

Finally, this research makes a tangible contribution beyond academia through the establishment of the TIM Review keystone organization. Not only does the research deliver an organization, which is a unique contribution on its own, but it delivers an organization in which the research methodology is embedded. As an embedded framework, this research increases the likelihood that the TIM Review will deliver its desired outcomes and provides the organization with a framework for continual improvement that is grounded in theory and informed by practice.

\subsection{Thesis Structure}

This thesis is organized into seven chapters. Chapter 1 introduces the thesis. In Chapter 2, the relevant literature is reviewed and the lessons learned are summarized. Chapter 3 provides background information on the OSBR, including lessons learned during its four years of operation. Chapter 4 details the research methodology, in which the results-based organization design approach is developed. Chapter 5 describes the results of the research, including the implementation of the design, launch of the TIM Review, and insights and data from the publication of its first six issues. Chapter 6 discusses the 
research results. Chapter 7 describes the limitations of the research, identifies opportunities for further research, and provides conclusions. 


\section{Literature Review}

Chapter 2 reviews the literature streams that are relevant to this research. The chapter is organized into six sections. The first five sections review the literature related to the domains of: i) constructive research; ii) organization design; iii) results-based management; iv) business ecosystems; and v) journal design. The final section, Section 2.6, summarizes lessons learned from the review of the five literature streams.

\subsection{Stream 1: Constructive Research}

A constructive approach is the use of "managerial problem solving through the construction of models, diagrams, plans, organizations, etc." (Kasanen, Lukka, \& Siitonen, 1993). The key difference between simply "building something" or "solving a problem" and performing constructive research is that the latter is grounded in theory and contributes back to the knowledge of the domain. In constructive research, theory and practice cannot be separated (Mir \& Watson, 2000).

Kasanen, Lukka, and Siitonen (1993) identify four essential elements of constructive research:

1. Practical relevance: the solution must be relevant to the real-world problem it is intended to solve. Related to this element, the solution must also be innovative; if the solution is not new, it will provide little value to the owner of the problem.

2. Practical functioning: it must be possible for the solution to be adopted and implemented into existing, real-world organization processes, cultures, etc. 
3. Theoretical connection: the problem and its solution must be tied to the accumulated theoretical knowledge in relevant domains.

4. Theoretical contribution: beyond being grounded in theory, the research must also make its own contribution to theory.

The practical usefulness of a solution developed using a constructive approach is the primary criterion upon which the results of constructive research should be measured (Kasanen et al., 1993). However, when viewed as "products competing in the market of solution ideas", Kasanen and colleagues (1993) assert that constructive research can be subject to the following market tests, which provide evidence of their usefulness:

1. Weak market test: this test is passed when a manager responsible for financial results is willing to implement the solution in their business.

2. Semi-strong market test: this test is passed when the solution is adopted widely by companies.

3. Strong market test: this test is passed when the solution has been demonstrated to deliver systematically better financial results.

Compared with other research approaches, constructive research has the advantage of simultaneously contributing to a body of knowledge while also providing a direct solution to a real-world problem. This is in contrast to a positive approach (i.e., where the research develops a theory with testable hypotheses and then test those hypotheses) and a grounded approach (i.e., where the researcher performs exploratory research to build theory by closely observing real data). However, while the direct goals of constructive 
research are neither to test hypotheses nor generate theory, hypotheses may be suggested through the experiences of the construction.

Constructive research has six phases (Kasanen et al., 1993):

1. Find a practically relevant problem which also has research potential.

2. Obtain a general and comprehensive understanding of the topic.

3. Innovate (i.e., construct a solution idea).

4. Demonstrate that the solution works.

5. Show the theoretical connections and the research contribution of the solution concept.

6. Examine the scope of applicability of the solution.

\subsection{Stream 2: Organization Design}

Researchers in the field of organization design seek to better understand the functions and processes of organizations and how they can be improved. A design perspective implies that organizations can be deliberately constructed (or changed) through research and are not simply the subjects of passive observation or theoretical models. In practice, organizations do not emerge fully formed from the ether, and while they may grow organically in response to internal and external demands, their creators often engage in a some degree of design process before and after their construction. What separates the practical activity of "designing organizations" from the research activity of "organization design" is that the latter is grounded in theory, which should improve the chances that the resulting organization will deliver the outcomes desired by its designer. 
The importance of the link between theory and practice in organization design was recognized by Georges Romme and colleagues, who developed a cyclical approach to designing and improving organizations based on a set of design principles. Design principles are sets of propositions that are grounded in theory and practice, that is, they draw upon lessons learned from both practical experience and from academic literature (Van Burg, Romme, Gilsing, \& Reymen, 2008; Romme \& Endenburg, 2006). Design principles inform subsequent design and implementation steps in the process originally proposed by Romme and Endenburg (2006), which they called "science-based organization design". Figure 1 illustrates the steps in this design process. These steps are:

1. Gather lessons from theory and practice. This step captures what is known about subjects relevant to the design task, including both practical experience and academic literature.

2. Formulate design principles (also known as construction principles). This step synthesizes the lessons from theory and practice into a set of propositions that provide a guiding light in the design process. Design principles are sufficiently general that they could be used by others faced with similar design challenges.

3. Formulate design rules. This step develops guidelines that are grounded in one or more design principles and are specific to the design context. Design rules are solution-oriented and make a logical connection between the focus of a given design activity and its expected outcome.

4. Design the organization. This step applies the design rules into the development of a specification for the intended organization. 
5. Implement the design. This step applies the design to the actual construction of the new organization.

6. Observe the new organization. This step determines how well the organization works. Based on observations (and possibly experiments as well), new ideas for improving the design may be generated. These ideas should be used to alter any or all of the previous steps through a redesign process. Thus, these steps do not describe a linear process, but rather form a closed-loop feedback system through which continuous improvements can be made.

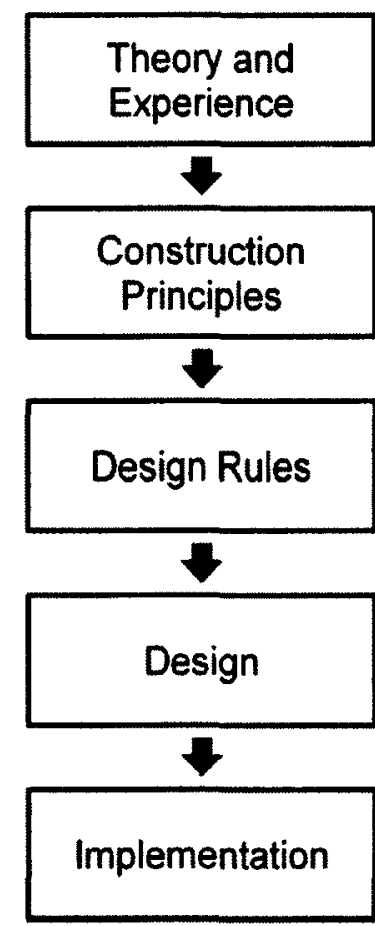

Figure 1. The organization design process

The formulation of design principles involves the synthesis of practical and theoretical knowledge; in fact, van Burg and colleagues (2008) advocate the development of two sets 
of principles (practice-based principles and research-based principles), which the researcher then synthesizes into design principles. In addition to these deliberate design steps, van Burg and colleagues (2008) also argue that researchers should make room for emergent design processes, particularly in the early stages of a design exercise. Thus, despite the important role that design principles can play in keeping a design process on track and driving improvements to it, not all design activities are the result of deliberate processes.

Eisenhardt and Sull (2001) argued that organizations benefit strategically by defining and implementing "a few straightforward, hard-and-fast rules that define direction without confining it." This statement could equally apply to organization design, where a good design rule will "contain information on what to do, in which situations, to produce what effect and offer some understanding of why this happens" (Denyer, Tranfield, \& van Aken, 2008). In this way, organization design is proactive, not reactive; once equipped with sufficient practical and theoretical knowledge about the relevant domains, designers can develop construction principles and design rules to increase the likelihood of a successful design compared with processes that depend on mere instinct or ungrounded notions.

When grounded in theory and practice, design principles, and the design rules that follow on from them, build a logical connection between individual aspects of a design and the outcomes they are intended to produce. Denyer, Tranfield, and van Aken (2008) advocate a "CIMO-logic" approach to the development of context-dependent design propositions 
(or rules), which are developed following this pattern: "in this class of problematic Contexts, use this Intervention type to invoke these generative Mechanisms(s), to these Outcome(s)." This prescriptive approach is of considerable help to organization designers because it provides them with a template to construct design rules that are built upon logic, that is, they can be reasonably expected to deliver the intended results.

In summary, the organization design process described above includes three important elements: i) grounding in both theory and practice; ii) logical connections between design elements and desired outcomes; and iii) a mechanism for ongoing improvement to the design. However, this overall process does not include specific guidance on how to relate design elements to outcomes on different timescales. Also, while emphasis is placed on the development of construction principles and design rules in the early stages of the process, I have found little practical guidance on how the feedback loop should be closed once the design has been realized (i.e., what data should be collected and how it should be used).

\subsection{Stream 3: Results-Based Management}

Managers often face the challenge of connecting what their organization is doing "on the ground" today with the broad-scale outcomes they ultimately hope to achieve. In some cases, the desired outcomes may be vague, poorly articulated, or disconnected from the actual activities the organization undertakes; in other cases, the outcomes may be undefined or not shared by all stakeholders. Furthermore, the ultimate outcome desired by an organization may require long-term commitment, and it may be difficult to know 
whether current, short-term activities are producing results that will lead the organization efficiently toward those outcomes. An approach that is ideally suited to such situations is "results-based management", which provides a set of working tools that allow managers to evaluate the performance of initiatives against defined outcomes.

Although results-based management can be applied in many different situations, it is common in the public sector and the third sector. It is especially common in international development contexts, where long-term development objectives, such as improving health in a particular region, are difficult to connect with the actual activities undertaken, such as providing health education services to individual communities within that region.

In this section, literature related to results-based management is reviewed. Section 2.3.1 describes a prominent example of a results-based management approach to introduce the general concepts and benefits of the approach. Section 2.3.2 describes key implementation challenges.

\subsubsection{CIDA's Approach to Results-Based Management}

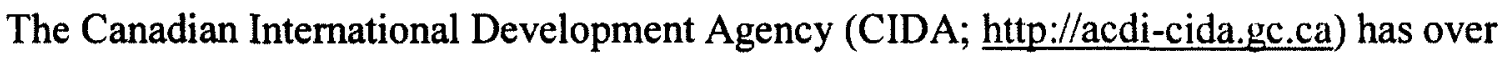
30 years of experience refining its results-based management approach, which it uses to better manage its international development projects and investments. In this context, results-based management improves decision making, transparency, and accountability (CIDA, 2008). 
At the core of CIDA's approach is the logic model, which is a common feature of resultsbased management. The logic model is "a depiction of the causal or logical relationships between inputs, activities, outputs, and the outcomes of a given policy, program or investment" (CIDA, 2008), as shown in Figure 2.

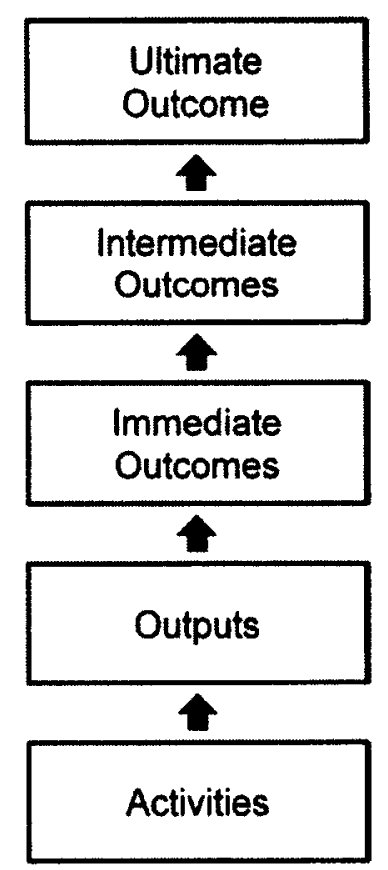

Figure 2. Conceptual links in a logic model

CIDA's descriptions of these components are summarized below:

1. Ultimate outcome. This is the long-term objective - the top-level, measureable change that the initiative is designed to effect. This component answers the question: "Why are we doing this?"

2. Intermediate outcomes. These are medium-term objectives that are expected to logically follow on from the achievement of the immediate outcomes.

Intermediate outcomes are usually associated with changes in behaviour or practices, and they must be measurable. 
3. Immediate outcomes. These are short-term objectives that are the direct result of the outputs of activities. Immediate outcomes are usually associated with increased awareness, skills, or access, and they must be measurable.

4. Outputs. These are the measurable products of activities.

5. Activities. These are the actual items of work undertaken to produce outputs.

6. Inputs. These are the financial, human, material, and information resources available to undertake activities. In CIDA's framework, including this component in the logic model is optional, although they obviously are still required to carry out the specified activities.

The format of the logic model is a table that lists the activities and outputs and the immediate, intermediate, and ultimate outcomes of an initiative (see Table 1). Cells near the top of the table may be merged with adjacent cells in the same row to indicate outcomes that are a product of multiple activities and outputs. Ideally, managers complete the logic model with input from stakeholders, which helps develop a complete and shared view of an initiative and its direction. The table may be completed from the top-down or the bottom-up, depending on the situation, but the essential aspect is the logical connection between each related component, which creates a vertical chain of results. 
Table 1. A logic model template

\begin{tabular}{|l|l|l|l|l|}
\hline $\begin{array}{l}\text { Ultimate } \\
\text { Outcome }\end{array}$ & \multicolumn{4}{|l|}{} \\
\hline $\begin{array}{l}\text { Intermediate } \\
\text { Outcomes }\end{array}$ & \multicolumn{2}{|l|}{} \\
\hline $\begin{array}{l}\text { Immediate } \\
\text { Outcomes }\end{array}$ & & & & \\
\hline Outputs & & & & \\
\hline Activities & & & & \\
\hline
\end{tabular}

The logic model is intrinsically linked to a second working tool: the performance measurement framework. The performance management framework uses the outcomes defined in the logic model to establish "a structured plan for the collection and analysis of performance information" (CIDA, 2008). This framework documents the major elements of the monitoring system, including performance indicators, baseline data, specified targets, and data sources. It also specifies whose responsibility it is to collect the data, how frequently it is to be collected, and how it will be collected (Table 2). 
Table 2. A performance management framework template

\begin{tabular}{|c|c|c|c|c|c|c|c|}
\hline $\begin{array}{l}\text { Expected } \\
\text { Results }\end{array}$ & Indicators & $\begin{array}{l}\text { Baseline } \\
\text { Data }\end{array}$ & Targets & $\begin{array}{l}\text { Data } \\
\text { Sources }\end{array}$ & $\begin{array}{l}\text { Collection } \\
\text { Methods }\end{array}$ & Frequency & Responsibility \\
\hline \multicolumn{8}{|l|}{$\begin{array}{l}\text { Ultimate } \\
\text { Outcome }\end{array}$} \\
\hline \multirow{2}{*}{\multicolumn{8}{|c|}{$\begin{array}{l}\text { Intermediate } \\
\text { Outcomes }\end{array}$}} \\
\hline & & & & & & & \\
\hline & & & & & & & \\
\hline \multirow{2}{*}{\multicolumn{8}{|c|}{ Immediate }} \\
\hline & & & & & & & \\
\hline & & & & & & & \\
\hline & & & & & & & \\
\hline \multicolumn{8}{|l|}{ Outputs } \\
\hline & & & & & & & \\
\hline & & & & & & & \\
\hline & & & & & & & \\
\hline
\end{tabular}

The logic model and performance management framework are used together to: i) define the logical relationships between what the initiative is meant to achieve and what activities are actually being done to work towards those outcomes and ii) monitor progress toward those outcomes, ensuring that the initiative will actually deliver what it was designed to achieve.

The logic model and performance measurement framework are two of the three main working tools CIDA has developed to facilitate its results-based management approach. The third tool is a risk register that is used to list risks and response strategies. The risk register is not discussed in detail here, but is used when a systematic approach to risk management is considered essential. 
CIDA's long history of using results-based management techniques means that its model it well developed, but it is not the only form of results-based management. In particular, the logic model component is a common feature of other approaches to results-based management, and there are numerous variants of the logic model approach described earlier. Examples of variations include the inclusion of assumptions, a requirement to include details required inputs/resources, and outcomes that focus more on timescales than dependencies on the achievement of earlier outcomes. For the research described in this thesis, the CIDA results-based management model was selected because: i) it is well developed and includes both a logic model and performance management framework; ii) CIDA provides detailed documentation; and iii) this particular approach was an area of active study and practice in the TIM program during the course of this thesis.

\subsubsection{Implementing Results-Based Management}

Clark and Swain (2005) argue that result-based management is a good idea that has been overused and applied in situations where it is not appropriate, especially in government contexts. Shacter (2007), a defender of results-based management, argues that the merits of the method should not be disregarded based on its misapplications.

Clark and Swain (2005) list several challenges in performance measurement and performance management, which they suggest make it unsuitable for use in the public sector: 
- These methods are best suited to "repetitive industrial activities with simple production functions and direct, unambiguous results". An example would be sorting mail.

- The most politically important objectives are impossible to measure.

- Key results may be beyond the control of the management team.

- The methods lack objectivity; measures are "subjective and value-laden".

- A focus on targets overemphasizes quantitative results.

- Design and administration costs are high.

Mayne (2007) and the Office of the Auditor General of Canada (2000) emphasize how to overcome the challenges of results-based management. Examples include: promoting favorable implementation conditions, setting realistic expectations, knowing the costs of measuring, overcoming the attribution problem, using a manageable number of indicators, using indicators that are most important not easiest to measure, developing measurement capacity, and overcoming the unique challenges of results-based management in the public sector. Although the details are beyond the scope of this review, several of the references cited in this section include detailed advice on implementing results-based management and overcoming its challenges and many more resources are readily available.

Perhaps the most important criticism of results-based management is its potential to become "a bureaucratic process in itself" (Ortiz, Kuyama, Münch, \& Tang, 2004). Thus, successful implementation of results-based management requires not only commitment 
from all stakeholders, it also requires diligence to ensure that all activities associated with the process are on track to deliver the desired outcomes. The bureaucratic risks also underscore the need to focus on the essential elements and omit aspects that do not add incremental value.

The Treasury Board Secretariat has developed a management accountability framework, which is used to assess managerial performance and best practices (Treasury Board Secretariat, 2011). While the management accountability framework is used to assess and support the accountability of managers, the performance of the management accountability framework itself is assessed using a results-based management approach (PricewaterhouseCoopers LLP \& Interis Consulting Inc., 2009). The Treasury Board Secretariat (2001) includes evaluations as part of its Results-Based Management and Accountability Framework to "bring about improvements to facilitate the achievement of outcomes or to determine the degree to which the policy, program, or initiative led to the achievement of desired outcomes." These evaluations typically occur at two points: i) formative evaluations occur in the very early stages, when the focus is on implementation issues and identifying whether adjustments are required and ii) summative evaluations occur "after a policy, program, or initiative has been in place long enough to expect that some outcomes may have been achieved", and here the focus is on the degree to which the outcomes have been achieved (Treasury Board Secretariat, 2001). Although longterm projects may require more evaluations and short-term projects may require only one evaluation, and the presence of evaluations does not preclude other types of adjustments mid-stream, this approach to results-based management puts a greater emphasis on 
performance reporting and measurement than on performance management; the latter term implies that continual adjustments are made in real-time.

It is one thing to measure performance on an ongoing basis; it is another to act on it on an ongoing basis. CIDA (2000) emphasizes iteration and flexibility should be built into a project "to allow for the adjusting of strategies midstream to ensure development results are achieved." The Treasury Board Secretariat (2001) describes performance measurement as an iterative process where measurement activities should evolve over time, thereby "enhancing the telling of the performance story". The question remains to what extent results-based management can be implemented in such as way that it manages based on results, rather than simply "telling the performance story".

While the suitability of results-based management in the public sector (where it is in regular use) is open to debate, perhaps a more important question relates to the types of initiatives where it is applied and where it may not be appropriate. Clark and Swain (2005) note that: "The difficulty arises when attempts are made to apply them to unique, creative, or highly discretionary activities, or to activities that are causally distant from the desired outcomes." They also note that "performance measurement systems are best suited to repetitive industrial activities with simple production functions and direct, unambiguous outcomes". In a similar vein, the observations by The J.W. McConnell Family Foundation suggest that logic models should not be considered static instruments; they should be expected to change and evolve over time, including starting over from scratch when required (Gamble, 2008). However, this advice is tempered by the 
acknowledgement that logic models are "implicitly linear" and therefore contain "but one path forward" (Gamble, 2008), which calls into question their suitability when innovation through rapid iteration and non-linearity is an objective.

Finally, the literature stresses that results-based management takes time to implement, but even more time is required for the benefits to be realized (and for the outcomes to be achieved). In the public sector, timescales of several years are reported (e.g., Mayne, 2007; Office of the Auditor General of Canada, 2000), although the timescales undoubtedly vary based on the context, implementation details, and progress toward outcomes. On the short end of the timescales, it may not be worth the effort of implementing results-based management if the desired outcomes are likely to be achieved within a matter of months.

\subsection{Stream 4: Business Ecosystems}

The framework of the biological ecosystem concept was first applied to the technology management field by Moore (1993) when he introduced the term "business ecosystem" in his article "Predators and Prey: A New Ecology of Competition". Moore used this new term to describe an economic community of organizations that co-evolved their capabilities around a particular innovation and work cooperatively to meet the needs of customers.

Moore's definition was been expanded by Bailetti (2010b) who, writing in the OSBR, described a business ecosystem as "a community of companies, organizations and 
individuals that: i) share a desire for achieving high-impact, system-level results; ii) deliver benefit to their customers, partners and community members from their interactions using a multi-sided platform; and iii) contribute to maintaining the health of their community." In this section, the literature underlying these aspects (and related concepts) will be reviewed.

Section 2.4.1 describes keystone organizations, which play the role of platform owner in business ecosystems. Section 2.4.2 provides an overview of multi-sided platforms as they relate to business ecosystems, including the development of unique value propositions for different groups in a business ecosystem. Section 2.4.3 explores the value of shared outcomes and collective action. Section 2.4.4 reviews the concept of ecosystem health. Section 2.4 .5 emphasizes the importance of trust in a business ecosystem.

\subsubsection{Keystone Organizations}

In an architectural arch, the wedge-shaped piece of stone in the centre is called the keystone (Figure 3). It is literally the "key stone" since it is regarded as holding all the other stones in place and the arch would collapse if it were removed. Although most arches would collapse upon the removal of any of the other stones, the keystone is usually the final stone put in place during construction and is required to realize the structural integrity of the arch. Accordingly, in addition to its central physical position in the arch, it has been given a symbolic position of disproportionate importance in relation to the other stones. 


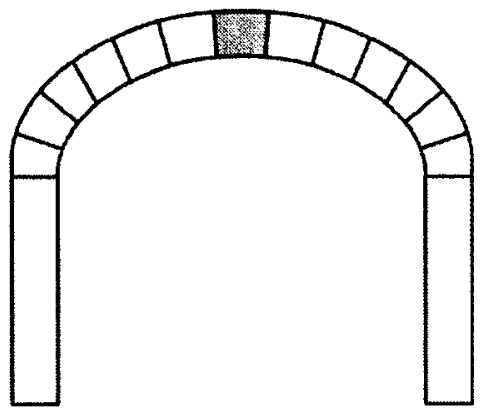

Figure 3. An architectural arch with its keystone highlighted

Image credit: Mats Hulldin Cosau, and MathKnigh!, licensed under Creative Commons BY

The strong symbolism of the keystone has lead to the term being applied to other situations and systems where one element exerts disproportionate influence over the other elements and therefore plays a role in maintaining the integrity of the system. In particular, the term has been adopted in the biology literature using the concept of a keystone species in an ecosystem or community (R. T. Paine, 1969; Power et al., 1996). In turn, the concept and its related research have been applied to the technology management literature where, instead of a keystone species, a particular organization or company plays the role of a keystone in a business ecosystem.

Although Moore (1993) described the role of "central ecological contributors", who exert great influence within the ecosystem and upon whom other members depend upon for their survival, he did not call this a keystone. As a central contributor, the ecosystem member is able to appropriate a disproportionate amount of value through their disproportionate contributions to the ecosystem and therefore this is not strictly analogous to the keystone species concept. Instead, it was Iansiti and Levien (2002, 2004a, 2004b, 2004c) who extended the business ecosystem concept and suggested that 
the keystone species concept in biological ecosystems can be usefully applied to business ecosystems. In particular, through their book The Keystone Advantage, Iansiti and Levien (2004a) popularized the concept of a strategically minded keystone organization:

"keystone strategies shape and coordinate the ecosystem, largely by the dissemination of platforms that form a foundation for ecosystem innovation and operations."

Iansiti and Levien studied literature on networks and complex systems and discovered that much of this literature suggested that it is common for "key players" or "network hubs" to emerge naturally in a wide variety of networks.

Among the roles played by a keystone organization, Bailetti (2010b) emphasized that keystones should:

- provide vision, leadership, and governance

- define member classes and an associated price structure

- set prices for transactions among members

- maintain the health of the ecosystem

- recruit new members and extend the ecosystem's reach

- set the ecosystem's intellectual property regime

- provides information that members value but cannot find on their own

- create new niches where members can add and extract value

\subsubsection{Multi-Sided Platforms and Value Propositions}

Moore's $(1993,2006)$ definition of a business ecosystem included companies coevolving around a particular innovation, with leadership in place to provide vision, 
guidance, and governance. Refinements of this original definition have emphasized the importance of the keystone organization creating value through the provision or support of a platform. Iansiti and Levien (2004c) define a platform as "an asset in the form of services, tools, or technologies that offers solutions to others in the ecosystem". Bailetti (2010b)(Bailetti, 2010b) extends this definition to emphasize the role the platform plays in anchoring the ecosystem. He defines a platform as a "product, process, location, service or technology" that is owned, operated, and evolved by the keystone to not only deliver value to the members of the ecosystem, but to act as a magnet to attract a diverse membership that provides further value to ecosystem members. By its actions and through its platform, the keystone carries out its two main responsibilities, which Bailetti identifies as increasing the "volume of transactions among members and efficiency of new product or service creation."

A key aspect of platforms is that they may attract different types of individuals and groups for different reasons. The various players in a business ecosystem "can be organized into member classes based on the value they derive from the platform" (2010b). For example, we can view an academic journal as a platform that attracts two obvious member classes: authors and readers. Each of these groups derives a different type of value from the journal; authors use the journal as a way to share their work and add to their publication portfolio, whereas readers use the journal as a source of knowledge. However, a journal has more than two sides. Consider advertisers, who derive value from the journal through "access to eyeballs", that is, exposure of their marketing messages to the journal subscribers, who are potential customers. 
The example above illustrates another important aspect of platform value. As the number of any one member class increases, the value to the other member classes also increases. For example, the value of the journal as a platform for advertisers increases in proportion to the number of eyeballs (readers). Similarly, the value of the journal to authors also increases along with readership since authors benefit from increasing exposure and credibility. This phenomenon, whereby the value to one group increase with the number of members in the other groups, is known as a "network effect". To attract members to its platform, the keystone organization must deliver value to each of the member classes and maximize any potential network effects.

To realize the potential power of a platform to act as a magnet that attracts members requires the keystone to develop unique value propositions for each member class that participates in the platform (Bailetti, 2010b). A value proposition describes the compelling points of difference in an organization's offering that will resonate with customers or partners (Anderson, Narus, \& Van Rossum, 2006). In a simple customersupplier relationship, the supplier can focus on the key benefits that will deliver value to specific customers or groups of customers. In a business ecosystem, different groups are attracted to the platform for different reasons; therefore, unique value propositions must be developed for each member class.

Value propositions developed for member classes may not fit the usual supplier-customer relationship described earlier. In some cases, members may function more like stakeholders than customers because ecosystem members have a greater interest in the 
performance of the ecosystem and the keystone. The keystone organization must identify the salient stakeholders and deliver value to these groups in particular. Jones, Felps, and Bigley (2007) provide insights into stakeholder saliency that are relevant here. They identify salient stakeholders as those with power (i.e., "the ability of the stakeholder group to bring about outcomes that it desires, despite resistance"), legitimacy (i.e., "the extent to which the stakeholder group's relationship with the firm is socially accepted and expected"), and urgency (i.e., "the degree to which the stakeholder group's claim is time sensitive and of critical importance to the group").

\subsubsection{The Value of Shared Outcomes}

Although members of business ecosystems may be attracted to a platform because of unique value propositions developed by the keystone organization, this may not be the only reason they participate. Members may also be compelled to join a platform because they are uniting under a shared outcome that is desired by all. It is up to the keystone organization to deliver the system-level outcomes that the ecosystem members desire (Bailetti, 2010a).

High-impact, system-level results can provide additional motivation for players to affiliate with the program and will also be used to brand the ecosystem (Bailetti, 2010b). This type of motivation is also seen in collective action. Collectives are diverse groups of people and organizations that come together to create something of value that none could have created on their own (Adner, 2006). Collectives harness diversity to produce significant system-level outcomes (McPhee \& Bailetti, 2011a). 
While the concept of collective action is not new and has been of interest to researchers since at least the 1960s (e.g., Olson, 1965), it has only relatively recently been applied to a business context, perhaps most notably with business ecosystems and the trend towards collectives of companies developing shared assets through their contributions to open source projects (Weiss, 2011). In a business ecosystem, the keystone must harness collective action to help others "achieve a better outcome than would be achieved in ungoverned production" (Boudreau \& Hagiu, 2009).

\subsubsection{Ecosystem Health}

Iansiti and Levien (2002) introduced the concept of ecosystem health, including three ways to measure it: i) robustness (e.g., participant survival rates, persistence of economic structure, predictability); ii) productivity (e.g., economic productivity, growth, efficiency, innovation); and iii) niche creation (e.g., variety, overall value). These measures reflect the extent to which an ecosystem is "durably growing opportunities for its members and for those who depend on it" (Iansiti \& Levien, 2002). While they argue that individual firms can influence not only their own health but the health of their ecosystem as well, they later assert that it is the keystone organization that is ultimately responsible for the diversity and collective health of the ecosystem (Iansiti \& Levien, 2004a). Similarly, Evans, Hagiu, and Schmalensee (2006) identify the platform as responsible for facilitating interactions between the different sides, a point which relates directly to ecosystem health. 
In short, the keystone organization must ensure that a sufficient diversity of players are attracted to participate in the platform, that the platform provides sufficient niches for players to create and retain value, that the ecosystem creates sufficient value for the platform to be attractive, and that the sufficient interactions between ecosystem members take place to facilitate deal making.

\subsubsection{The Importance of Trust}

Eduardo Moraes (2010) discussed the role that trust plays in marketplaces such as business ecosystems. He described the three dimensions of trust: i) ability (i.e., belief that the trustee is able to deliver what they said they will deliver); ii) integrity (i.e., belief that the trustee will fulfill agreements as promised); and benevolence (i.e., belief that the trustee has the truster's best interests in mind). In a business ecosystem, a participant can either establish trust along these three dimensions directly through interactions with other members, or they can establish trust indirectly, through recommendations made by others. This latter form or trust establishment, called trust transitivity, can facilitate deal making, and therefore it can be encouraged and facilitated by the keystone organization. The keystone can reduce transaction costs and increase the number of deals in an ecosystem by providing tools that allow ecosystem members to measure the ability, integrity, and benevolence of other members and the keystone itself (Moraes, 2010). 


\subsection{Stream 5: Journal Design}

The literature on how to design organizations that produce journals is scant. The literature search showed that articles relating to journal design typically focus on the following topics:

- visual layout or feature design

- peer-review processes and potential sources of bias

- metrics related to a journal's impact or status (e.g., citation rates)

- issues relating to indexing, retrieval, and archiving

- solutions to the challenge of mounting subscription costs (i.e., the "serials crisis")

- the benefits and economics of open-access publishing versus subscription models

Most of the topics in this list focus on the physical design of publications or aspects quite specific to strictly academic settings. However, the literature contains few examples of how the organizations behind the journals were designed beyond high-level discussions of business models (i.e., paid subscription versus open access) that are beyond the scope of this research, at least for now. The lack of reference points for the design of journals as organizations may be due to confidentiality issues; however, there are two examples that provide some degree of insights.

Boudreau and Hagiu (2009) use the Harvard Business School as an example of a multisided platform, with an emphasis on the school's practitioner-focused journal, the Harvard Business Review. In essence, the platform attracts academics and practitioners (who contribute and consume articles), readers (who purchase subscriptions and receive 
valuable information), and Harvard professors (who receive support for case study research and writing). Thus, the platform delivers unique benefits to a number of member classes, including the school itself, which benefits from enhancements to its reputation. This example was put forth as a brief example of a multi-sided platform, so it contains few details and yields few specific insights that could inform the design of another such journal, beyond what can be surmised from the review of the business ecosystems literature.

The second example comes from the Public Library of Science (http://www.plos.org/), which was originally designed to be an advocacy organization, but later became a publisher so that it could "catalyze a revolution in scientific publishing by providing a compelling demonstration of the value and feasibility of open-access publication" (Brown, Eisen, \& Varmus, 2003). This example is relevant because it provides design details about open-access publishing as an alternative to pay-for-access models. When the goal is to make content available to a much wider audience, then the open-access model is preferred. However, open-access publishers must then develop viable business models that do not depend on subscription fees. These models typically pass the costs of content production on to authors, research sponsors, funding agencies, and other institutions (Brown, Eisen, \& Varmus, 2003).

\subsection{Lessons Learned from the Literature}

In the subsections that follow, I have summarized the lessons learned from the review of each of the literature streams discussed in this chapter. 


\subsubsection{Lessons from Stream 1: Constructive Research}

The following lessons were learned from the review of the literature about constructive research:

1. Constructive research involves solving problems by constructing solutions that are grounded in theory. Thus, this type of research simultaneously contributes to a body of knowledge while also providing a direct solution to a real-world problem.

2. Constructive research must have the following elements: practical relevance, practical functioning, a theoretical connection, and a theoretical contribution.

3. The success of a constructive solution is measured primarily through its practical usefulness, although market tests of various strength (i.e., based on a single case of adoption, widespread adoption, and demonstrated superiority) provide evidence of the quality of the solution compared with available alternatives.

\subsubsection{Lessons from Stream 2: Organization Design}

The following lessons were learned from the review of the literature about organization design:

1. The key aspect that separates organization design as a research activity from other design exercises is that organization design is grounded in theory. 
2. The approach developed by Romme and colleagues is grounded in both lessons from theory and lessons from experience; together, these lessons are synthesized to develop design principles that guide subsequent design steps.

3. Solution-oriented design rules provide a logical connection between the focus of a particular design activity and its expected outcome.

4. The approach includes a closed-loop feedback system, through which continuous improvements can be made to a design. This loop also provides a natural mechanism for the research to capture practical lessons learned and contribute back to the literature.

5. There is a lack of specific guidance on how to relate design elements to outcomes on different timescales.

6. There is little practical guidance on how the feedback loop should be closed once the design has been realized (i.e., what data should be collected and how it should be used).

\subsubsection{Lessons from Stream 3: Results-Based Management}

The following lessons were learned from the review of the literature about organization design: 
1. A logic model helps practitioners build logical links between activities and outputs and the immediate, intermediate, and ultimate outcomes they are intended to deliver. It defines the logical relationships between what the initiative is meant to achieve and what activities are actually being done to work towards those outcomes.

2. A performance management framework not only monitors the performance of specified indicators, it provides an explicit link to the causal assumptions of the logic model.

3. Results-based management may not be well suited to highly iterative, innovative projects. That is not to say they cannot deliver innovative outcomes, but it would be inefficient to develop logic models and performance management frameworks if managers expect regular and fundamental changes to a project. The timescales of performance measurement should be similar to the expected pace of iteration.

4. Results-based management should not be implemented in such as way that it tracks everything; the focus should be on the most important elements that will deliver the most value. Otherwise, results-based management may become a merely bureaucratic, table-filling exercise; if it is not meaningful to the practitioner and tied directly to what really matters in the real world, then it will fail or be abandoned quickly. 
5. Results-based management can be iterative and flexible; it is up to managers to implement it in such as way that ongoing changes are possible and encouraged.

6. Results-based management would benefit from more explicit grounding in theory. While detailed instructions are available for completing logic models (CIDA, 2011; Treasury Board Secretariat, 2001), the process for establishing the causal links between components appears to place greater emphasis on group brainstorming, collaboration, participation, and consensus among team members and stakeholders than on grounding these links in a theoretical domain. Although the Treasury Board Secretariat, for example, states that "these linkages illustrate the theorised causal connections from the activities to the outcomes" [emphasis added], their documentation implies that this means grounding the logic model in assertions based on practical experience and common sense, rather than theory. CIDA includes "analysts and specialists" as examples of stakeholders that should be involved in the process (CIDA, 2011), and perhaps their inclusion would inject a theoretical basis to the causal links. However, it appears that results-based management would benefit from stronger and more explicit grounding in lessons from theory, as is found in the organization design approach described earlier.

7. The performance management framework lends itself to quantitative data. The temptation to use primarily quantitative data is practical from an administrative point of view; however, qualitative data is also important. Furthermore, 
interpretation of the data should draw upon related qualitative and quantitative data.

8. While commonly used to facilitate international development initiatives, the results-based management approach and templates are readily adapted to other contexts, provided earlier lessons relating to timescales and the pace of iteration are kept in mind.

9. The benefits of results-based management would complement the benefits (and shortcomings) of the organization design methodology described earlier. The logic model provides an architecture for the development of design rules because connects the construction principles, context, and desired outcome of the design rule. In fact, any vertical path through a logic model (i.e., the links between activities and outcomes) is analogous to a design rule, therefore the logic model provides a mechanism to develop integrated design rules that target outcomes across multiple timescales. Furthermore, the performance measurement framework helps close the feedback loop, thereby providing a mechanism for triggering change "upstream" in the cycle (i.e., enabling ongoing improvement to the design and its practical and theoretical foundations).

\subsubsection{Lessons from Stream 4: Business Ecosystems}

The following lessons were learned from the review of the literature about business ecosystems: 
1. Business ecosystems are often indentified by a central platform around which members of the collective create value, a process that is encouraged and overseen by the owner of the platform: the "keystone" organization.

2. The keystone must deliver value to all sides of a multi-sided platform; this means developing unique value propositions for each member class.

3. The most effective value propositions deliver compelling points of difference that will resonate with customers.

4. Some members of a business ecosystem may also be considered stakeholders; the keystone should pay close attention to stakeholders with power, legitimacy, and urgency.

5. Through collective action, business ecosystems allow diverse groups to create something together that none could have created on their own.

6. The keystone organization plays a central role in helping ecosystem members achieve better outcomes than they could achieve when working alone.

7. The keystone must deliver shared, system-level outcomes that the community desires. 
8. The keystone is responsible for the overall health of the ecosystem, which includes its robustness, productivity, and niche creation.

9. While much is known about the responsibilities of a keystone organization, such as its role in providing leadership and governance, defining member classes and the associated price structure, and maintaining the health of the ecosystem (Bailetti, 2010b), there is a little practical guidance available about how to design a keystone organization to deliver outcomes related to these responsibilities.

10. Trust is an important mechanism for reducing transaction costs and increasing the number of deals in business ecosystems. Therefore, keystone organizations demonstrate their own trustworthiness and provide tools to allow ecosystem members to measure the ability, integrity, and benevolence of other members.

\subsubsection{Lessons from Stream 5: Journal Design}

The following lessons were learned from the review of the literature about business ecosystems:

1. There is little literature on how to design an organization that produces and disseminates content in the form of a journal.

2. Journals can be viewed as multi-sided platforms. 
3. Open-access publishers must develop viable business models that do not depend on subscription fees. These models typically pass the costs of content production on to authors, research sponsors, funding agencies, and other institutions. 


\section{Background and Lessons Learned from the Open Source Business}

\section{Resource}

Chapter 3 provides background information on the Open Source Business Resource (OSBR). Section 3.1 provides an overview of why the OSBR was launched in 2007. Section 3.2 describes the design and format of the OSBR. Section 3.3 describes the environmental and organizational changes that drove the need to change the OSBR and ultimately transform it into the TIM Review as the focus of this research. Section 3.4 summarizes the lessons learned from the operation of the OSBR over its four-year existence.

Some of the material in this section is adapted from an article I wrote for the August 2011 issue (McPhee, 2011a), which was entitled "Reflecting on Fifty Issues of the OSBR". That was the last article ever published in the OSBR, which was transformed into the TIM Review the following month.

\subsection{Launching the OSBR}

Dru Lavigne, the Editor-in-Chief of the OSBR for its first three years of existence, described 2007 as a time when few companies were making money from open source, largely because the strategic implications of open source were poorly understood (D. Lavigne, pers. comm., July 13, 2011). Even when companies had well-considered business reasons for using open source approaches, many encountered significant challenges in shifting their perspectives, adapting their processes, and understanding how to effectively interact with open source communities. 
In July 2007 , the OSBR was launched as "a resource for promoting an open dialog on the issues involved with making money from open source" (Lavigne, 2007a). Dru Lavigne opened the journal's first editorial with the following statement:

"Recently, a Carleton University student asked his professor "how do you make money from open source?" An excellent question for which there is no short answer. If anything, it appears to lead to a conundrum: aren't the motivators behind open source diametrically opposed to those that drive business? Dig deeper and you'll find that open source and business have much to gain from each other. The difficulty is finding accurate information from those who understand both the business and open source environments." (Lavigne, 2007a)

Although the motivation to create the OSBR was triggered by the question of how to make money with open source, the answer was not readily answered with the information available at the time, nor was this simple question likely to have a simple answer. The next section provides details of the design and format of the journal that would help readers better understand this complex question and find answers that they could apply to their own situations.

\subsection{OSBR Format and Design}

The OSBR was a monthly publication of the Talent First Network and the TIM program at Carleton University in Ottawa, Canada. The publication was free of charge; readers would access html or PDF versions of articles online. Authors did not pay to publish their work in the OSBR nor were they compensated for doing so, but they retained full 
copyright to their individual works, which were published under a Creative Commons Attribution 3.0 Unported license (http://creativecommons.org/licenses/by/3.0/).

A journal format was adopted and all articles were peer reviewed by the OSBR advisory board. The journal format lends itself to a scholarly approach, but the OSBR also published non-scholarly articles, which also benefited from the formality and in-depth analysis the format demanded. Regardless of their background, all authors were encouraged to thoroughly explore their topic and include practical insights gained from experience; the assumption was that readers would benefit from the diversity of perspectives that this approach enabled. Figure 4 shows the diversity of author perspectives in the OSBR in terms of the economic sector(s) that they represented.

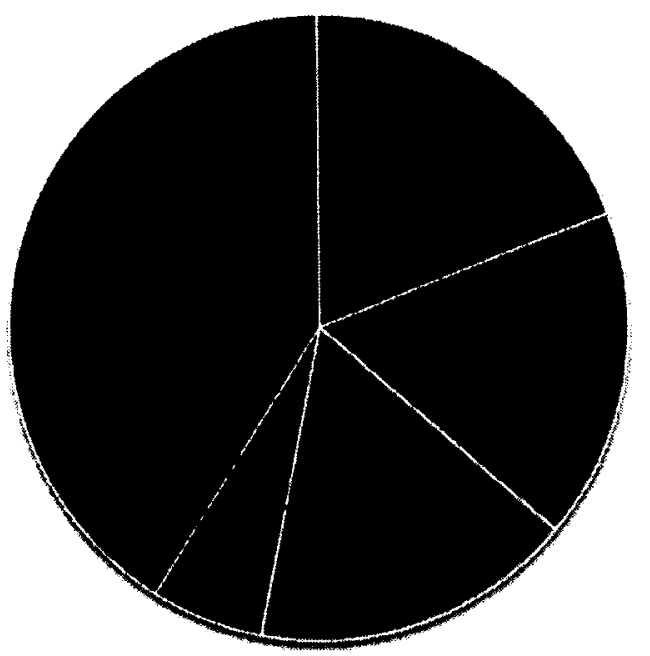

Figure 4. OSBR author perspectives by sector

Figure 4 shows one measure of diversity across all issues; however, another objective was to maximize the diversity of perspectives along a number of dimensions within each issue. 
As might be expected from a technology business publication, there was a strong gender bias in the composition of authors: $78 \%$ of OSBR authors were male. However, some of the most popular issues of the OSBR were the themes of "Women in Open Source" (June, 2009) and "Women Entrepreneurs" (July, 2011).

With its origin at Carleton University, many of the articles come from its professors and graduate students and from the local Ottawa community. However, perspectives that extend well beyond the city and Canada were encouraged. In fact, more than half of all articles published in the OSBR came from authors based outside of Ottawa, as indicated by Figure 5 . Similarly, web analytics showed that approximately $45 \%$ of the visitors to the OSBR website were from outside Canada.

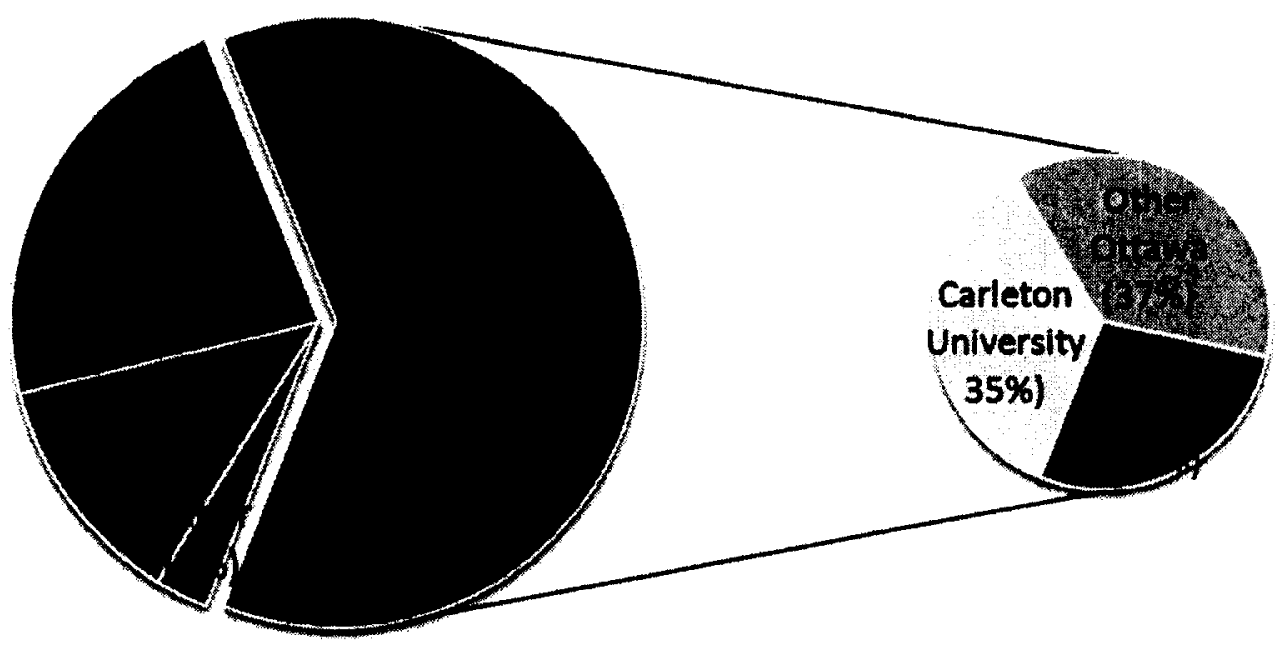

Figure 5. OSBR author perspectives by location

In addition to articles, the OSBR featured Q\&A pieces, recent reports, news, and upcoming events, along with weekly columns from expert practitioners. Over the course of its four years, the OSBR published 50 issues, which included more than 300 contributions. All of these contributions were organized, formatted, and displayed using 
open source tools wherever possible, including Scribus for the PDF layout, Open Journal Systems for the website, and a LAMP stack (Linux, Apache, MySQL, and PHP) providing the underlying framework. The website was hosted at Carleton University and the server was maintained by technical staff in the Department of Systems and Computer Engineering.

Nearly all of the day-to-day activities were performed by the Editor-in-Chief, including issue theme definition, author communications, peer-review coordination, substantive editing, copy editing, layout and formatting of the online and PDF versions of articles, issue publishing, subscriber administration, and issue announcements and related marketing activities. This work was supported by the OSBR Advisory Board, a panel of 8 to 10 members, and the TIM program itself. Within the faculty of the TIM program, the journal's champion was the program's Director, Tony Bailetti, who played an essential and active role in advising on the journal's direction, content, author/guest editor recruitment, and quality throughout its history. Finally, the Talent First Network - a Carleton University organization associated with the TIM program - administered funding for the journal and was listed as its official publisher.

\subsection{A Change in Leadership and Scope}

In June 2010, the OSBR's original Editor-in-Chief, Dru Lavigne, moved on to pursue other opportunities after having guided the OSBR through its original design, implementation, and three years functioning during which 37 issues related to "open 
source business" were published. At this point, I took the reins of Editor-in-Chief and the research described in this thesis formally began.

The original goal of the OSBR was "to provide quality and insightful content regarding the issues relevant to the development and commercialization of open source assets" (Lavigne, 2007b). By 2010, not only had the OSBR contributed substantially to the understanding of how business can profit through free software, open source had become "mainstream" and successful business models that rely on open source had become commonplace. In fact, this period marked a transition where some businesses no longer self-identified as open source businesses (Aslett, 2011). Instead of being a unique differentiator, open source had become an ingrained element within the toolkits of technology businesses.

Aside from the OSBR having served its original outward purpose, an informal change of scope was also being reflected in its pages, which mirrored changes in the scope of the TIM program. While maintaining expertise in the innovation management and open source business domain, the TIM program was expanding its expertise on the topics of business ecosystems, technology entrepreneurship, and economic development. The journal played a prominent role in reflecting the expertise of the program, attracting new talent to the TIM program's ecosystem and the academic program itself, and building local and global communities to create knowledge in domains of interest. To support these aims, it was time for the publication to evolve. 
The change in scope associated with the transformation of the OSBR into the TIM Review formalized and continued a gradual scope shift that was already occurring in the OSBR. As Figure 6 shows, general articles that would appeal to anyone with an interest in the business aspects of early-stage technology gradually took an increasing share relative to articles on "open" topics (e.g., open source, open data, open government, open education) in the OSBR. In the TIM Review, open source business would remain a core focus, but it would share the spotlight with topics such as managing innovation, technology entrepreneurship, and economic development.

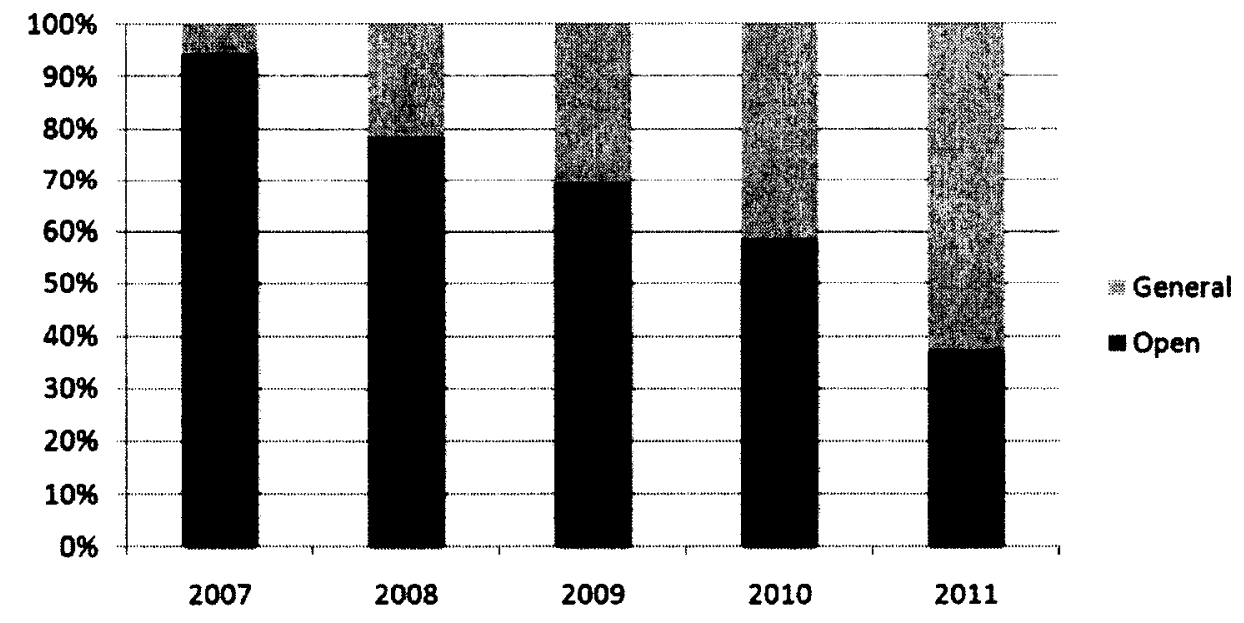

Figure 6. OSBR article topics by year

\subsection{Lessons Learned from the OSBR}

The following lessons were learned from the practical experience of operating the OSBR between July 2007 and August 2011. Some of these lessons were transferred to me by Dru Lavigne (the former Editor-in-Chief) and members of the Advisory Board, although the lessons below primarily reflect my experiential learning from June 2010 to the present day. 
1. Issue themes attract multiple perspectives on a topic. Early on, the OSBR introduced editorial themes, in which a particular topic would be the focus for each issue. Themes add value by bringing together different author perspectives on a particular topic, and they give both authors and readers the opportunity to collectively explore a topic in both depth and breadth.

2. Issue themes influence author recruitment. Themes would be announced several months in advance on the website and in each issue, which gave potential authors the opportunity to assess the fit between an upcoming issue and their areas of expertise. On one hand, themes helped with author recruitment. The OSBR would sometimes receive unsolicited submissions relating to an upcoming theme. More commonly, themes helped the Editor-in-Chief, members of the Advisory Board, past authors, and readers indentify potential authors within their networks who might be able to contribute relevant articles. In this way, issue themes also expand the journal's reach. On the other hand, themes may have been somewhat detrimental to author recruitment. Although the journal was always open to unsolicited submissions, in some cases authors would send in articles (or ideas for articles) that did not match any of the upcoming themes. In most cases, these articles eventually were published in a related issue; some of these submissions even inspired new issue themes. Even so, the number of unsolicited submissions was very low and the presence of themes may have left some potential authors "waiting for the right theme to come along". 
The notion that themes might inhibit unsolicited submissions in some cases was tested with the August 2011 issue. In the call for papers, I invited authors to submit proposals for articles that were not tied to a particular theme; two reactions to this invitation were particularly interesting. A Twitter message sent by a regular OSBR author to his followers hinted at the restricted nature of themed issues: "Get your open source ideas published, it's anything goes for the Aug OSBR" (Freeform Solutions, 2011), which implied that themes were a barrier to potential authors, even though the journal openly encourages submissions from anyone, provided their article fits within the broad scope of the publication. Similarly, one reader posted: "The Open Source Business Resource magazine is going with a rare unthemed issue in August. So, this is your chance to get published on your own specific business/open source topic!" [emphasis in the original] (Sherrill, 2011). The title of that blog post was "August OSBR open", which also implied that themed issues are considered at least somewhat "closed". Even so, the call for papers yielded only one new article submission for that issue. Of the other four articles in the issue, one of the articles was submitted before the call for papers and had been "waiting for a theme", another was planned in advance of the call for papers, and I actively recruited authors for the final two spots. This anecdote suggests that themed issues are not a significant barrier to author recruitment and that the benefits of themes far outweigh their drawbacks.

3. Guest editors facilitate author recruitment and expand the journal's reach. Over the course of the first year of publishing monthly issues consisting of between 
four and eight articles per issue, the journal depended to a great extent on the networks of the Advisory Board members and Editor-in-Chief for author recruitment. Starting in August 2008, to extend the reach of the journal to new authors and readers, guest editors were invited to add their perspective (and networks) to relevant issue themes. Guest editors became a regular feature of the OSBR and their presence dramatically facilitated author recruitment.

4. The journal's association with the university and TIM program brought important legitimacy to the journal. However, the OSBR website and PDF files of individual issues did not make a strong link to Carleton University or the TIM program. For most of the OSBR's history, the TIM program was simply described as a "sponsor" on secondary pages of the website or near the end of the PDF versions of issues. The brand of the Talent First Network as publishers of the OSBR was more accessible to readers through the journal, although few of them understood what the Talent First Network was and even fewer of them knew it was associated with Carleton University. Even in the first issue of the OSBR, neither the TIM program nor Carleton University was mentioned in the editorial titled "Introducing the OSBR" (Lavigne, 2007a). When recruiting authors, I sometimes encountered resistance based on the author not understanding the origin of the journal. However, when the journal was described as "coming out Carleton University" or as "the journal of the TIM program", some authors (especially academic authors) were much more willing to contribute. Thus, the brands of Carleton University and the TIM program were valuable complementary assets 
that brought legitimacy to the publication. Over time, these associations accordingly became more prominent on the journal's website and in its issues. However, the next lesson demonstrates that these associations were not always helpful when recruiting authors and guest editors.

5. The journal's association with the university brought legitimacy, but could also discourage recruitment in some cases. A differentiating feature of the OSBR was the diversity of authors and perspectives. However, this element also introduced challenges for author recruitment. Non-academic authors were not always so keen to consider writing for an "academic journal" even though the publication outwardly positioned itself as a hybrid, practitioner-focused publication and was frequently referred to as a "journal" and a "magazine" by different readers.

A related challenge came about during early discussions about changing the scope of the journal, including selecting a new name. The working title was the Carleton Technology Business Review, but initial feedback from select contributors and stakeholders from inside and outside the university quickly highlighted drawbacks of such overt association with the university. Some were concerned about any name change at all, because it would erode a brand that had been built up over a 4 year-period. Others were concerned that the inclusion of the word "Carleton" in the name would imply that it was a publication just for Carleton authors or just for Carleton readers. One advisory board member noted that the proposed name was ambiguous in terms of what specific department or 
school was the behind the journal. In the end, the decision was made to rename the journal the Technology Innovation Management Review, and prominently display the journal's association with Carleton University on the website, PDF versions of issues, and other marketing materials. The new name made a direct connection with the TIM program, but was also clearly defined the scope of the journal, especially to those who were not familiar with the TIM program, but could appreciate "technology innovation management". Hopefully, the new name would deliver value to the journal's most salient stakeholder, while bringing legitimacy and outside contributions to the journal.

6. It is difficult to solicit contributions if the advertised niche does not match the organization's objectives. As illustrated in Figure 6, the topics of articles published in the OSBR had been shifting away from open source business; by 2011, articles on "open" topics represented less than half of the journal's output. Although this shift was intentional and reflected a shift in the scope of topics covered in the TIM program, it became increasingly difficult to recruit authors for issue themes that were not related to open source business when the title of the journal was the Open Source Business Resource. Not surprisingly, potential authors would frequently respond with: "but I don't know anything about open source!" when invited to contribute to non-open-source issues because of this mismatch between the journal's new, informal scope and its formal, advertised scope. This experience contributed to the decision to rename the journal, despite the respect the OSBR brand had built up since 2007. 
7. A well-defined niche makes it easy to attract interested parties and communities. The OSBR brand and scope was specific enough that it made it relatively easy to identify communities that might be interested in reading the journal or contributing articles relating to specific editorial themes. The open and collaborative nature of open source communities undoubtedly contributed to this effect.

8. If the organization's vision is not continuously reinforced, contributions may drift away from the organization's objectives. Despite the ease by which open source communities can be identified, as described in the previous lesson, not every potential open source expert is interested in (or has expertise in) the business side of open source. Equally, many readers may be interested in individual articles on open source topics, even if insights related to the business side are absent. It was a challenge was to maintain a strong focus on the business angle; at times, the journal ran the risk of expanding its scope to areas such as "open source software development" and other "open" topics that may not have had a commercialization element. The resolve of the Editor-in-Chief and Advisory Board would be tested in this regard when deadlines were looming and content was scarce.

9. The organization must consider the different reasons that motivate authors to contribute. In journals where the authors are almost exclusively academic, the value proposition to authors is clear: author primarily seek publication credit in a well-respected (high-impact) journal that has substantial readership among peers, 
which brings opportunities for professional advancement, collaboration, and sharing of work. In a practitioner-focused journal like the OSBR, the diversity of contributors requires the organization to consider multiple value propositions. Example reasons why non-academics contributed to the OSBR include: "building my personal brand", "building my organization's brand", "spreading the word about X", "making a difference", "contributing back", and "because someone told me I had to". Some of these motivations also apply to academics publishing in academic journals, but to varying degrees. However, academics also have different motivations for contributing to practitioner-focused journals, which include the desire to build links and reputation with business communities. These different motivations affect author recruitment (e.g., how the benefits are described), the journal format (e.g., the presence of author biographies), website tools (e.g., methods of encouraging discussions between authors and readers), and other aspects.

10. Different types of authors require different types of support. Author diversity brings many benefits, but also presents challenges for the organization in terms of supporting a diversity of needs. For example, on one hand, academic authors write regularly and are used to somewhat standardized article formats and practices (e.g., abstracts, citations), as well as the nature of review and editing processes. Changes to expected "standards" to accommodate a diverse authorship and readership base require editorial support and instruction, including help for academics in presenting their insights to general audiences and in distilling the 
practical implications of their work. On the other hand, non-academic experts may not write regularly in a formal style or may not be familiar with journal article formats and review processes. Here, practical insights may abound, but editorial support is often required to encourage subject experts to express the full depth of their insights in a formal style and structure. The OSBR also encourages articles from graduate student authors, who may also lack experience in one or more of these areas. These observations are certainly generalizations, but they highlight the need for diverse support mechanisms, include an editor who can appreciate the needs of diverse authors and has the communication and technical skills to support them.

In discussing these challenges with stakeholders, a frequent suggestion was to simply shift the formats and processes to one end of the spectrum or offer different article formats for different types of authors, in other words to publish issues comprised of "academic papers" and "practitioner articles", each labeled as such and featuring different formats and review processes. A shift in focus too far toward the needs of one authorship or readership group creates a risk that the value proposition to one or more other groups will be eroded. Similarly, differentiating articles based on the author's role or sector undermines the value of diverse perspectives by segregating their contributions; it also increases the number of formats and processes that must be supported. This latter suggestion also implies that authors sort neatly into discrete categories (including the artificial "academic" and "non-academic" generalizations used above); in reality 
the diversity within authorship groups can be substantial and should be acknowledged.

11. Seek and promote diversity, using proxy measures if necessary. Many of the lessons above emphasize the importance of diversity in a publication like the OSBR, while acknowledging that individuals can be difficult to categorize. With the OSBR, demographic metrics of authors, such as sector, role, and location were used as practical proxies for the diversity of perspectives within and across issues - as illustrated in Figure 4 and Figure 5 - while acknowledging that authors may fall into multiple categories. During author recruitment for the OSBR, we actively sought out diversity along these lines and promoted the levels of diversity we achieved, for example in editorials introducing the articles in an issue.

12. Some groups and stakeholders are easier to "track" than others. To deliver value to multiple stakeholders and support diverse contributions and perspectives, the organization must be able to identify these groups. However, with the OSBR, more was known about authors than readers, for example. Detailed information about authors was readily available from the biographies they supplied to accompany their articles. In fact, the data presented in Figure 4 and Figure 5 was manually extracted from author biographies. Information about readers was limited to standard website analytics, through which it is easier to learn what type of browser or operating system they were using than what type of perspective they offered or wished to hear from. In part, this was due to the technical 
limitations of the OSBR website (and prompted specific data collection activities at the point of account creation on the TIM Review website).

13. Tools can help promote engagement, interaction, and collaboration. Online journals provide opportunities that extend well beyond the pre-Internet focus on content dissemination. However, not all journal platforms offer modern tools for collaboration and social media. The OSBR was built on an open source publishing platform, Open Journal Systems (OJS; http://pkp.sfu.ca/ojs), which is a powerful and popular platform designed for managing and publishing academic journals. In 2007, OJS was a practical solution, particularly for a journal that published content related to open source software. However, as a hybrid, practitioner-focused journal with a small editorial team and quick turn-around times, the OSBR did not need the elaborate workflow management tools OJS provided. The OSBR had a greater need for easy-to-use commenting features, flexible visual design capabilities, social media integration, and the flexibility to integrate collaboration tools such as blogs, wikis, and forums, which were (and still are) shortcomings of the OJS platform. For example, while OJS provides tools for readers to add comments to articles, these tools are difficult to use and were almost never used by OSBR readers. Also, the "dated" visual design of the OSBR was identified by potential sponsors and funders as a barrier to their engagement with the OSBR and OJS offered limited flexibility to improve the visual design of the journal. Even if changes to the scope and brand of the OSBR were not being planned, the journal would benefit from a platform that would 
deliver the flexibility to support the diversity of interactions the journal desired to help meet its objectives.

14. Diversity needs active maintenance. Even when an organization makes concerted efforts to deliver value to multiple sides or present a variety of perspectives, some groups may be neglected. Diligence is required to ensure the importance of this diversity remains a top priority because neglected groups may not openly express their neglect. In other words, key groups may "vote with their feet" and quietly stop contributing, rather than announcing their departure. In part, this is because diversity is not a set of discrete groups that act in a coordinated, deliberate fashion. Despite being a powerful force, diversity comes from individuals with interests that only partly overlap, most of whom are loosely connected to each other and act independently.

15. The organization must consider more than just authors and readers. Despite the focus on authorship and readership, a journal does not participate in a two-sided market. The needs of various stakeholders beyond authors and readers must be considered, including sponsors, reviewers, advisors, etc.

16. Some stakeholders warrant greater attention than others. Ideally, every stakeholder would have equal opportunity to shape the journal. However, the demands of publishing a free monthly journal quickly reveal the importance of stakeholders that can help "get things done" (e.g., provide financial or advisory 
support, help recruit authors, review and write articles) or that exert disproportionate influence on decision making. With the OSBR, the TIM program exerts disproportionate influence over the journal's activities. If the journal is not meeting the needs of the program, it would withdraw its support and this would likely mean the end of the journal. However, it is also in the program's best interest to act benevolently toward contributors and other stakeholders or else the journal will not succeed and deliver value to the program. This power relationship is further complicated by the fact that I was both Editor-in-Chief of the OSBR and a graduate student in the TIM program. Key members of the journal's Advisory Board are faculty in the TIM program, including my thesis supervisor, Tony Bailetti, who is also the Director of the TIM program. For the OSBR, the TIM program is a source of individuals who "get things done" and who exert disproportionate influence.

17. Short publication timelines offer benefits, but also bring challenges. The OSBR was a very nimble publication. With nearly all of the day-to-day work aside from article authoring being done by a single person, the journal could act and react quickly. Also, the publication timelines were deliberately short, particularly compared to academic publications; entire issues were regularly written, reviewed, edited, and published in less than a two-month period. These timelines meant that the journal could produce articles and issues that were of topical interest in response to recent events. However, the timelines also posed challenges for authors, reviewers, and the Editor-in-Chief. Constant diligence was required to 
ensure that a sufficient number of articles were in the pipeline and that the short timelines did not negatively affect the quality of the content. Also, the Editor-inChief became a potential bottleneck. Readers and authors frequently commented that it was remarkable that the OSBR accomplished so much on a monthly basis over so many years.

One particular area that became a concern with respect to timescales was the review process, which used a review-by-committee approach. The Advisory Board members were collectively responsible for reviewing all of the articles in an issue once all (or most) of the articles in an issue were sufficiently complete. This step usually happened over a 5-day period close to the issue publication date, which meant reviewers had limited time to review the articles and authors had limited time to respond. Furthermore, this process could be held up by a small number of articles that lagged behind the others, which was an unnecessary dependency. Under such tight timelines, reviewers were limited in their ability to add value to articles or influence the overall quality of the publication. Also, the task of reviewing articles fell to an "advisory" board, which meant most of their volunteered time was spent reviewing articles, not advising on the performance and direction of the publication. Changes to the review process were needed, both to maintain high quality standards and demonstrate the legitimacy of the journal in terms of a solid peer-review process. The key would be to find the right balance so that the publication could remain nimble and of high quality. 


\section{Method}

Chapter 4 describes the method used to produce the deliverables of this research. The chapter is organized into four sections. Section 4.1 describes the reasons for selecting a constructive research approach. Section 4.2 describes the unit of analysis. Section 4.3 describes the study period. Section 4.4 provides an overview of the steps undertaken to complete the research; its sub-sections detail the research method, including data acquisition and analysis.

\subsection{Approach}

A constructive approach was selected for this particular research for a combination of scholarly, pragmatic, and personal reasons:

1. There was strong pull from a key stakeholder, the Technology Innovation Management program at Carleton University (http://carleton.ca/tim), which desired a means to: i) continuously create value for its students by showcasing their personal brands; ii) showcase the differentiating features of the program; iii) increase engagement between students and local companies and communities; and iv) contribute to regional economic development through partnerships with organizations interested in creating and retaining benefits for Canada's Capital Region and other relevant communities. To contribute to the solution of this particular real-world problem, a constructive approach was appropriate because it would yield an immediate practical contribution in addition to other research outputs. 
2. By 2011 , the OSBR had been sufficiently successful within its niche, but the premise on which it was based (i.e., How do you make money with open source?) had largely been addressed through its four years of publication (McPhee, 2011). It was time for the publication to evolve to meet the changing needs of its stakeholders, including its readers. A constructive research approach would yield a functioning solution to meet these needs.

3. A constructive research approach provided an opportunity to apply the theoretical foundation and lessons learned through the courses in the Technology Innovation Management program to a real-world problem, while contributing back to the relevant bodies of knowledge. Given that business ecosystems in particular have been a dominant theme in recent years, both in the program and in the OSBR, this motivation is akin to "practicing what you preach".

4. Acting as both researcher and practitioner in a highly visible initiative, a constructive research project provided me with an ownership-level experiential learning experience, as well as opportunities to expand my network and develop my professional brand within and beyond the university.

5. A constructive research approach aligns with Carleton University's four "pillars of identity" as defined in its strategic plan: i) innovation, ii) location, iii) engagement with the community, and iv) solutions to real-world problems (Carleton University, 2009). 


\subsection{Units of Analysis}

The units of analysis are the attributes of the organization and the publication it produces. These attributes include metrics such as levels of readership, the topics covered within articles and issues, and the demographics of authors, readers, and board members.

\subsection{Study Period}

This research formally began in June, 2010 when I became Editor-in-Chief of the OSBR. The first issue of the TIM Review was published in October, 2011. This research captures data and lessons learned up until the publication of the sixth issue of the new publication in March, 2012.

\subsection{Research Steps and Methodology}

Table 3 identifies the six steps carried out in this research. These steps build on the phases of constructive research identified by Kasanen and colleagues (1993). 
Table 3. Phases of constructive research

\begin{tabular}{ll}
\hline Phase* & Steps Followed \\
\hline $\begin{array}{ll}\text { 1. Find a practically relevant } \\
\text { problem that also has }\end{array}$ & $\begin{array}{l}\text { Identified the problem of designing a keystone } \\
\text { organization to produce and disseminate content } \\
\text { research potential. }\end{array}$ \\
in the knowledge economy.
\end{tabular}

2. Obtain a general and comprehensive understanding of the topic.
- Reviewed literature on constructive research, organization design, results-based management, and business ecosystems.

- Captured lessons learned from first four years of OSBR.

3. Innovate (i.e., construct a solution idea).

- Developed the "results-based organization design" approach, which combines an organization design approach with a results-based management approach.

- Used this new approach to apply ecosystem theory and lessons from OSBR to the creation of design principles to inform the design of a keystone organization to produce and disseminate content.

- Improved the organization continuously over time by virtue of a closed-loop feedback framework embedded within the design.

4. Demonstrate that the solution works.
- Implemented the design, including the launch of the Technology Innovation Management Review.

- Gathered performance-related data.

- Used data to inform changes to organization design and implementation.

- Developed design principles based in part on research-based principles.

- Showed the theoretical connections of this research in a literature review and a discussion of the research results.

- Discussed how the methodology and design principles can be applied to other contexts.
6. Examine the scope of applicability of the solution.

* Adapted from Kasanen et al. (1993) 


\subsubsection{Phase 1: Defining the Problem}

The research problem presented itself in early 2010 when I was given the opportunity for experiential learning and research through the role of Editor-in-Chief of the OSBR. The problem, as described by the staff and faculty of the Technology Innovation Management program at Carleton University, was composed of the following elements:

1. Scope. The scope of the OSBR needed to change. Aside from a general increase in the understanding of open source business (to which the OSBR contributed), the scope no longer reflected the breadth of topics of interest within the Technology Innovation Management program. In particular, the topics of technology entrepreneurship, innovation management, and economic development were deemed particularly important.

2. Collaboration model. The OSBR organization was overly focused on dissemination; greater opportunities for reader input and collaboration were sought. Given the program's expertise and emphasis on business ecosystems, a related publication model was desired.

3. Sustainability. The OSBR was not financially sustainable; it depended on opportunistic piecemeal funding. 
4. Reach. While the content quality was considered high and the OSBR had been successful in reading a substantial audience, readership numbers were not yet at desired levels.

In consultation with the faculty of the TIM program, these elements were synthesized into the following research question: How can a real-world organization be designed and constructed to produce and disseminate content about the growth of early-stage technology companies in a way that draws upon knowledge from both practice and theory, particularly about business ecosystems?

\subsubsection{Phase 2: Obtaining Understanding of the Topic}

The second phase of the research was dominated by two activities: i) studying potentially relevant literature and ii) experiential learning obtained by operating the OSBR. In Chapter 2, the literature streams deemed most relevant to the research approach that was ultimately adopted are reviewed: i) constructive research; ii) organization design; iii) results-based management; iv) business ecosystems; and v) journal design. Chapter 3 captures the experiential lessons learned from publishing issues of the OSBR from July, 2010 to August, 2011 and from gathering feedback from stakeholders and the former Editor-in-Chief, Dru Lavigne, about the lessons learned from 2007 to June, 2010.

\subsubsection{Phase 3: Designing a Solution}

The approach I developed to design a solution to the research problem combines the organization design and results-based management approaches, as shown in Figure 7, and 
so I called it "results-based organization design". This combined approach provides the benefits of both constituent approaches (described in Chapter 2) which are synthesized below. This approach includes:

1. Design principles, through which the design is grounded in both theory and practice. Design principles also provide generalizability; they are sufficiently general that they can be applied to other contexts.

2. A logic model, through which design principles are logically connected to desired outcomes. The logic model replaces and extends the organization-design concept of design rules, which also include outcomes and are built upon logic. The logic model considers outcomes at multiple horizons, and it also provides mapping and logical connections to the inputs, activities, and outputs required to realize the design and achieve the desired outcomes. Furthermore, when combined with the design principles from organization design, the logic model becomes grounded by theory and practice. Together, they provide a natural link both to a method to measure the performance of the design and a way to close the feedback loop and make continuous improvements

3. A performance management framework, which provides a means to measure progress against targets related directly to outcomes at multiple horizons. 
4. A closed feedback loop, within which changes can be made at any point in the framework in response to the designs ongoing performance and through which insights that add to the bodies of practical and theoretical knowledge can be contributed.

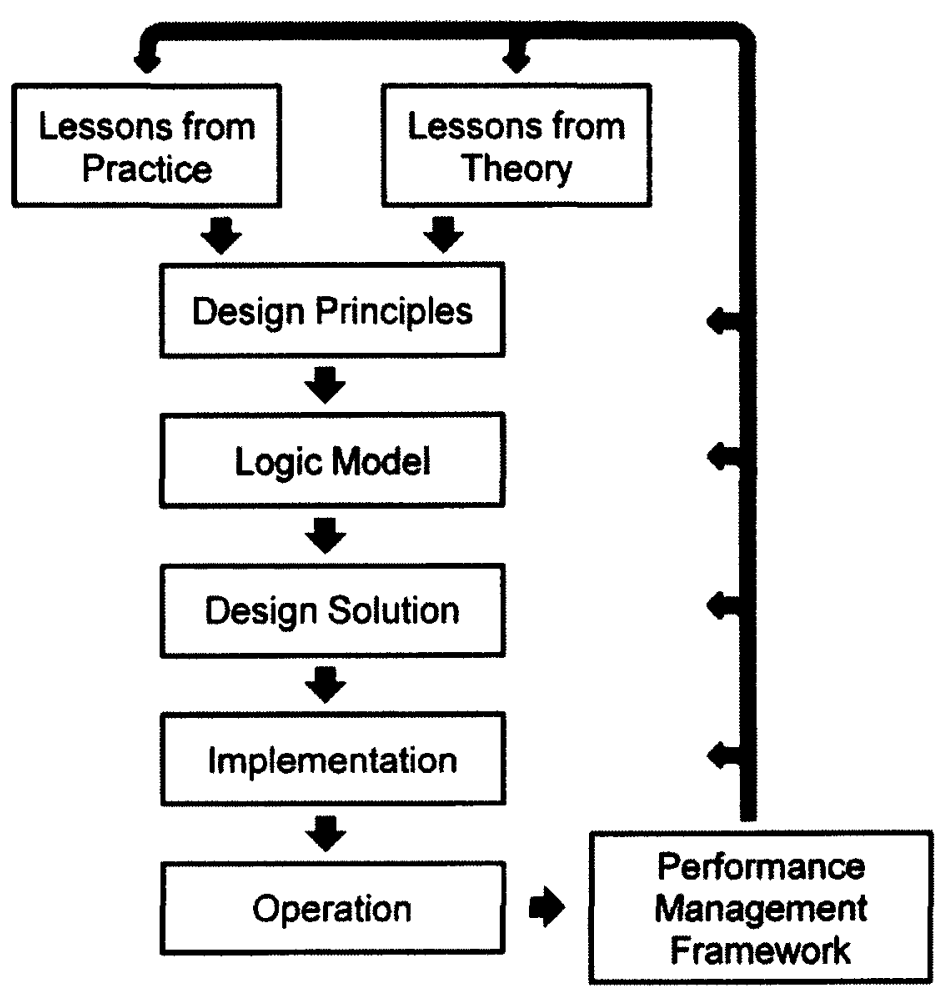

Figure 7. The results-based organization design approach

Using the combined approach described above, the steps followed in the design of the keystone organization for the TIM Review were as follows:

1. Research-based principles were derived from the lessons learned from the literature on business ecosystems (see Chapter 2, Section 2.6.4). 
2. Practice-based principles were derived from the lessons learned operating the OSBR (see Chapter 3, Section 3.4).

3. The derived research-based and practice-based principles were synthesized into design principles.

4. Activities, outputs, immediate outcomes, and intermediate outcomes were determined based on the logical connections between actions and their expected contributions to desired outcomes, particularly the desired ultimate outcome. This step yielded a completed logic model.

5. Metrics associated with the outputs and outcomes from the logical model (i.e., immediate outcomes, intermediate outcomes, and the ultimate outcomes) were determined, along with the requisite baseline data and data collection processes, as described in the results-based management section of Chapter 2.

The resulting design principles, logic model, and performance management framework, were used to design the keystone organization. In the terminology of Kasanen and colleagues (1993), this phase yielded a "solution idea"; in the terminology of van Burg and colleagues (2008), this phase yielded a "design solution". Here, we refer simply to the "design", which is in fact a re-design given that the starting point was an existing organization (i.e., the OSBR). This situation is not uncommon; as Jelinek and colleagues put it: "much organization design is redesign" (2008). 
Details of the design resulting from this phase are described in Chapter 5, which include not only the mechanical elements related to the production and dissemination of the

content (e.g., the website, page layout); these details also describe any relevant processes, guidelines, and structures that the organization requires to carry out its planned activities.

\subsubsection{Phase 4: Implementing the Solution and Gathering Data}

The solution implementation phase involved executing the activities outlined in the logic model. Key components of this phase were the implementation of a design for website, the organization's policies, and board member recruitment. The design implementation included establishing processes for gathering the data specified in the performance management framework. The data were gathered from the following sources, as described in detail in the performance management framework in Chapter 5:

1. Quantitative data about users and user behaviour on the journal website that was logged by the website application

2. Quantitative data about visitors that was gathered through third-party website analytics

3. Quantitative data about authors, articles, and reviewers that I gathered manually through the course of editorial workflows as the researcher-practitioner

4. Qualitative data (i.e., observations and anecdotes) that I gathered as the researcher-practitioner

While implementing the initial design and gathering data about its performance can be considered a distinct phase with a start and end, the methodology dictates that there is an 
ongoing process of re-design and performance measurement, which is embedded within the organization. The closed-loop feedback framework is a key feature of results-based organization design because it provides the mechanism for ongoing improvement. The data collected are compared with pre-defined parameters that indicate whether the desired performance is being achieved and if not, the data inform changes to one or more aspects of the design (i.e., the practice-based principles, the research-based principles, the design principles, the logic model, or the performance-management framework). Changes to the framework also may be triggered by changes in the environment, new stakeholder input, or completion of particular initiatives that have endpoints. In Chapter 5, I will report the results of one complete cycle of results-based organization design, beginning with setting the principles and carrying through the initial design and implementation, followed by a subsequent re-design based on the design's performance.

\subsubsection{Phase 5: Showing Theoretical Connections and Research Contributions}

Since the results-based organization design approach described in this chapter includes: i) design principles that are grounded in theory and ii) a closed-loop feedback system that allows the performance of the design to contribute back to the theoretical knowledge in relevant domains, a method to demonstrate the theoretical connections and is built into the methodology. This means that, in this research, the fifth phase of constructive research actually occurs earlier in the research process, however Kasanen and colleagues (1993) noted that the order of these phases may vary from case to case. 


\subsubsection{Phase 6: Examining the Scope of Applicability of the Solution}

Chapter 6 includes a discussion of how the results-based organization design methodology, and the design principles themselves, can be applied to other contexts. 


\section{Results}

Chapter 5 describes the results of the design and implementation process using the results-based organization design approach described in Chapter 4 to transform the OSBR into the TIM Review. This chapter is organized into six sections. Section 5.1 describes the synthesis of research-based principles based on lessons learned from the literature (see Section 2.6) and practice-based principles based on lessons learned from operating the OSBR (see Section 3.4) into design principles. Section 5.2 describes the development of the logic model for the TIM Review organization based on the design principles from the previous section. Section 5.3 describes the activities undertaken to develop and implement the initial design. Section 5.4 describes the performance management framework that is used to measure progress of the TIM Review organization towards the outcomes defined in the logic model, as well as the data gathered over the first six months following the design implementation. The shell of the performance management framework was developed at the same time as the logic model (i.e., before the organization was designed), although it is presented together with the results of the data collection for presentation purposes. Section 5.5 summarizes the key lessons learned operating TIM Review organization for six months. Section 5.6 describes subsequent changes to the design in response to the lessons learned and performance of the initial design. Together, these sections report on one full cycle of the closed-loop feedback framework, from initial design to subsequent re-design.

To limit the scope of this thesis, I have reported on components of the design relating to only three design principles. These principles relate to: multiple value propositions, a 
shared ultimate outcome, and business ecosystem health. These three principles were selected because they had the greatest impact on the design and subsequent re-design of the TIM Review organization, they best illustrate the methodology, and they were strongly influenced by business ecosystem theory.

Three other design principles, relating to legitimacy, trust, and financial sustainability (and the related design components developed during the course of this research), are not reported on or discussed here because they were not sufficiently supported by theoretical evidence or did not provide additional, incremental value to the logic model and thesis.

\subsection{Design Principles Synthesized from Practice and Research}

Table 2 shows the synthesis of selected lessons from theory (see Section 2.6) and practice (see Section 3.4) into three design principles. The design principles are shown in the first column to improve the presentation of the table, but they represent a synthesis of the lessons from the second and third columns. 
Table 4. Design principles derived from theory and practice

\begin{tabular}{|c|c|c|}
\hline Design Principles & Lessons from Theory & Lessons from Practice \\
\hline $\begin{array}{l}\text { 1. Develop } \\
\text { multiple value } \\
\text { propositions } \\
\text { (i.e., for each } \\
\text { stakeholder) }\end{array}$ & $\begin{array}{l}\text { Organizations must recognize } \\
\text { and deliver compelling points } \\
\text { of difference that will resonate } \\
\text { with customers (Anderson et } \\
\text { al., 2006) } \\
\text { The keystone must deliver } \\
\text { value to all sides of a multi- } \\
\text { sided platform (Bailetti, 2010a) } \\
\text { - Salient stakeholders are those } \\
\text { with power, legitimacy, and } \\
\text { urgency (Jones et al., 2007) }\end{array}$ & $\begin{array}{l}\text { Consider the different reasons why } \\
\text { authors contribute (e.g., goodwill, brand } \\
\text { building, marketing, required to). } \\
\text { - Provide different types of support to } \\
\text { different authors (e.g., editorial support, } \\
\text { different formats). } \\
\text { - Consider more than authors and readers } \\
\text { (e.g., sponsors, reviewers, advisors). } \\
\text { Actively encourage diversity by seeking } \\
\text { diverse contributions; neglected groups } \\
\text { may not speak up directly (e.g., they just } \\
\text { stop contributing). } \\
\text { Give some stakeholders greater attention } \\
\text { if they are powerful or help "get things } \\
\text { done" (e.g., provide financial or advisory } \\
\text { support, recruit authors, review articles). }\end{array}$ \\
\hline $\begin{array}{l}\text { 2. Unite } \\
\text { stakeholders } \\
\text { under a shared } \\
\text { ultimate } \\
\text { outcome }\end{array}$ & $\begin{array}{l}\text { Ecosystems/collectives allow } \\
\text { diverse groups to create } \\
\text { something together that none } \\
\text { could have created on their } \\
\text { own (Adner, 2006; McPhee \& } \\
\text { Bailetti, 2011b) } \\
\text { - A keystone can help others } \\
\text { "achieve a better outcome than } \\
\text { would be achieved in } \\
\text { ungoverned production" } \\
\text { (Boudreau \& Hagiu, 2009). } \\
\text { The keystone must deliver } \\
\text { system-level outcomes that the } \\
\text { community desires (Bailetti, } \\
\text { 2010a). }\end{array}$ & $\begin{array}{l}\text { - Continuously reinforce the organization's } \\
\text { vision, or else contributions may drift } \\
\text { from objectives (e.g., articles that do not } \\
\text { closely match journal's scope). } \\
\text { Define a niche to make it easier to attract } \\
\text { interested parties and communities (e.g., } \\
\text { open source business). } \\
\text { Align the advertised niche with the } \\
\text { organization's objectives to encourage } \\
\text { contributions (e.g., mismatch between } \\
\text { OSBR's advertised scope and objectives } \\
\text { just prior to re-design). } \\
\text { Carefully consider associations with } \\
\text { organizations; some may bring } \\
\text { legitimacy, but may also turn away } \\
\text { "outside" contributors (e.g., OSBR not } \\
\text { overtly tied to Carleton brand). }\end{array}$ \\
\hline $\begin{array}{l}\text { 3aintain and } \\
\text { promote } \\
\text { ecosystem } \\
\text { health }\end{array}$ & $\begin{array}{l}\text { The keystone is responsible for } \\
\text { maintaining and measuring } \\
\text { health, including diversity and } \\
\text { productivity (lansiti \& Levien, } \\
\text { 2004a) } \\
\text { The platform is responsible for } \\
\text { facilitating interactions } \\
\text { between sides (Evans et al., } \\
\text { 2006; Iansiti \& Levien, 2004a) }\end{array}$ & $\begin{array}{l}\text { Seek and promote diversity by sector, } \\
\text { location, role, etc. as proxies for diversity } \\
\text { of perspectives (e.g., author diversity } \\
\text { within issue themes). } \\
\text { Develop methods to track all types of } \\
\text { stakeholders; some are easier to track } \\
\text { than others (e.g., more is known about } \\
\text { OSBR authors than readers). } \\
\text { Provide tools to promote engagement, } \\
\text { interaction, and collaboration, and make } \\
\text { them easy to use (e.g., underused } \\
\text { comments facility on OSBR website). }\end{array}$ \\
\hline
\end{tabular}




\subsection{Logic Model}

Table 5 shows the first logic model that was developed. It guided the initial design of the organization. This logic model is grounded by the three design principles (and lessons from practice and theory) described in Table 4. Each of these elements is discussed in greater detail in the sections that follow.

Note that the logic model does not capture every element of the design - it is meant to capture the essential aspects that are grounded in theory and practice. Other aspects of the design: i) maintained the status quo of the OSBR; ii) were not relevant to the principles underpinning the logic model; or iii) related to a level of finer detail that was not practical or desirable to capture within this framework. 


\begin{tabular}{|c|c|c|c|c|c|c|c|c|}
\hline $\begin{array}{l}\text { Ultimate } \\
\text { Outcome }\end{array}$ & \multicolumn{8}{|c|}{$\begin{array}{l}\text { A popular practitioner-focused joumal that delivers value to all stakeholders concemed with the issues relating to launching and growing } \\
\text { technology companies }\end{array}$} \\
\hline $\begin{array}{l}\text { Intermediate } \\
\text { Outcome } \\
\text { (changes in } \\
\text { practice and } \\
\text { behaviour) }\end{array}$ & $\begin{array}{l}\text { Website } \\
\text { referred by } \\
\text { others as a } \\
\text { destination } \\
\text { for } \\
\text { knowledge }\end{array}$ & \multicolumn{3}{|c|}{$\begin{array}{l}\text { Diverse authorship and readership in line with } \\
\text { scope }\end{array}$} & \multicolumn{4}{|c|}{ Self-sustaining growth of diverse contributions and readership } \\
\hline $\begin{array}{l}\text { Immediate } \\
\text { Outcome } \\
\text { (changes in } \\
\text { access, ability, } \\
\text { and awareness) }\end{array}$ & $\begin{array}{l}\text { Access to } \\
\text { articles and } \\
\text { awareness } \\
\text { of new } \\
\text { organization }\end{array}$ & \multicolumn{2}{|c|}{$\begin{array}{l}\text { Greater input into themes, } \\
\text { authors, and guest editors }\end{array}$} & $\begin{array}{l}\text { New } \\
\text { readers, } \\
\text { authors, and } \\
\text { sponsors } \\
\text { attracted }\end{array}$ & $\begin{array}{l}\text { Users } \\
\text { attracted to } \\
\text { articles that } \\
\text { closely fit } \\
\text { with new } \\
\text { brand }\end{array}$ & $\begin{array}{l}\text { Increased } \\
\text { awareness } \\
\text { of diversity } \\
\text { of readers } \\
\text { and authors }\end{array}$ & \multicolumn{2}{|c|}{$\begin{array}{l}\text { High levels of contribution and } \\
\text { readership }\end{array}$} \\
\hline Outputs & $\begin{array}{l}\text { TIM } \\
\text { Review } \\
\text { website }\end{array}$ & $\begin{array}{l}\text { Advisory } \\
\text { Board } \\
\text { composed of } \\
\text { salient } \\
\text { stakeholders }\end{array}$ & $\begin{array}{l}\text { Engagement } \\
\text { campaign }\end{array}$ & $\begin{array}{l}\text { Brand, } \\
\text { including } \\
\text { clearly } \\
\text { identifiable } \\
\text { niche }\end{array}$ & $\begin{array}{l}\text { Published } \\
\text { issues that } \\
\text { match new } \\
\text { scope }\end{array}$ & $\begin{array}{l}\text { Author and } \\
\text { reader } \\
\text { database }\end{array}$ & $\begin{array}{l}\text { Recruitment } \\
\text { is a part of all } \\
\text { mandates } \\
\text { (board } \\
\text { members and } \\
\text { guest editors) }\end{array}$ & $\begin{array}{l}\text { Tools to } \\
\text { promote } \\
\text { engagement }\end{array}$ \\
\hline Activities & $\begin{array}{l}\text { Select } \\
\text { technology } \\
\text { and build } \\
\text { platform }\end{array}$ & $\begin{array}{l}\text { Gather } \\
\text { feedback, } \\
\text { define board } \\
\text { mandate, } \\
\text { recruit diverse } \\
\text { board members }\end{array}$ & $\begin{array}{l}\text { Engage with } \\
\text { readers and } \\
\text { authors to } \\
\text { refine value } \\
\text { propositions } \\
\text {, suggest } \\
\text { themes, and } \\
\text { recruit }\end{array}$ & $\begin{array}{l}\text { Define } \\
\text { journal } \\
\text { scope and } \\
\text { brand }\end{array}$ & $\begin{array}{l}\text { Recruit } \\
\text { authors with } \\
\text { expertise in } \\
\text { new scope }\end{array}$ & $\begin{array}{l}\text { Collect data } \\
\text { about } \\
\text { authors and } \\
\text { readers }\end{array}$ & $\begin{array}{l}\text { Encourage } \\
\text { others to } \\
\text { recruit on } \\
\text { organization' } \\
\mathrm{s} \text { behalf }\end{array}$ & $\begin{array}{l}\text { Encourage } \\
\text { interaction } \\
\text { between } \\
\text { stakeholders }\end{array}$ \\
\hline $\begin{array}{l}\text { Design } \\
\text { Principles }\end{array}$ & \multicolumn{3}{|c|}{ Value Propositions } & \multicolumn{2}{|c|}{ Shared Outcomes } & \multicolumn{3}{|c|}{ Ecosystem Health } \\
\hline
\end{tabular}




\subsection{Design Implementation Activities}

This section describes the implementation of the design, which was based on the activities described in the logic model (Table 5) and was guided by the design principles

(Table 4). Although some of these activities are ongoing, for presentation purposes, they are described in a mostly chronological sequence rather than the order in which they are presented in the logic model.

\subsubsection{Activity: Define journal scope and brand}

As described in Chapter 3, the scope of the OSBR had been gradually changing on an informal basis even before I became Editor-in-Chief in June 2010, and this change in scope reflected changes in the scope of the TIM program. The TIM Review formalized this scope by defining four key topics:

1. Managing Innovation

2. Technology Entrepreneurship

3. Open Source Business

4. Economic Development

The first topic was an obvious fit to the underlying foundation of the TIM program; the second and fourth topics reflected new areas of expertise that were receiving increasing attention because of changes in the global economy, a downward turn in the local technology sector including the demise of Nortel, and the rise of the knowledge economy, all of which indicated that business needed novel strategies and tools to succeed in this new environment. The third topic, open source business, remained a focus 
within the TIM program and created a degree of continuity between the OSBR and TIM Review.

On the website, I described this new scope as follows:

The Technology Innovation Management Review (TIM Review) provides insightful content about the issues and emerging trends relevant to launching and growing technology businesses. The TIM Review focuses on the theories, strategies, and tools that help small and large technology companies succeed.

Our readers are looking for practical ideas they can apply within their own organizations. The TIM Review brings together diverse viewpoints - from academics, entrepreneurs, companies of all sizes, the public sector, the third sector, and others - to bridge the gap between theory and practice, with a particular focus on the following topics: Managing Innovation, Technology Entrepreneurship, Economic Development, and Open Source Business. (McPhee, 2011b)

In Chapter 3, I also noted that the journal title of Technology Innovation Management Review was chosen in favour of the working title of Carleton Technology Business Review based on feedback from stakeholders and potential sponsors. This close alignment with the TIM brand made some branding decisions for the TIM Review straightforward. The TIM program and its logo already carried the red and black colours of Carleton University. Accordingly, I used the logo from the TIM program to create a logotype for 
the TIM Review (Figure 8). I also used the Carleton/TIM colours when I developed the visual design for the website (http://timreview.ca) and PDF layout (Figure 9), both of which prominently displayed the Carleton University logo.

\section{Tiun Technology Innovation Management Review}

Figure 8. TIM Review logotype

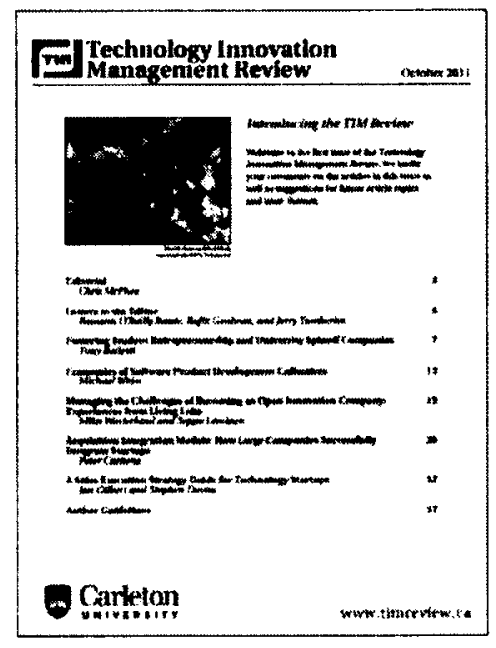

Figure 9. Cover of the first issue of the TIM Review: October 2011

\subsubsection{Activity: Gather feedback, define board mandate, recruit diverse board} members

Based on experiential learning and feedback from stakeholders, I indentified a risk that the existing review process for the OSBR did not contribute to several value propositions, notably those for authors and the Advisory Board. The review process did not regularly generate substantial feedback to help authors improve their articles and, when it did, authors had little time to act upon the feedback before the articles were due to be 
published. Similarly, the potential workload for the Advisory Board members (who were volunteers) was too high and came in sudden bursts, which meant they did not feel they could give the review tasks the attention they deserved. As a result, many board members did not contribute at all. Changes were needed.

Changes to the review process held promise for not only directly impacting the quality of articles, if designed properly, they could also increase the legitimacy of the organization and increase the value propositions to key stakeholders. The feedback from academic authors in particular indicated that the journal's perceived legitimacy in academic circles would increase with a more traditional peer review process where individual articles would be assigned to individual reviewers shortly after submission. The challenge was to develop an editorial process that could be managed by one editor, would allow the TIM Review to maintain the benefits of the tight timelines from the OSBR, and would deliver legitimacy and improved value propositions.

An improved editorial process was only half the solution, however. The other challenge was to ensure that the organization was enabling the Advisory Board to act in an advisory capacity, given that, with the OSBR, the volunteered time of Advisory Board members was mostly spent reviewing articles. Accordingly, I decided to design two boards - an Advisory Board and a Review board - and define mandates for each one, as described in Table 6. These new boards clearly split the duties of advising and reviewing, but also made author recruitment and theme identification a specific part of each board's mandate. 
Table 6. Mandates of the TIM Review Advisory Board and Review Board

Advisory Board Mandate

1. Ensure the TIM Review organization continues to provide benefits to its members and deliver system-level outcomes.

2. Advise on issue themes based on industry trends, feedback from users, opportunities, and members' interests.

3. Help recruit guest editors and authors for upcoming themes.

4. Advise on other top-level aspects, including the website, marketing, readership, processes, events, sponsorship opportunities, etc.

\section{Review Board Mandate}

1. Ensure article quality is high by reviewing individual articles.

2. Give input into improving processes and standards for quality.

3. Suggest authors or guest editors for upcoming themes.

Once the board structure had been designed, the following editorial process was designed for the TIM Review:

Every article submitted to the Technology Innovation Management Review is reviewed by the Editor-in-Chief and a designated member of the Review Board who has expertise related to the article's topic. The reviewers will assess the quality of the article in terms of its insights and fit to the publication's scope and upcoming themes. Reviewers may request clarification or offer suggestions to authors to improve their articles. Feedback will also be given to improve the article's content, format, and readability.

If the article has been accepted for publication and the requested revisions have been made, the article will be formatted for publication. Authors will be notified 
prior to the issue's announcement so they can review the final versions of their articles in PDF and HTML formats.

This new editorial process was designed to improve the perceived legitimacy of the organization. As the organization grew, the process could be expanded to include two reviewers for each article, but it was hoped that this starting point would increase the quality of the reviews and of the resulting final versions of articles. A key element of the review process was the establishment of a board of identifiable reviewers, rather than pulling in reviewers as required for particular topics. Not only would this facilitate the editor's job of finding reviewers, it would make the reviewers an explicit part of the ecosystem and the organization could deliver additional value to the reviewers through promotion of their efforts on the website (e.g., http://timreview.ca/reviewboard).

Once the board mandates were established and the editorial process was in place, a recruitment process for board members began. Criteria were put in place to guide the appointment of Advisory Board and Review Board members. The objective was to assemble diverse boards that would enhance the legitimacy of the publication. After an initial recruitment effort to populate the boards, recruitment would be an ongoing process to ensure the board composition was diverse and effective. Also, the Review Board would be gradually expanded over time to expand the pool of reviewer expertise and spread out the workload of reviewers. 


\subsubsection{Activity: Select technology and build platform}

As described in Chapter 3, the OJS publishing platform provided limited flexibility in terms of visual design improvements and collaborative features. After assessing the various platforms available, an initial attempt was made in Spring 2011 to use OJS as a foundation and then integrate other components to provide collaborative features and an improved visual design. Although the prototype was eventually abandoned because of complications in integrating the visual designs, features, and account sign-on capabilities of multiple platforms, this experience considerably helped refine the requirements and design directions, which was essential once the organization design process was initiated a few months later. This prototype work was made possible with funding and development support from Coral CEA (http://www.coralcea.ca)).

I selected the technology platform for the production website in mid-July, 2011, based on meetings and technology assessments with the team of fellow students in the TIM program's lab at Carleton University. The selected technology was Drupal (http://drupal.org), an open source content management platform. The primary development work was done over a two-month period by a single developer, Nathaniel Hudson, who was a Carleton University summer student in the TIM lab. By midSeptember, the website was sufficiently developed to invite increasing numbers of users to create accounts and test the website. The August 2011 issue was the last OSBR issue; the first issue of the TIM Review was published on the new website (http://timreview.ca) on October 7, 2011. 
Relative to the OSBR website, the new website delivered increased value to multiple stakeholders. Key features of the new website included:

- new branding and up-to-date visual design

- ease of use and navigation (for readers, authors, editors, and administrators)

- improved account database (discussed below)

- improved comments facilities and social media integration

- improved email notifications

- blog integration

- more prominent author biographies and user profiles

- migrated OSBR articles (issue archive)

- new ways of organizing and linking content (e.g., topic hubs)

- flexibility to customize the website and add further features

\subsubsection{Activity: Collect data about authors and readers}

To ensure that the TIM Review could create a healthy ecosystem, a method of collecting information about ecosystem members and their engagements with the journal was needed. Accordingly, the account creation process on the website was designed to collect important demographic data about users. Table 7 lists the information collected about users at the point of account creation (http://timreview.ca/user/register). Note that the questions relating to their perspectives allow the user to select more than one option. The intention was to map to the activities of different types of users on the website; it could also be aggregated to provide indicators of ecosystem health, such as the diversity of 
readers and authors. Related metrics are included at various points in the performance management framework, which is introduced in Section 5.4.

Table 7. Data collected during account creation on TIM Review website

\begin{tabular}{|c|c|}
\hline Data Requested & Description / Field Type \\
\hline Username & Text \\
\hline Email address & Text \\
\hline First name / Last name & Text \\
\hline Organization & Text \\
\hline Country & $\begin{array}{l}\text { Drop-down list } \\
\text { (If Canada is selected, a check box appears, asking "Are you a resident of } \\
\text { Ottawa/Gatineau?") }\end{array}$ \\
\hline Sectors & $\begin{aligned} \text { What sectors best represent your viewpoints? } \\
-\quad \text { Academia } \\
-\quad \text { Private Sector } \\
\text { - } \quad \text { Public Sector (excluding academia) } \\
\text { - } \quad \text { Third Sector (e.g., non-profits, foundations) }\end{aligned}$ \\
\hline Roles & $\begin{array}{l}\text { What organizational roles best represent your viewpoints? } \\
- \text { Executive } \\
- \text { Manager } \\
- \text { Employee } \\
- \text { Consultant } \\
- \text { Entrepreneur } \\
- \text { Professor } \\
- \text { Student }\end{array}$ \\
\hline Type of user & $\begin{aligned} \text { As a user of this website, what roles best represent your viewpoints? } & \text { - } \\
\text { - } & \text { Author } \\
\text { - } & \text { Member of Advisory Board or Editorial Board } \\
\text { - } & \text { TIM Student } \\
\text { - } & \text { TIM Staff or Faculty } \\
\text { - } & \text { Sponsor or Advertiser }\end{aligned}$ \\
\hline Topics of interest & $\begin{array}{l}\text { Which topics are most relevant to you? } \\
-\quad \text { Managing Innovation } \\
-\quad \text { Technology Entrepreneurship } \\
-\quad \text { Economic Development } \\
-\quad \text { Open Source Business } \\
-\quad \text { Other }\end{array}$ \\
\hline
\end{tabular}


At the side of the account creation screen, a box explicitly explains to users why this information is collected:

The Technology Innovation Management Review serves a diverse group of users.

The information we collect about our users will help us understand the different perspectives they bring to this website and how they use it.

If we find that some perspectives are underserved or underrepresented, we can take steps to improve the publication and attract a healthy diversity of viewpoints, which we believe will bring value to all users. We may also display this data in aggregated and anonymized forms on our website to illustrate the overall diversity of our users.

\subsubsection{Activity: Engage with readers and authors to refine value propositions, suggest themes, and recruit}

This activity is an ongoing effort. Prior to the launch, the focus was on going through existing feedback from users and ensuring that the new design reflected their expressed needs as much as possible. Also, I wrote an article in the last issue of the OSBR, explaining the reasoning behind the re-branding to the TIM Review and inviting ongoing feedback and contributions (McPhee, 2011a). The engagement campaign that was initiated after the launch is described in greater detail in Section 5.4.1. 


\subsubsection{Activity: Recruit authors with expertise in new scope}

For the first two issues of the TIM Review (i.e., October 2011: Introducing the TIM Review, and November 2011: Recent Research), authors were recruited from our local ecosystem to demonstrate the new scope of the journal and the local expertise in the key topics that would be featured in the TIM Review. For subsequent issues, the goal was to define themes based on feedback from users and board members and use these mechanisms to recruit authors.

\subsubsection{Activity: Encourage others to recruit on organization's behalf}

With the OSBR, it was relatively easy to make a list of interesting issue themes for future issues. However, author and guest editor recruitment was always a challenge. Often, recruitment was opportunistic and reactive, and it fell to me and Tony Bailetti (Director of the TIM Program and TIM Review Advisory Board member) to find many of the authors and guest editors. Therefore, recruitment mechanisms were made an explicit part of the new design. In particular, the mandates of the Advisory Board and Review Board (Table 6) made recruitment an explicit part of board members' roles. Efforts would also be made to encourage readers and authors to suggest potential author and guest editors for future issues.

\subsubsection{Activity: Encourage interaction between stakeholders}

The OSBR primarily followed a "produce and disseminate" model. Aside the open invitation to contribute new articles, there were few opportunities for readers and authors to co-create knowledge or share insights, even through simple website comment features, 
which were of limited value on the OSBR website. The selection of a flexible technology platform would enable a wide variety of tools to be developed; ideas for such tools included: i) wiki-like literature reviews with multiple authors; ii) user forums; iii) physical events; and iv) virtual events, perhaps including authors answering reader questions through integrated web conferencing tools.

\subsection{Performance Management Framework and Early Performance Data}

This section describes the performance management framework associated with the first logic model for the TIM Review. For each of the outputs and outcomes in the logic model, subsections detail how progress toward the outcomes are measured, how the data are collected, who collects the data, and what targets have been set to evaluate performance. While the performance management framework is nominally a single table, for convenience of presentation and discussion, the framework has been divided into multiple tables: one for each output and outcome cell of the logic model, prefixed in the table title by "PMF".

Each subsection also summarizes the early data collected for the relevant component of the performance management framework. The data-collection period extends from the launch of the TIM Review in October 2011 until the publication of its sixth issue in March 2012. The data collection is ongoing because this framework is embedded with the TIM Review organization, but March 21, 2012 was chosen as the endpoint in terms of reporting the initial results in this thesis. 
To improve the legibility of the tables, the final "Responsibility" column has been omitted in the subsections that follow; in all cases it was my responsibility - as Editor-inChief of the TIM Review, not as the researcher - to collect the relevant data. These data are not outputs of this research; they are outputs of the ongoing operation of the organization. While most of the relevant data are presented here to help interpret the results of this research, in some cases, the values are omitted or reported without scale to protect the confidentiality of data related to business concerns.

The following conventions have been used to simplify the tables that comprise the PMF:

1. Where information has been omitted for confidentiality reasons, this is denoted by "omitted". Where possible, qualitative statements about the data are included in the text in lieu of specific numeric data; for example, whether or not the omitted data meets performance expectations without revealing the exact expectations.

2. Where the data source is listed as "website", this refers to the TIM Review website.

3. Where the information required for a cell is not applicable, this is denoted by "n/a".

4. Where the information required for a cell was not collected (e.g., where baseline data would have been too time-consuming to collect, this situation is denoted by "not collected".

5. Where continuous, automated data collection is possible, the frequency may indicate "monthly", which is the minimum frequency at which I plan to examine the data. 


\subsubsection{Outputs}

This section describes how the data related to the performance of the outputs of the initial TIM Review logic model are collected and interpreted. It also reports on the associated data collected during the first six months following the launch of the TIM Review. This section is presented in the left-right order that these outputs are listed in the logic model (Table 5).

\subsubsection{Output: TIM Review website}

The output relating to the development of the new website for the TIM Review was a straightforward project-like activity. Although website development would continue after the launch, the output was considered complete once the first issue had been published. The performance indicator was the percentage of website development that was complete and the target date was to complete the website in time for the first issue of the TIM Review to be published on September 1, 2011 (Table 8). Aside from the developer tasks of customizing the Drupal platform to function as a journal according to my specifications, this output target included the website graphics, structure, and content, for which I was responsible.

Table 8. PMF for Output: TIM Review website

\begin{tabular}{llllll}
\hline Indicators & Baseline Data & Targets & Data Sources & $\begin{array}{l}\text { Data } \\
\text { Collection }\end{array}$ & Frequency \\
\hline $\begin{array}{l}\text { \% complete } \\
\text { (development) }\end{array}$ & $\mathrm{n} / \mathrm{a}$ & $\begin{array}{l}\text { Launch by } \\
\text { Sept. 2011 }\end{array}$ & $\begin{array}{l}\text { Development } \\
\text { team }\end{array}$ & Manual & Weekly \\
\hline
\end{tabular}


The website was sufficiently ready to publish an issue in the first week of September; however, the submissions for the first issue were considerably late. Rather than rush the content for the first issue, I decided to delay it until October and use the extra time in September for refining and testing the website, while ensuring the content was of sufficiently high quality to make a good first impression.

The first issue was published on October 7,2011. Although an issue was skipped during the transition to the TIM Review, this critical output was successfully delivered after only two months of one developer working less than full time on this particular project.

\subsubsection{Output: Advisory Board composed of salient stakeholders}

Members of the Advisory Board was recruited based on the following criteria:

1. Their degree of stakeholder salience; in other words, we would invite those groups that had the most power, legitimacy, and urgency (Jones et al., 2007).

2. Their ability to: provide valuable input into theme identification, identify market trends, and recruit authors or guest editors from their networks.

3. Their moralist stance; in other words, the degree to which they would take the interests of others into account when contributing advice or input into decisions (Freeman, Wicks, \& Parmar, 2004; Jones et al., 2007).

4. Proven points that demonstrate they would add value, including any history of contributions as a member of the OSBR advisory board.

5. Their incremental value; in other words the extent to which their skills and perspectives were already present on the Advisory Board. 
Members of the Advisory Board were primarily recruited based on the fit of their areas of expertise to the new scope of the journal and their willingness to contribute. Reviewers also had to meet the criteria in one of the following reviewer categories:

1. Academic: $\mathrm{PhD}$ in a related field

2. Executive: five years of experience launching new lines of business in large companies at VP/Director level or higher

3. Serial Entrepreneur: founder of three or more technology companies

For both the Advisory Board and Review Board, an additional criterion was the stakeholder group(s) they represented. The target was to ensure representation of all stakeholder groups on both boards, as shown in the performance management framework for this output (Table 9).

Table 9. PMF for Output: Advisory Board composed of salient stakeholders

\begin{tabular}{lccccc}
\hline Indicators & Baseline Data & Targets & Data Sources & $\begin{array}{l}\text { Data } \\
\text { Collection }\end{array}$ & Frequency \\
\hline $\begin{array}{l}\text { \# stakeholder types not } \\
\text { represented on Advisory }\end{array}$ & $50 \%$ & 0 & Website & Manual & Monthly \\
\begin{tabular}{l} 
Board \\
\hline $\begin{array}{l}\text { \# stakeholder types not } \\
\text { represented on Review } \\
\text { Board }\end{array}$
\end{tabular} & n/a & 0 & Website & Manual & Monthly \\
\hline
\end{tabular}

As of March 21, 2012, the six members of the Advisory Board represented: the TIM program (2), academics (3), entrepreneurs (1), and the private sector (2). However, no members of the Advisory Board represented the public sector or the third sector.

Together, the eleven members of the Review Board represented: the TIM program (3), 
academics (7), entrepreneurs (1), and the private sector (3). However, no members of the Review Board represented the public sector or the third sector. Both targets associated with this output remain unmet, with an obvious need to recruit board members from the public sector and third sector. These gaps inhibit the organization's ability to create and deliver unique value propositions to these members of the ecosystem and limit its capacity to receive input into themes, authors, and guest editors from these sectors.

\subsubsection{Output: Engagement campaign}

Another important method of refining the value propositions to members of the ecosystem is to solicit input from individual readers and authors through an engagement campaign. The performance management framework for this output tracks the number of different engagement types, with the target set at five (Table 10).

Table 10. PMF for Output: Engagement campaign

\begin{tabular}{lcclll}
\hline Indicators & Baseline Data & Targets & $\begin{array}{l}\text { Data } \\
\text { Sources }\end{array}$ & $\begin{array}{l}\text { Data } \\
\text { Collection }\end{array}$ & Frequency \\
\hline \# engagement types & 2 & 5 & Multiple & Manual & Monthly \\
\hline
\end{tabular}

Once the new website was launched, the engagement campaign focused on blog posts and issue editorials inviting readers to provide feedback and theme suggestions. I also gathered feedback from readers and authors through email exchanges and direct meetings. However, these activities were limited by my time demands and, although I could count these activities as delivering three engagement types, the effort level in this 
area was modest and it is a stretch to describe them as an "engagement campaign" at this point. Help is needed in this area.

\subsubsection{Output: Brand, including clearly identifiable niche}

This is another project-like output where an endpoint can be identified, even though there may be refinement over time. Accordingly, the target in the performance management framework simply requires that the brand to be defined prior to the launch (Table 11).

Table 11. PMF for Output: Brand, including clearly identifiable niche

\begin{tabular}{llclll}
\hline Indicators & Baseline Data & Targets & $\begin{array}{l}\text { Data } \\
\text { Sources }\end{array}$ & $\begin{array}{l}\text { Data } \\
\text { Collection }\end{array}$ & Frequency \\
\hline $\begin{array}{l}\text { \% complete (website and } \\
\text { assets) }\end{array}$ & $100 \%$ & $100 \%$ & Website & Manual & $\begin{array}{l}\text { Weekly } \\
\text { before } \\
\text { launch }\end{array}$ \\
\hline
\end{tabular}

This target was met, and details about the completion of this output already have been discussed in detail in Section 5.3.2 in relation to the related activities. However, in terms of a clearly identifiable niche, there are two differences worth noting about the new scope compared with the scope of the OSBR. First, the potential market for the TIM Review is larger, which is beneficial in terms of a larger potential base of readers, authors, and sponsors. However, second, the communities and pockets of expertise associated with this wider niche are more diffuse and less readily identifiable than open source communities. Related to this, greater competition with other information sources will be encountered in the new and wider niche. Different strategies for identifying and reaching potential readers, authors, and sponsors may be required. 


\subsubsection{Output: Published issues that match new scope}

It is important that the content of the TIM Review closely reflect its new scope as the organization tries to reach new audiences. While the baseline data in the performance management suggests that about half of the last 12 OSBR issues were a close fit to its advertised scope, the new target is $100 \%$ (Table 12). Although it may seem obvious that a journal should publish only content that is related to its scope, the practice-based lessons learned from operating the OSBR show that drift is possible. The target for this output reinforces the need for diligence in this area.

Table 12. PMF for Output: Published issues that match new scope

\begin{tabular}{llclll}
\hline Indicators & Baseline Data & Targets & $\begin{array}{l}\text { Data } \\
\text { Sources }\end{array}$ & $\begin{array}{l}\text { Data } \\
\text { Collection }\end{array}$ & Frequency \\
\hline $\begin{array}{l}\text { \# issues strongly matching } \\
\text { advertised scope }\end{array}$ & $\begin{array}{l}\sim 50 \% \text { in last } \\
12 \text { issues }\end{array}$ & $100 \%$ & Website & Manual & Monthly \\
\hline
\end{tabular}

Based on their editorial themes and article topics, all of the issues published in the first six issues were deemed a close fit to the advertised scope. The editorial themes of the first six issues were:

1. October 2011: Introducing the TIM Review

2. November 2011: Recent Research

3. December 2011: Intellectual Property Issues

4. January 2012: Open Source Business

5. February 2012: Technology Entrepreneurship

6. March 2012: Technology Entrepreneurship 


\subsubsection{Output: Author and reader database}

The customization of the account creation process to capture additional data about users is another project-like output, where there is a defined endpoint. Whereas this information was available for nearly all OSBR authors by manually extracting information from their author biographies and elsewhere, the target for the TIM Review is to automatically gather this user data from all account holders (Table 13).

All authors will be asked to create accounts on the website. An account delivers extra value to authors because the website automatically generates a list of all of their publications, which is linked to all of these articles and their user profile; it also enables them to see preview versions of their articles on the website just before they are published.

The target for readers is not $100 \%$ because readers are not required to create an account to access the TIM Review - it is truly "open access". The data will be collected for any readers who create accounts for the purposes of adding comments to articles, subscribing to email notifications, or accessing other current and future tools available to account holders. This is an improvement over the situation with the OSBR, where the information was available (with effort) for nearly all of the authors but none of the readers, including readers who had accounts. 
Table 13. PMF for Output: Author and reader database

\begin{tabular}{llllll}
\hline Indicators & Baseline Data & Targets & $\begin{array}{l}\text { Data } \\
\text { Sources }\end{array}$ & $\begin{array}{l}\text { Data } \\
\text { Collection }\end{array}$ & Frequency \\
\hline$\%$ complete (development) & $\begin{array}{l}\text { Nearly } 100 \% \\
\text { for authors; } \\
\text { unknown for } \\
\text { readers }\end{array}$ & $\begin{array}{l}100 \% \text { of } \\
\text { account } \\
\text { holders }\end{array}$ & Website & Manual & $\begin{array}{l}\text { Weekly } \\
\text { before } \\
\text { launch }\end{array}$ \\
\hline
\end{tabular}

This output was successfully completed before the launch. How the collected data have been used to learn about users of the TIM Review website is described in later sections.

\subsubsection{Output: Recruitment is a part of all mandates (board members and guest editors)}

For the TIM Review, the responsibility for author recruitment is shared across different types of contributors, including readers. This will help the organization tap into new networks and reach new pockets of expertise. Recruitment will be an explicit part of the mandate of board members (see Table 6) and guest editors. This project-like outcome is tracked by the completion of documentation reflecting the role of recruitment in these mandates (Table 14).

Table 14. PMF for Output: Recruitment is a part of all mandates (board members and guest editors)

\begin{tabular}{llclll}
\hline Indicators & Baseline Data & Targets & $\begin{array}{l}\text { Data } \\
\text { Sources }\end{array}$ & $\begin{array}{l}\text { Data } \\
\text { Collection }\end{array}$ & Frequency \\
\hline $\begin{array}{l}\text { \% complete } \\
\text { (documentation) }\end{array}$ & $\begin{array}{l}\text { n/a for board } \\
\text { members; } \\
100 \% \text { for } \\
\text { guest editors }\end{array}$ & $100 \%$ & Website & Manual & $\begin{array}{l}\text { Weekly } \\
\text { before } \\
\text { launch }\end{array}$ \\
\hline
\end{tabular}


This output was successfully completed before the launch. The mandate of the Advisory Board is explicitly stated on the website (http://timreview.ca/advisoryboard), whereas Review Board members and guest editors are informed of their role in author recruitment at the time they are recruited themselves.

\subsubsection{Output: Tools to promote engagement}

The website was designed to accommodate tools to encourage interaction between stakeholders, including authors and readers. The OSBR website included two such tools: a tool to add comments to articles and a tool whereby account holders could email the authors of articles. The target for the TIM Review is to increase the number of engagement tools to five (Table 15).

Table 15. PMF for Output: Tools to promote engagement

\begin{tabular}{lcclll}
\hline Indicators & Baseline Data & Targets & $\begin{array}{l}\text { Data } \\
\text { Sources }\end{array}$ & $\begin{array}{l}\text { Data } \\
\text { Collection }\end{array}$ & Frequency \\
\hline \# tools & 2 & 5 & Website & Manual & Monthly \\
\hline
\end{tabular}

As of March 21, 2012, two engagement tools were in place on the TIM Review website. As with the OSBR website, one is for adding comments to articles, although the usability and prominence of this tool is superior to the OSBR website. The second is an email tool that enables emails to be sent from one user to another, provided they have not disabled this feature. While the OSBR email tool enabled only reader-to-author engagement, the TIM Review email tool enables engagement between any type of account holder (i.e., reader-to-author, author-to-author, author-to-reader). 
Early development work was undertaken to examine the feasibility of other tools for engagement such as forums and wikis, although these tools have not yet been exposed to users. The website will support these tools, the only development barriers are the clarification of the use case for such tools and the time required to set up and administer them. However, this does not mean users will necessarily use the tools once they have been developed.

A Twitter account (http://twitter.com/timreview) and a LinkedIn group (http://www.linkedin.com/groups?home=\&gid=814407) are also actively used for the TIM Review (as they had been for the OSBR). Although these tools perform similar engagement functions, the outcome described here focuses on tools that are integrated into the TIM Review website.

\subsubsection{Immediate Outcomes}

This section describes how the data related to the performance of the immediate outcomes of the initial TIM Review logic model are collected and interpreted. It also reports on the associated data collected during the first six months following the launch of the TIM Review. This section is presented in the left-right order that the immediate outcomes are listed in the logic model (Table 5).

\subsubsection{Immediate Outcome: Access to articles and awareness of new organization}

With the completion of the new website, the mechanism for creating access and awareness of the new organization was in place. The indicators for this component of the 
performance management framework include the availability of new articles every month and the visits of readers coming to the website to read them (Table 16).

Table 16. PMF for Immediate Outcome: Access to articles and awareness of new organization

\begin{tabular}{llllll}
\hline Indicators & Baseline Data & Targets & $\begin{array}{l}\text { Data } \\
\text { Sources }\end{array}$ & $\begin{array}{l}\text { Data } \\
\text { Collection }\end{array}$ & Frequency \\
\hline \# articles published & $\sim 6$ per issue & 6 per issue & Website & Manual & Monthly \\
\hline \# unique visitors & Omitted & Omitted & $\begin{array}{l}\text { Google } \\
\text { Analytics }\end{array}$ & Reports & Monthly \\
\hline
\end{tabular}

Across the six issues published between October, 2011 and March, 2012, the average number of articles per issue was 5.16, which falls below the target value of 6 . Thus, further efforts should be made to recruit high-quality submissions for publication in the journal.

Although the precise readership levels are omitted here, Figure 10 illustrates the growth in readership during the six-month period from October 1, 2011 to March 31, 2012. The spikes in the graph correspond to the release of new issues in the early part of each month, which is accompanied by an email notification to all subscribers. The dip in visitors at the end of December corresponds to the Christmas holiday. However, the most interesting aspect of Figure 10 is the sudden increase in readership beginning in January 2012, which is sustained through the end of March. The current level of unique visitors represents the highest level of readership since I became Editor-in-Chief of the OSBR 22 months ago. 


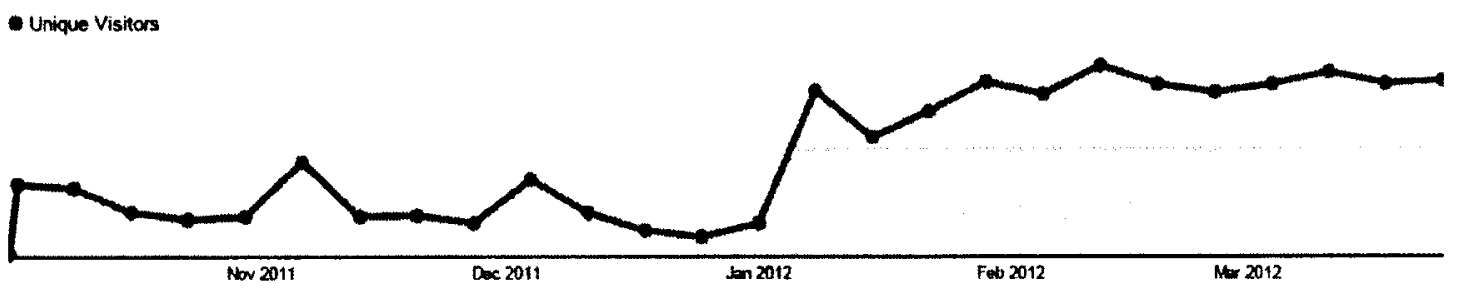

Figure 10. Unique visitors to TIM Review website, by week

So, what accounts for this surge in readership? The surge began with the release of the January issue, which had the theme of "Open Source Business". While it is ironic (and a potential source of worry) that an issue that closely matches the old scope of the OSBR would encourage such high readership levels, it is worth investigating the circumstances of this surge in readership to understand what is behind it.

In the January issue, one article in particular attracted a lot of attention. The article was written by Ruth Suehle, who works for Red Hat, a company that was on the verge of becoming the world's first "open source business" with $\$ 1$ billion in annual revenue. The article was titled "What is the Secret of Red Hat's Success?" (Suehle, 2012) and was promoted through Red Hat's communications channels. The article also was shared by readers at unprecedented levels through the TIM Review website's social media links, which allow articles to be posted to LinkedIn, Twitter, and Facebook. While other articles in the issue were very popular, it is likely that they benefited from the exposure the issue received from this particular article. 
Another explanation for the sudden interest in the topic that was the focus of the OSBR is the migration of the subscriber base from the OSBR website to the TIM Review website. Although the scope of the journal has changed, the core of the subscriber base remained the same; it is possible that the surge in readership was partly due to a fit between the key interest of the subscriber base and this particular issue. In this case, however, a drop in readership back to previous levels following the January issue might be expected and this did not occur.

So, what accounts for the sustained high levels of readership? Investigation into the website analytics suggests that three factors may be contributing to this pattern:

1. Two articles in the February 2012 issue were referenced on Wikipedia articles, which prompted a surge in referral traffic after that issue was published.

2. The Suehle (2012) article continued to draw traffic, along with the other articles in the January 2012 issue.

3. The surge in readership experienced in January extended the reach of the journal to new audiences, who returned to read new issues released in February and March.

The readership targets have been omitted here, but the pattern in the data associated with this outcome is encouraging. Even so, the numerical values still fall short of the targets set for this early stage of the TIM Review's existence. The bar is set high. 


\subsubsection{Immediate Outcome: Greater input into themes, authors, and guest editors}

This outcome is linked to efforts to encourage board members, readers, and authors to suggest themes and play a role in the recruitment of authors and guest editors. This portion of the performance management framework focuses on tracking how many of the themes published in the last 12 months were suggested by board members or readers (Table 17).

Table 17. PMF for Immediate Outcome: Greater input into themes, authors, and guest editors

\begin{tabular}{llllll}
\hline Indicators & Baseline Data & Targets & $\begin{array}{l}\text { Data } \\
\text { Sources }\end{array}$ & $\begin{array}{l}\text { Data } \\
\text { Collection }\end{array}$ & Frequency \\
\hline $\begin{array}{l}\text { \# published themes } \\
\text { suggested by Advisory } \\
\text { Board* }\end{array}$ & $\begin{array}{l}1 \text { in last } 12 \\
\text { issues }\end{array}$ & $\begin{array}{l}3 \text { in last } 12 \\
\text { issues }\end{array}$ & Multiple & Manual & Monthly \\
\hline $\begin{array}{l}\text { \# published themes } \\
\text { suggested by Review } \\
\text { Board } \dagger\end{array}$ & n/a & $\begin{array}{l}3 \text { in last } 12 \\
\text { issues }\end{array}$ & Multiple & Manual & Monthly \\
\hline $\begin{array}{l}\text { \# published themes } \\
\text { suggested by readers } \ddagger\end{array}$ & $\begin{array}{l}0 \text { in last } 12 \\
\text { issues }\end{array}$ & $\begin{array}{l}3 \text { in last } 12 \\
\text { issues }\end{array}$ & Multiple & Manual & Monthly \\
\hline
\end{tabular}

"Excluding themes decided upon by Editor-in-Chief and Director of TIM program (who is an Advisory Board member) +Excluding Advisory Board members who are also on the Review Board

Across the first six issues of the TIM Review, none of these indicators suggested good performance toward this immediate outcome. The December 2012 issue on Intellectual Property Rights was suggested by Peter Carbone, an Advisory Board member, who also acted as guest editor for that issue. The themes for the other six issues were decided upon by me and Tony Bailetti, both of whom are excluded from these measures. In part, these results reflect deliberate planning of the themes of the six issues simply because they 
were the first ones to reflect the new scope. Looking ahead to the editorial calendar for the next six issues suggests that these indicators will soon show more encouraging results.

\subsubsection{Immediate Outcome: New readers, authors, and sponsors attracted}

With its new scope and brand, the TIM Review moves into a new market compared to the OSBR. The expectation is that readers, authors, and sponsors will be attracted to the new scope and this will be reflected in growth among these groups (Table 18).

Table 18. PMF for Immediate Outcome: New readers, authors, and sponsors attracted

\begin{tabular}{llllll}
\hline Indicators & Baseline Data & Targets & $\begin{array}{l}\text { Data } \\
\text { Sources }\end{array}$ & $\begin{array}{l}\text { Data } \\
\text { Collection }\end{array}$ & Frequency \\
\hline \% new visitors & $\mathrm{n} / \mathrm{a}$ & $\begin{array}{l}>50 \% \text { of } \\
\text { visitors } \\
\text { new per } \\
\text { quarter }\end{array}$ & Analytics & Automated & Quarterly \\
\hline \# new authors & Not collected & $\begin{array}{l}>50 \% \text { of } \\
\text { authors } \\
\text { new per } \\
\text { quarter }\end{array}$ & Website & Manual & Quarterly \\
\hline Sponsorship \$ attracted & Omitted & Omitted & $\begin{array}{l}\text { Financial } \\
\text { records }\end{array}$ & Manual & Quarterly \\
\hline
\end{tabular}

With a new or re-launched publication, a growth in readership early on is not only desirable, it may be predicted simply based on novelty. Also, as shown in Figure 10 and as described in Section 5.4. 2.1, the TIM Review experienced a sudden surge in readership in January, 2012. Based on the former expectation and the latter observation, it is not surprising that the ratio of new to returning visitors exceeded the targets in both the 
last quarter of 2011 (60\% new versus $40 \%$ returning) and the first quarter of 2012 ( $70 \%$ new versus $30 \%$ returning).

However, upon further consideration, it is not clear whether this particular indicator is measuring the effect of interest in terms of progress toward this immediate outcome. While an objective may be to encourage new readers to visit the site, it is not their percentage relative to returning visitors that is of interest, particularly since the retention of the existing readership base and repeat visits are also important. A better approach might be to focus on growth in the total number of unique visitors. However, even in this case, the indicator would need to be chosen carefully to supply meaningful results in cases like the surge in visitor numbers in January, for example. Ideally, a new indicator should be chosen that directly measures the causal link to this outcome in the logic model.

In terms of attracting new authors, the results depend on how "new" is defined. If we consider "new" to mean authors that have never had articles published in the TIM Review, then the first six issues included 35 authors that were published in the journal for the first time, compared with four authors who published in the journal twice in the first six months. If we consider "new" to mean authors that have never published in the TIM Review or the OSBR, then the first six issues of the TIM Review included 27 new authors compared to 12 authors that had previously been published in the journal. Regardless of how a new author is defined, the target for this indicator was met, both on a quarterly basis and when examining the first six issues together. 
The data relating to sponsorship has been omitted. However, no new sponsorship money was attracted during the first six months, nor was it sought. The strategy was to first establish the TIM Review and its new brand, build readership levels to a substantial level, and then approach sponsors.

\subsubsection{Immediate Outcome: Users attracted to articles that closely fit with new brand}

With articles being published under the new, formalized scope of the TIM Review, a desired immediate outcome was that readers would be interested in the articles relating to the new scope. Given that the new scope includes four areas of focus (i.e., managing innovation, technology entrepreneurship, open source business, and economic development), the indicator associated with this outcome would examine the relative interest across these four topics (Table 19).

The data for this indicator come from topic tags that I place on each article as it is published; depending on its topic, each article is tagged with one or more topic tags. These tags allow users to find articles of interest through "topic hubs" (e.g., http://timreview.ca/topic/technology-entrepreneurship), which are sections of the website where content relating to a particular topics is collected and potentially curated through additional weighting parameters. However, these tags also can be used to track the popularity of articles on each topic. Although some topics were bound to be more popular than others, the target for the indicator in Table 19 is designed to check that there is 
sufficient interest in the least popular topic. In other words, it provides a warning if there are any weak spots in the journal's scope.

Table 19. PMF for Immediate Outcome: Users attracted to articles that closely fit with new brand

\begin{tabular}{llllll}
\hline Indicators & $\begin{array}{l}\text { Baseline } \\
\text { Data }\end{array}$ & Targets & $\begin{array}{l}\text { Data } \\
\text { Sources }\end{array}$ & $\begin{array}{l}\text { Data } \\
\text { Collection }\end{array}$ & Frequency \\
\hline \# views of articles, by topic & $\mathrm{n} / \mathrm{a}$ & $\begin{array}{l}\text { Least popular } \\
>15 \% \text { of total }\end{array}$ & Website & Automated & Monthly \\
& & & & & \\
\hline
\end{tabular}

After the first six months, the results for this indicator did not meet the target. The weakest topic, economic development, represented only $5 \%$ of the total new-article views. Even when all articles were considered (i.e., including the migrated OSBR articles in the analysis), articles tagged with economic development still only drew $7 \%$ of the total. These results are not surprising, considering that articles tagged as relating to economic development comprised only $5 \%$ of new articles and $5 \%$ of all articles. This suggests that the target is not very useful because it depends on the number of articles tagged with each topic. Rather than indicate a lack of interest in the topic of economic development among readers, it may simply reflect the low number of articles published on this topic in the journal. Nonetheless, the organization is left with a decision about whether or not to increase its efforts in this particular area.

Despite the target likely not being appropriate for measuring progress toward this immediate outcome, there were two other interesting aspects of the results from this indicator that I decided to investigate further: 
1. The relative rankings of individual topics, not just the results for the weakest topics (Table 20).

2. Visits to the home pages of the topic hubs (shown in the last two columns of Table 20). These visits reflect an active choice by the user; by choosing to visit a particular topic hub, they are expressing a preference for that topic. This matches the spirit of the outcome in this section and does not depend on how many articles have been published on these topics, either recently or historically.

Table 20. Article popularity by topic based on percentage of views

\begin{tabular}{lcccccc}
\hline & \multicolumn{2}{c}{$\begin{array}{c}\text { Visits to New } \\
\text { Articles }\end{array}$} & \multicolumn{2}{c}{$\begin{array}{c}\text { Visits to All } \\
\text { Articles }\end{array}$} & \multicolumn{2}{c}{$\begin{array}{c}\text { Visits to Topic } \\
\text { Hubs }\end{array}$} \\
Topic & $\%$ & Rank & $\%$ & Rank & $\%$ & Rank \\
\hline $\begin{array}{l}\text { Technology } \\
\text { Entrepreneurship }\end{array}$ & $53 \%$ & 1 & $27 \%$ & 2 & $33 \%$ & 1 \\
\hline $\begin{array}{l}\text { Open Source } \\
\text { Business }\end{array}$ & $22 \%$ & 2 & $43 \%$ & 1 & $27 \%$ & 3 \\
\hline $\begin{array}{l}\text { Managing } \\
\text { Innovation }\end{array}$ & $20 \%$ & 3 & $23 \%$ & 3 & $32 \%$ & 2 \\
\hline $\begin{array}{l}\text { Economic } \\
\text { Development }\end{array}$ & $5 \%$ & 4 & $7 \%$ & 4 & $8 \%$ & 4 \\
\hline
\end{tabular}

Table 20 shows that, for articles published in the first six months of the TIM Review, technology entrepreneurship is by far the most popular article topic, followed by open source business, managing innovation, and economic development. When comparing the totals for all articles (i.e., including migrated OSBR articles), open source business 
becomes the most popular topic, which likely reflects the large number of articles published on this topic over the four years of the OSBR. However, rankings of topics are different when considering visits to topic hubs. Here, readers are preferentially selecting the technology entrepreneurship topic above the others; the managing innovation topic hub is the second-most popular, followed by the topic hubs for open source business and economic development. Although these values have not been analyzed statistically, the top-three topic hubs might be considered roughly equal in popularity, with the economic development topic hub drawing less than $8 \%$ of visits. Taken together, these results suggest that the users are attracted to the topics that the organization has prioritized. Also, these results suggest that readers show low interest in the economic development topic and the organization has not make a significant effort to make this a prominent topic.

\subsubsection{Immediate Outcome: Increased awareness of diversity of readers and} authors

As a keystone organization that is responsible for the health of the ecosystem, the TIM Review should encourage diversity among its members and make its members aware of this diversity. The indicators associated with this outcome measure the diversity of authors and readers by sector, role, and geography (Table 21).

The data for these indicators are drawn from the information users provide when creating accounts on the TIM Review website, as described earlier and shown in Table 7. Although authors are required to create accounts, readers are not. Therefore, the results presented in this section are not necessarily indicative of the diversity of the perspectives 
of the full readership base; it only reflects the diversity of users who have created accounts. Also note that users have the option of selecting multiple sectors or roles when they create an account; the aggregated data are intended to reflect the overall diversity of user perspectives, not the distribution of different types of individuals. Also, all account holders are considered readers, therefore the data about readers includes authors.

Table 21. PMF for Immediate Outcome: Increased awareness of diversity of readers and authors

\begin{tabular}{|c|c|c|c|c|c|}
\hline Indicators & Baseline Data & Targets & $\begin{array}{l}\text { Data } \\
\text { Sources }\end{array}$ & $\begin{array}{l}\text { Data } \\
\text { Collection }\end{array}$ & Frequency \\
\hline \# authors, by sector & See Figure 4 & $\begin{array}{l}\text { Diversity across } \\
\text { sectors }\end{array}$ & Website & Automated & Monthly \\
\hline \# authors, by role & $\mathrm{n} / \mathbf{a}$ & $\begin{array}{l}\text { Diversity across } \\
\text { roles }\end{array}$ & Website & Automated & Monthly \\
\hline $\begin{array}{l}\text { \# authors, by } \\
\text { location }\end{array}$ & See Figure 5 & $\begin{array}{l}\text { Diversity across } \\
\text { geography }\end{array}$ & Website & Automated & Monthly \\
\hline \# readers, by sector & $\mathrm{n} / \mathbf{a}$ & $\begin{array}{l}\text { Diversity across } \\
\text { sectors }\end{array}$ & Website & Automated & Monthly \\
\hline \# readers, by role & $\mathbf{n} / \mathbf{a}$ & $\begin{array}{l}\text { Diversity across } \\
\text { roles }\end{array}$ & Website & Automated & Monthly \\
\hline $\begin{array}{l}\text { \# readers, by } \\
\text { location }\end{array}$ & $n / a$ & $\begin{array}{l}\text { Diversity across } \\
\text { geography }\end{array}$ & Website & Automated & Monthly \\
\hline
\end{tabular}

The distribution of author and reader perspectives by sector in the first six months of the TIM Review is shown in Figure 11. For both groups, the dominant perspectives are from academia and the private sector. The high level of private-sector representation is encouraging for a university-based publication, although the public sector and third sector perspectives are not strongly represented. Among OSBR authors, the third-sector perspective represented $17 \%$ of the total, which came at the expense of the academic 
perspective (Figure 4). However the third-sector category includes open source foundations, which may explain some of the difference. Nonetheless, the underrepresentation of the public sector and third sector mirrors the results seen earlier with regards to the composition of the Advisory Board and Review Board, both of which may limit the organization's ability to deliver the diversity-dependent outcomes that depend on ecosystem health.

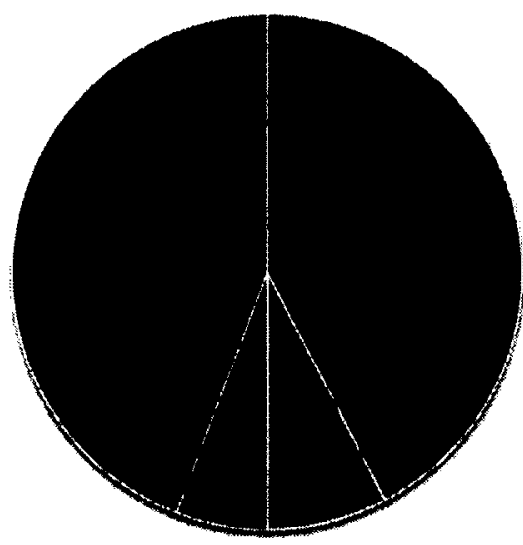

Authors

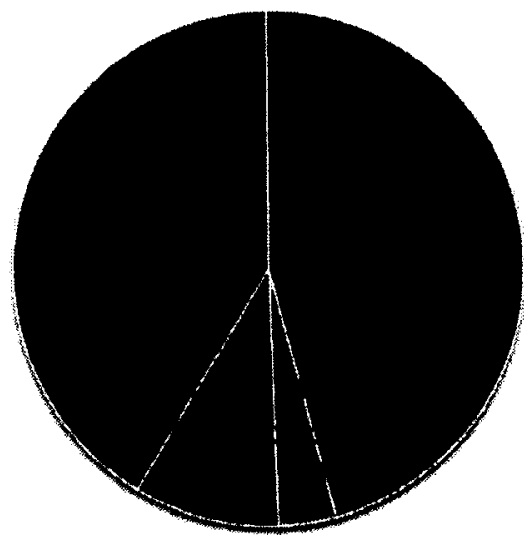

Readers

Figure 11. TIM Review author and reader perspectives by sector

The distribution of author and reader perspectives by role in the first six months of the TIM Review is shown in Figure 12. For both groups, the perspectives are quite evenly spread; there are no particularly dominant or particularly under-represented perspectives. Among authors, professors (23\%) make up the most common perspective; among readers, students (20\%) make up the most common perspective. 


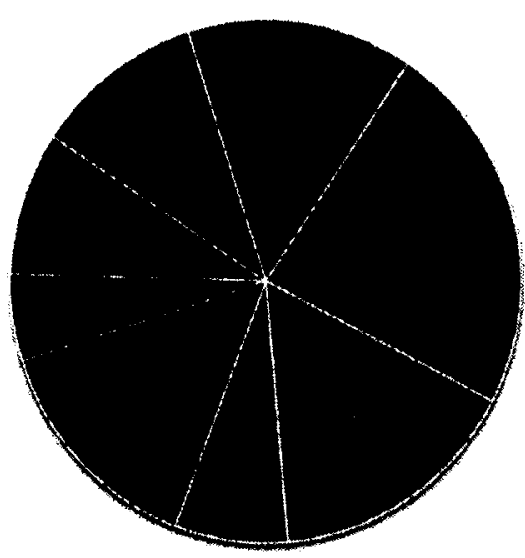

Authors

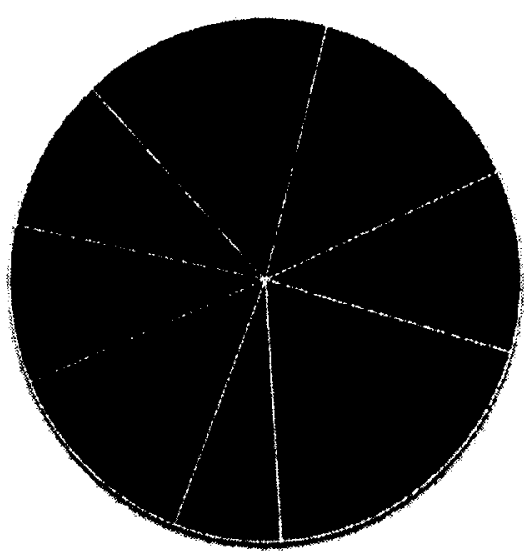

Readers

Figure 12. TIM Review author and reader perspectives by role

The distribution of authors and readers by location in the first six months of the TIM Review is shown in Figure 13. Both groups show similar patterns. Most authors and readers are based in Canada, and more than $50 \%$ of those based in Canada are at Carleton University. Compared to the OSBR (Figure 5), the representation of authors across Canada, but outside of Ottawa, is low ( $28 \%$ versus $15 \%$ ). Also, the OSBR showed greater representation from the United States (23\%). Outside of Canada, there is strong representation from Europe, which partly reflects the TIM program's connections to past and future faculty members who have established professional networks in Denmark and Finland. Overall, these results indicate that, to improve the diversity of perspectives by location, the organization should make greater efforts to increase representation outside of Ottawa. However, at least for authors, these results are not unexpected. An underlying theme of the first six issues was the desire of stakeholders to demonstrate local expertise. Future issues will expand the geographical representation of authors. 


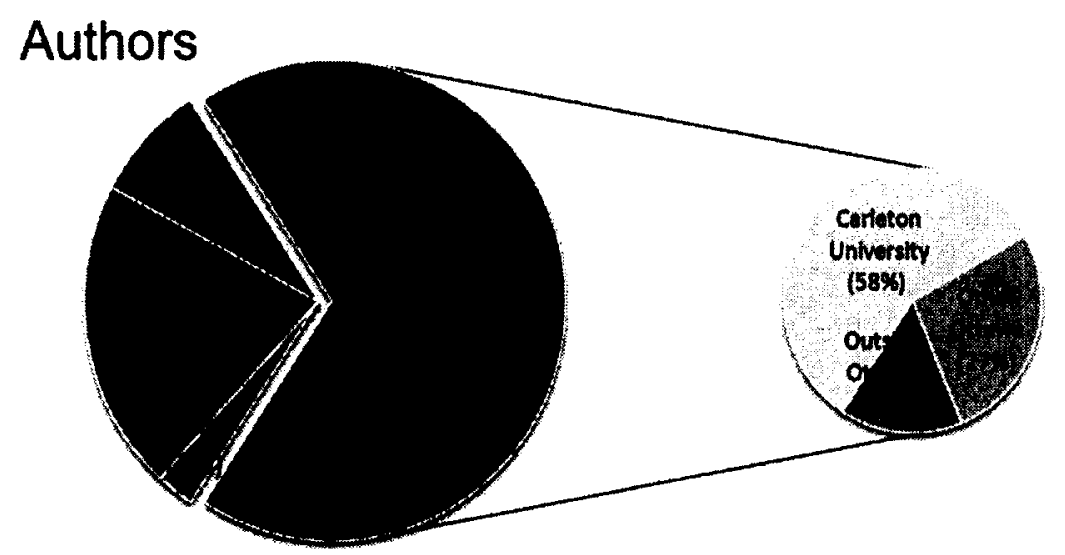

\section{Readers}

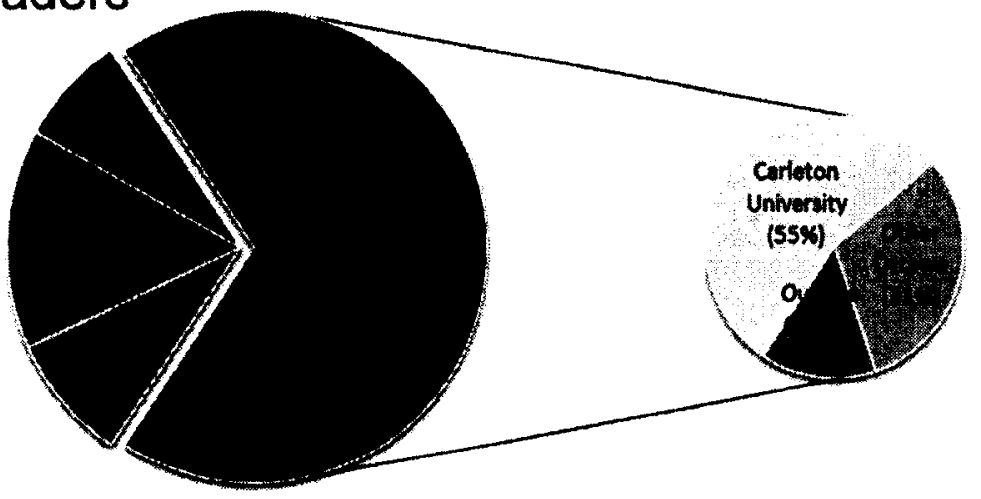

Figure 13. TIM Review author and reader perspectives by location

While management insights have been gleaned from the results presented in this section, caution should be exercised given that these results draw from a relatively small number of user accounts. As of March 21, 2011 only 80 accounts have been created, which includes 37 author accounts. All account holders are considered readers, but this value is very low compared to the total number of unique visitors to the website. Thus, the readership data may not reflect the true perspectives of the readership base. Also, because authors are considered readers, they make a substantial contribution to the readership results, limiting the differences seen between the two groups. 
Finally, the data presented here reflect the diversity within the ecosystem, which should be celebrated and shared with the members of the ecosystem, because this may positively influence ecosystem health and recruitment if the data paint a sufficiently positive picture of the ecosystem. Efforts are underway to develop tools that will display these diversity measures in real-time on the website. Also, I am investigating potential barriers to account creation. Anecdotal reports from users suggests that they have not been deterred from filling out the form, which more than one has described as "quick and easy to complete"; however, these reports come only from users who have completed the form, not those who have decided not to complete it. In any case, it appears that the value proposition to potential account holders is not sufficiently strong to encourage them to create an account. As further engagement and collaboration tools are developed, the value proposition may become stronger. If more users create accounts, the organization can learn more about those users and can share a more accurate picture of the diversity within the ecosystem.

\subsubsection{Immediate Outcome: High levels of contribution and readership}

The activities designed to encourage others to recruit on the organization's behalf and to encourage interaction between stakeholders are expected to increase the levels of contribution and readership. The indicators associated with this immediate outcome are shown in Table 22. 
Table 22. PMF for Immediate Outcome: High levels of contribution and readership

\begin{tabular}{llllll}
\hline Indicators & Baseline Data & Targets & $\begin{array}{l}\text { Data } \\
\text { Sources }\end{array}$ & $\begin{array}{l}\text { Data } \\
\text { Collection }\end{array}$ & Frequency \\
\hline \# visits & Omitted & Omitted & Analytics & Automated & Monthly \\
\hline \# articles & $\sim 6$ per issue & 6 per issue & Website & Manual & Monthly \\
\hline \# RSS subscriptions & $\mathrm{n} / \mathrm{a}$ & Omitted & Website & Automated & Monthly \\
\hline \# Twitter followers & $\sim 500$ & Omitted & Twitter & Automated & Monthly \\
\hline \# comments on articles & Nearly zero & $\begin{array}{l}\text { Avg }>5 \\
\text { per article }\end{array}$ & Website & Automated & Monthly \\
\hline
\end{tabular}

The results relating to the number of visits and articles have been discussed earlier; the key messages were that the results are encouraging but still fall below expectations at this stage in the journal's development.

The indicator related to RSS subscriptions (i.e., web feeds) is another way of measuring readership. However, the tools used to collect data about RSS activity proved unreliable and this indicator was dropped from the performance management framework soon after the launch.

The TIM Review Twitter account (http://twitter.com/timreview) had 602 followers as of March 21, 2011, which reflects modest growth since the account was switched over from the OSBR. I use Twitter to announce new issues and articles and to pass on relevant information to followers. The time demands of the launch and thesis preparation have recently limited my efforts with respect to Twitter. However, I suspect that this is an area where increased effort could yield substantial gains in readership, contribution, and engagement for the organization. 
Finally, the indicator related to the number of comments yielded disappointing results.

The target was more than five comments per article, but only five comments were made on the entire site between October 1, 2011 and March 31, 2012. It was hoped that the new website, with its easier-to-use comments facility, would encourage reader comments, but it did not. The low number of user accounts is a related observation, but further investigation and research are needed to develop strategies for promoting engagement and interaction.

\subsubsection{Intermediate Outcomes}

This section describes how the data related to the performance of the intermediate outcomes of the initial TIM Review logic model are collected and interpreted. It also reports on the associated data collected during the first six months following the launch of the TIM Review. This section is presented in the left-right order that the intermediate outcomes are listed in the logic model (Table 5).

\subsubsection{Intermediate Outcome: Website referred by others as a destination for} knowledge

Once readers are aware of the TIM Review and a substantial body of articles relating to the new scope can be accessed, they will begin to refer others (providing the journal quality and value are sufficiently high). For this intermediate outcome, the indicator tracks the number of referral visits to the TIM Review website (Table 23), that is the number of visitors who reach the website through a link on another website, as opposed 
to directly typing the website address or reaching the website by typing keywords into a search engine.

Table 23. PMF for Intermediate Outcome: Website referred by others as a destination for knowledge

\begin{tabular}{llllll}
\hline Indicators & Baseline Data & Targets & $\begin{array}{l}\text { Data } \\
\text { Sources }\end{array}$ & $\begin{array}{l}\text { Data } \\
\text { Collection }\end{array}$ & Frequency \\
\hline \# referral visits & Omitted & Omitted & Analytics & Automated & Monthly \\
\hline
\end{tabular}

The absolute number of referral visits is not reported here for confidentiality reasons, but it fell below the target. However, related metrics provide an important, related message. Of all visitors between October 1, 2011 and March 31, 2012, 46\% reached the website from a search engine, $26 \%$ reached the website by directly typing a site address (mostly the home page: http://timreview.ca/), and $28 \%$ reached the website by following a link. Of this $28 \%$ referral traffic, the main sources (in order) were:

1. Wikipedia (http://wikipedia.org/), where several TIM Review articles have been referenced. These references had a substantial impact on website traffic.

2. Twitter (http://twitter.com/), where issue announcements are broadcast. Along with email notifications, this is one of the main ways readers find out about new issues. 
3. The Faculty of Graduate and Postdoctoral Affairs website (http://www.carleton.ca/fgpa/) at Carleton University, for which I wrote two cross-promotion articles about fellow TIM students who are also entrepreneurs and included a link to OSBR articles they had written (McPhee, 2011c, 2011d). Additional traffic from the Carleton University website came through an article written about the launch of the TIM Review (Moody, 2011).

\begin{abstract}
Although the absolute number of referral visits to the website fell below the target, the results suggest that individual events can have a strong impact on the results, especially while the journal is in its early stages. For example, the Wikipedia references and the articles on the Carleton website were important sources of referral traffic. They do not add up to a very large absolute number of visits, but they suggest that there is sensitivity in the values and that increased efforts to generate referral traffic can improve readership levels.
\end{abstract}

\title{
5.4.3.2 Intermediate Outcome: Diverse authorship and readership in line with
} scope

This intermediate outcome is meant to draw a link between the diversity of the ecosystem and the diversity of content published within the journal's new scope. The indicators for this outcome track the diversity of perspectives in published issues (Table 24). 
Table 24. PMF for Intermediate Outcome: Diverse authorship and readership in line with scope

\begin{tabular}{llllll}
\hline Indicators & $\begin{array}{l}\text { Baseline } \\
\text { Data }\end{array}$ & Targets & $\begin{array}{l}\text { Data } \\
\text { Sources }\end{array}$ & $\begin{array}{l}\text { Data } \\
\text { Collection }\end{array}$ & Frequency \\
\hline $\begin{array}{l}\text { \# issues with 2 or more } \\
\text { sector perspectives }\end{array}$ & $\begin{array}{l}\text { Not } \\
\text { collected }\end{array}$ & 9 per 12 issues & Website & Manual & Monthly \\
\hline $\begin{array}{l}\text { \# issues with 2 or more role } \\
\text { perspectives }\end{array}$ & $\begin{array}{l}\text { Not } \\
\text { collected }\end{array}$ & 9 per 12 issues & Website & Manual & Monthly \\
\hline $\begin{array}{l}\text { \# issues with 2 or more } \\
\text { geographical perspectives }\end{array}$ & $\begin{array}{l}\text { Not } \\
\text { collected }\end{array}$ & 9 per 12 issues & Website & Manual & Monthly \\
\hline
\end{tabular}

In all cases, the issues published in the first six months of the TIM Review met the performance targets for three indicators. This is likely because a single author may have multiple perspectives, making the targets relatively easy to meet. However, in hindsight, it is not clear that these indicators closely track the performance of the organization toward this particular outcome, especially when considering readers. This outcome and its indicators should be revisited in subsequent revisions of the logic model.

\subsubsection{Intermediate Outcome: Self-sustaining growth of diverse contributions and readership}

The expectation is that the efforts to encourage recruitment, diversity, and interaction will lead to self-sustaining growth of both readership and contributions. This is reflected in the indicators in Table 25. 
Table 25. PMF for Intermediate Outcome: Self-sustaining growth of diverse contributions and readership

\begin{tabular}{llllll}
\hline Indicators & Baseline Data & Targets & $\begin{array}{l}\text { Data } \\
\text { Sources }\end{array}$ & $\begin{array}{l}\text { Data } \\
\text { Collection }\end{array}$ & Frequency \\
\hline Readership growth & Omitted & Omitted & Analytics & Automatic & Monthly \\
\hline$\%$ articles unsolicited & $<10 \%$ & $>50 \%$ & $\begin{array}{l}\text { Email } \\
\text { records }\end{array}$ & Manual & Monthly \\
\hline
\end{tabular}

The specific data about readership growth has been omitted for confidentiality reasons, but, as shown in Figure 10, a substantial increase in the number of unique visitors was experienced in January, 2012 and this higher level has been sustained through March, 2012. However, the periods between October and January and between February and March showed relatively flat visitor numbers. The current levels are substantial, but are still below desirable levels.

Of the 31 articles that were published in the first six issues, only 3 were unsolicited. An unsolicited article is defined as a submission that may have resulted from a general invitation for authors to contribute (i.e., a broadcasted message), but was not the result of invitation to a specific individual. These results are not surprising given that an objective of the initial issues was to demonstrate expertise within the TIM program's ecosystem, which meant that individual invitations were issued to many authors. The current results fall well short of the target of more than $50 \%$ unsolicited articles, however this target may need upward or downward refinement over time as experience with this measure grows. It can also be impacted by different types of recruitment, some of which are highly 
desirable. For example, the guest-editor model for recruiting authors does not many yield unsolicited articles, but it is still a desirable mechanism for expanding the journal's reach.

This outcome would also benefit from additional indicators that measure the diversity of contributions and readership, although these indicators are present in other cells of the performance management framework.

\subsubsection{Ultimate Outcome}

Table 26 shows how data related to the progress toward the ultimate outcome listed in the initial TIM Review logic model are collected and interpreted. The ultimate outcome is: "A popular practitioner-focused journal that delivers value to all stakeholders concerned with the issues relating to launching and growing technology companies".

Table 26. PMF for Ultimate Outcome

\begin{tabular}{llllll}
\hline Indicators & Baseline Data & Targets & $\begin{array}{l}\text { Data } \\
\text { Sources }\end{array}$ & $\begin{array}{l}\text { Data } \\
\text { Collection }\end{array}$ & Frequency \\
\hline \# Unique visitors & omit & omit & Analytics & Automatic & Monthly \\
\hline Stakeholder satisfaction & $\mathrm{n} / \mathrm{a}$ & $\begin{array}{l}\text { Most } \\
\text { satisfied; } \\
\text { none } \\
\text { dissatisfied }\end{array}$ & Survey & Manual & Annual \\
& & & & \\
\hline
\end{tabular}

Progress toward the ultimate outcome is in its early stages, as would be expected:

1. The results relating to the number of unique visitors have been discussed earlier. The key message is that readership growth by the six-month milestone has been 
encouraging, but the absolute levels are somewhat below desirable levels for this stage and are well below what is desirable as an ultimate outcome.

2. A stakeholder satisfaction survey has not yet been conducted. The goal is to initiate this survey around the one-year anniversary of the launch, in October, 2012.

\subsection{Lessons Learned From First Six Issues of the TIM Review}

This section captures lessons learned based on the experience of using the results-based organization design approach to design and run the TIM Review for six months. Section 5.5.1 presents lessons learned about the TIM Review, with an emphasis on the actions these lessons suggest the organization should take. Section 5.5.2 presents lessons learned about the research methodology.

\subsubsection{Lessons Learned About the TIM Review}

During this research study, the following lessons were learned about the TIM Review:

1. Further efforts should be made to recruit high-quality submissions for each issue given that the average number of articles per issue is below six. The organization should develop strategies for identifying and reaching potential readers, authors, and sponsors in the journal's new and wider niche. 
2. Including the responsibility for author and guest editor recruitment in the mandates of the Advisory Board and Review Board does not guarantee that these groups will have suggestions for authors and guest editors. Members were more likely to suggest interesting themes without accompanying names of individuals who might be able to deliver issues relating to these themes. Efforts should continue to find new sources of authors and guest editors.

3. The organization needs to increase representation of the public and third sector on the boards and among readers and authors.

4. To improve the diversity of perspectives, the organization should make greater efforts to increase representation outside of Ottawa.

5. The organization needs to determine whether the topic of economic development should a prioritized in decisions around issue themes, article topics, and contributor recruitment. Alternatively, indicators related to the popularity of topics should be adjusted.

6. Individual articles can have a large effect depending on how they are promoted and who promotes them (e.g., communications channels of large companies, social media links, Wikipedia). Sensitivity in the indicators related to readership levels suggests that increased efforts to generate referral traffic can improve readership levels. 
7. Similarly, an author's networks can have a substantial impact on readership. Authors should be encouraged to help promote their articles and be provided with suggestions of how to do so.

8. Help is needed to support an engagement, social media, and marketing campaign. This represents a time gap as much as it represents a skills gap.

9. Sponsorship recruitment efforts should follow readership growth. The priority at the moment should be to increase readership levels while developing a model for future sponsorship.

10. Possible barriers to account creation and commenting need investigation.

11. Decisions about the development of additional tools to encourage engagement with readers should be made alongside the investigation of barriers into account creation, particularly if those tools require the user to have accounts. Although new tools may strengthen the value proposition to account holders, they might also suffer from neglect if the number of account holders is low.

12. Several performance indicators and targets need refinement or replacement. 
13. A planned dashboard to display indicator data within the administrative screens of the website would be beneficial, provided the tool could be developed and refined in step with refinements to the methodology over time.

\subsubsection{Lessons Learned About the Research Methodology}

The following lessons were learned about the methodology by applying it to the design and operation of the TIM Review:

1. Although the practice-based lessons and research-based lessons were synthesized into design principles, the design process still drew upon the specific insights from the original lessons of both types. In this way, the design principles became helpful reminders about the overall principles guiding the design, and the individual lessons provided specific directions to overcome design challenges.

2. Early design prototyping can helpful inform later design decisions even when the technology selected for the final platform is different.

3. The design principles and higher-level outcomes were useful beyond the practical steps of designing the organization. They can set a tone in the culture of the organization and may influence decision making in subtle ways. 
4. The effort required to construct a meaningful logic model should not be underestimated. This lesson was a surprise; logic models look deceptively simple, but the process of determining the causal links between components is difficult. Although problems can be corrected in subsequent iterations, many downstream actions depend on the logic model, so it is worth spending extra time at the start to make it as sound as possible.

5. It was difficult to know whether key elements were missing from the logic model. A logic model is not an exhaustive list of all activities, outputs, and outcomes; nonetheless, there is no way to verify that the logic model captures all of the important elements. CIDA's approach is to ensure that "the right people are at the table" (CIDA, 2011); the implication is that a participatory approach is more likely to yield meaningful results and ensure that nothing is overlooked. Similarly, the Treasury Board Secretariat (2001) recommends that managers solicit the feedback of "individuals who are familiar with the policy, program, or initiative but who were not part of the working session, to verify that all necessary elements are represented in the model." Still, reviewers are much more likely to point out faults in the elements that are present than to notice what is missing. The logic model development process would benefit from a more rigorous mechanism for determining what the most important components will be and ensuring that they are all captured in the model; such a mechanism would be particularly helpful when the stakeholder pool is small or confidentiality is important. 
6. Practical use of the design revealed problems with the logic model and some indicators and their associated targets, particularly higher up in the logic model. Given that this particular model was built from the bottom up, additional top-down verification (perhaps using dummy data) in the earlystages would have provided a beneficial test of the specific model. While it can be expected that indicators will change over time, especially in light of practical experience, some of the problems with indicators in this research could have been foreseen with additional scrutiny and testing at the time they were created.

7. Related to the previous lesson, a further lesson is that the results should not be taken at face value, particularly if they do not conform to expectations. There may be problems with the indicators, which can be revealed with further investigation. It is worth remembering that the logic model and performance management framework are not perfect, especially at the start; they will evolve over time and the indicators in particular may need to be refined.

8. For some types of data, six months is not a lot of time over which to assess performance. The overall period seems long, but given the effect that individual articles or issue themes can have on the results, six issues do not yield a lot of data for some indicators. 
9. Project-like outputs are helpful during the initial design phase, but can be removed from the logic model once substantially completed, unless any ongoing, lower-level activities substantially contribute to related outcomes.

10. The practical demands of running an organization on a daily basis can impact how frequently the performance management indicators are examined. For most indicators, the goal was to examine the data every month as soon as an issue was published. In practice, this was much easier for some indicators than others. Where data manipulation or manual extraction was required, regular inspection of the data did not always happen. It would be better to automate these processes as much as possible or reduce the number of indicators.

11. Repetition in the performance management framework may signal problems with the logic in the logic model. If an indicator is meant to measure progress toward a particular outcome, and there is a causal link between that outcome and an earlier outcome, output, or activity, then repetition elsewhere in the performance management framework suggests that one of the causal links is incorrect or overlaps conceptually. If designers are confronted by repetition, or are tempted to repeat an indicator, the related areas of the logic model should be re-examined.

12. It is difficult to create measureable long-term outcomes since the concepts have a tendency to become somewhat abstract or repeat indicators used to 
evaluate outcomes lower down in the logic model. Higher-level outcomes likely become more refined (and measurable) over time.

\subsection{Refined Logic Model}

In this final section of Chapter 5, I present a draft of a refined logic model (Table 27), which is based on:

1. The data I have gathered through the first six issues of the TIM Review.

2. New lessons learned through the first six issues of the TIM Review, as outlined in the previous section.

3. Completion of project-like outputs in the initial logic model, which can now be removed.

4. Changes in the external or internal environment, notably a renewed primary focus of the TIM program on technology entrepreneurship and commercialization; the TIM Review will help the program attain a global leadership position in that domain and a new ultimate outcome will reflect this.

5. Increasing pressure to make the journal financially sustainable, because the journal depends, in part, on time-limited funding sources.

6. Additional feedback from stakeholders, including readers.

Overall, the changes to the logic model are intended to improve the organization's sustainability, degree of collaboration, and reach. The new logic model is grounded by the same design principles as the logic model described in Table 5. However, along with 
the new practice-based lessons and research-based lessons described in Chapter 4 and 5 , which contribute back to the domain, the refinement of the logic model completes the first loop of the organization design cycle. 


\begin{tabular}{|c|c|c|c|c|c|c|c|}
\hline \multirow{2}{*}{$\begin{array}{l}\text { Ultimate } \\
\text { Outcome } \\
\text { Intermediate } \\
\text { Outcome } \\
\text { (changes in } \\
\text { practice and } \\
\text { behaviour) }\end{array}$} & \multicolumn{7}{|c|}{ A practitioner-focused joumal that holds a dominant global position in the field of technology entrepreneurship and commercialization } \\
\hline & $\begin{array}{l}\text { Website } \\
\text { referred by } \\
\text { others as a } \\
\text { destination for } \\
\text { knowledge }\end{array}$ & \multicolumn{4}{|c|}{ Diverse authorship and readership in line with scope } & $\begin{array}{l}\text { Financial } \\
\text { sustainability, } \\
\text { allowing } \\
\text { increased staff and } \\
\text { expenditures to } \\
\text { grow the journal }\end{array}$ & $\begin{array}{l}\text { Journal becomes } \\
\text { a hub where } \\
\text { contributors } \\
\text { come to both } \\
\text { shape and } \\
\text { consume content }\end{array}$ \\
\hline $\begin{array}{l}\text { Immediate } \\
\text { Outcome } \\
\text { (changes in } \\
\text { access, ability, } \\
\text { and awareness) }\end{array}$ & $\begin{array}{l}\text { Increased } \\
\text { access to } \\
\text { articles and } \\
\text { awareness of } \\
\text { new } \\
\text { publication }\end{array}$ & \multicolumn{2}{|c|}{$\begin{array}{l}\text { Greater input into themes, } \\
\text { authors, and guest editors }\end{array}$} & $\begin{array}{l}\text { Users attracted to } \\
\text { articles that closely } \\
\text { fit with new brand }\end{array}$ & $\begin{array}{l}\text { Increased } \\
\text { awareness of } \\
\text { diversity of } \\
\text { readers and } \\
\text { authors }\end{array}$ & Revenue & $\begin{array}{l}\text { High levels of } \\
\text { contribution and } \\
\text { readership }\end{array}$ \\
\hline Outputs & $\begin{array}{l}\text { Promotion } \\
\text { campaign }\end{array}$ & $\begin{array}{l}\text { Advisory } \\
\text { Board } \\
\text { composed } \\
\text { of salient } \\
\text { stakeholders }\end{array}$ & $\begin{array}{l}\text { Engagement } \\
\text { campaign }\end{array}$ & $\begin{array}{l}\text { Published issues } \\
\text { that match new } \\
\text { scope }\end{array}$ & $\begin{array}{l}\text { Improved } \\
\text { account } \\
\text { creation } \\
\text { process }\end{array}$ & Business model & $\begin{array}{l}\text { Tools to promote } \\
\text { collaboration } \\
\text { (e.g., wiki-like } \\
\text { literature } \\
\text { reviews, forums) }\end{array}$ \\
\hline Activities & $\begin{array}{l}\text { Promote } \\
\text { journal to } \\
\text { different } \\
\text { stakeholder } \\
\text { groups }\end{array}$ & $\begin{array}{l}\text { Gather } \\
\text { feedback, } \\
\text { define board } \\
\text { mandate, } \\
\text { recruit } \\
\text { diverse } \\
\text { board } \\
\text { members }\end{array}$ & $\begin{array}{l}\text { Engage with } \\
\text { readers and } \\
\text { authors to } \\
\text { refine value } \\
\text { propositions, } \\
\text { suggest } \\
\text { themes, and } \\
\text { recruit }\end{array}$ & $\begin{array}{l}\text { Formally recruit } \\
\text { authors and } \\
\text { partnerships that } \\
\text { will bring expertise } \\
\text { in new scope } \\
\text { (especially } \\
\text { technology } \\
\text { entrepreneurship) }\end{array}$ & $\begin{array}{l}\text { Research } \\
\text { barriers to } \\
\text { account } \\
\text { creation and } \\
\text { encourage } \\
\text { readers to } \\
\text { create } \\
\text { accounts }\end{array}$ & $\begin{array}{l}\text { Develop a } \\
\text { business model } \\
\text { with a focus on } \\
\text { sponsorship }\end{array}$ & $\begin{array}{l}\text { Encourage } \\
\text { interaction } \\
\text { between } \\
\text { stakeholders and } \\
\text { provide } \\
\text { opportunities to } \\
\text { shape content }\end{array}$ \\
\hline $\begin{array}{l}\text { Design } \\
\text { Principles }\end{array}$ & \multicolumn{3}{|c|}{ Value Propositions } & Shared Outcomes & \multicolumn{3}{|c|}{ Ecosystem Health } \\
\hline
\end{tabular}


Key differences between the initial logic model presented in Table 5 and the logic model in Table 27 are:

1. Refinement of the ultimate outcome to: "A practitioner-focused journal that holds a dominant global position in the field of technology entrepreneurship and commercialization". This outcome closely aligns with the objectives of the TIM program and is more readily measurable than the previous ultimate outcome.

2. Inclusion of outcomes relating to financial sustainability and collaborative engagement (i.e., opportunities for contributors to shape content in different ways beyond writing static articles).

3. Outputs related to marketing, promotion, and partnerships.

The next step is to circulate this draft logic model to the Advisory Board for feedback. The final version of this redesigned logic model (and performance management framework) will thereby give me direction to proceed with agreed activities for the near future. The Advisory Board will share ownership of this logic model and the mandate it provides. 


\section{Discussion}

Chapter 6 summarizes the key findings of the research presented in this thesis. Section 6.1 discusses results of this research. Section 6.2 connects this research to the literature in the relevant domains.

\subsection{Discussion of Results}

In sub-sections that follow, Section 6.1.1 discusses the results from applying the resultsbased organization design to the transformation of the OSBR into the TIM Review, Section 6.1.2 describes the extent to which this research is repeatable, and Section 6.1.3 interprets several idiosyncrasies of the research.

\subsubsection{Applying Results-Based Organization Design to the TIM Review}

The results described in Chapter 5 demonstrate one cycle of the results-based organization design approach. Starting with lessons from practice and theory, design principles were synthesized. These design principles were then used to ground the development of a logic model and its associated performance management framework, which in turn informed the development and implementation of the design. Once the design solution was operational, the organization's performance was assessed using indicators from the performance management framework. Based on the analysis of the data collected, refinements were made to the upstream components, which closed the feedback loop and initiated a new design cycle. 
This approach was developed and applied to the construction of the TIM Review organization as the focus of this research. Six months following the publication of the first issue of the new journal, the data analysis reveals the potential for this research methodology to guide management decisions and to provide a mechanism for continuous improvement to the organization.

Most organizations use some form of data to measure their progress, even if the desired long-term outcomes of the organization have not been articulated. However, the approach described here provides a clear mechanism for managers to decide, in advance, what data should be collected, why it is being collected, and what the results indicate. All of this is in accordance with a map of the activities and outputs that can be expected to lead to the desired outcomes because they are causally linked and grounded in lessons from both practice and theory. An important benefit of such a rigorous design framework can be seen in the list of lessons learned (Section 5.5.1): most of these lessons suggest clear managerial actions to guide changes. Thus, with the desired outcomes of a design predefined and causally linked to activities and outputs, the evaluation of the design solution's performance provides a continuous and direct path to action.

Finally, a key benefit of this approach is that it is embedded into the design of the organization; therefore, the approach will inform the ongoing operation and management of the organization beyond the timescales described in this research study. 


\subsubsection{Scope of Applicability}

The general approach developed through this research (i.e., results-based organization design) is applicable beyond the scope of this research context. Broadly, the approach can be applied to any design challenge where a framework for ongoing measurement and improvement would be beneficial. However, there may be limitations that relate to the innovation and timescales.

Due to the linearity of the logic underpinning results-based management and the need to develop performance indicators to track progress against outputs and outcomes in the logic model, this research methodology may not be suitable when innovation through rapid iteration and non-linearity is an objective. In such situations, a logic model may not be appropriate; non-linear processes may be desirable and lead to new combinations of ideas (Gamble, 2008). Clark and Swain similarly caution against results-based management approaches for "unique, creative, or highly discretionary activities, or to activities that are causally distant from the desired outcomes." Using this approach with innovation strategies that depends on rapid iteration also may not be appropriate, given the time and care required to develop a sound logic model and associated performance management framework. Timescales are also relevant here. Rapid iteration may depend upon immediate performance results, which this approach is not ideally suited to deliver. Consider technology startups as an example where the approach might be applied; in this context, the points above suggest that the approach may be better suited to the design of the companies themselves than to the design of their products. 
The specific design solution described in this thesis is repeatable, but it is tailored to the context of the TIM Review. However, aspects of the design are generalizable to related contexts, such as other publications or other keystone organizations. In this way, not only can the research methodology be applied, but the design rules, elements of the logic model and performance management framework, and the lessons learned can be applied to related design challenges. However, the research methodology and design solution are not equivalent to a recipe that anyone can follow; they depend on specific practical knowledge about the domain and context.

\subsubsection{Idiosyncrasies}

In this context, idiosyncrasies refer to unique or peculiar aspects of the research that depend on the specific context within which it was conducted. The following list considers idiosyncrasies of the research by asking how the research outcomes might be different if these aspects of the research context were different:

1. Strictly speaking, this research describes the re-design of an existing organization, not the design of a new organization. Given that "much organization design is redesign" (Jelinek et al., 2008), this aspect of the research is perhaps not idiosyncratic; however it is instructive to ask how the research outcomes might have been different if the TIM Review were being built from scratch. One key difference might be the lack of practice-based lessons with which to formulate design principles. Even where practice-based lessons are available, they would likely be from a rather different context compared with the evolutionary 
transformation of the OSBR into the TIM Review. Similarly, there would be a lack of a starting point in terms of articles, readers, author networks, and brand. For example, even before the first issue of the TIM Review was published, the organization possessed a subscriber list and a pool of existing articles that had been migrated to the new website. Not only were the shelves not empty, neither was the rolodex. If the organization were starting from scratch, many additional activities might have focused on promotion and ensuring the website provided sufficient value to readers beyond the small initial batch of articles. As a redesign, it was not only the TIM Review that benefited from these pre-existing assets; the research also benefitted from having early data, both in the sense of instant traffic to the website with minimal promotion and by the existence of baseline data against which to compare progress.

2. A unique aspect of this research is my dual position as Editor-in-Chief of the journal and as graduate student in the academic program that is the journal's most salient stakeholder. Thus, key members of the Advisory Board are also my professors, one of which is supervising this research. In my dual position, I have been given a substantial amount of freedom to act in the organization's best interests; this freedom is part of the academic culture of the organization, which emphasizes experiential learning and experimentation. But how might the research and results be different if the power relationships were different? Imagine a setting where, for example, I held more power than the key stakeholders. On one hand, it is tempting to think that the outcomes of branding 
decisions, for example, might have been different. Similarly, the scope of the journal might not be so closely tied to the scope of the TIM program. On the other hand, regardless of these power relationships, the TIM program is an important complementary asset for the TIM program and perhaps these aspects of the design might be similar despite a different power balance or power relationship, for example if the TIM program were my client.

3. A unique aspect of the TIM Review is that single person is responsible for nearly all of the day-to-day activities. This aspect offers advantages in terms of efficiency and commitment, but has disadvantage in terms of time demands and the limited perspective imposed by a single point of view. How might this research be different if it centred on a large company with many employees? Likely, the research processes and lessons would identify challenges in encouraging "buy in" at all levels of the organization. For example, I am responsible for collecting all of the data in the performance management framework for the TIM Review. This is relatively straightforward because I am responsible for each of these areas and have access to the related data. On one hand, in a large company, the task of gathering data for each of the indicators might cross many internal boundaries and require substantial effort to regularly obtain, format, and interpret the latest version of each data type. These challenges can be substantial; even with the TIM Review, some of the website data was not easily extracted and I needed hire a development team to extract a single spreadsheet containing most of the data about user accounts so that it could be 
processed more efficiently. On the other hand, a large company might be able to devote sufficient human resources to the data collection problem that the ownerresearcher is free to focus on other activities.

4. My existing editorial skills and previous industry experience were a good fit for experiential learning as Editor-in-Chief of the OSBR, particularly when complemented by the more pedagogic elements of graduate studies in the TIM program. How might the research have been different if my experiential domain knowledge were different or if the experiential learning component were absent? As an example, without domain knowledge related to journals and editing, it would not only have been impossible to undertake the editorial functions of the journal; it would have been difficult to extract insights that would help develop value propositions for authors and readers. Also, it is worth remembering that the practice-based lessons that were directly linked to this unique context were a direct result of experiential learning from running the OSBR for more than a year.

\subsection{Theoretical Connections and Research Contribution}

This section draws connections between this research and related theoretical domains, including the contribution that the research makes to those domains. Section 6.2 .1 links the research to the constructive research domain. Section 6.2.2 links the research to the organization design and results-based management domains. Section 6.2 .3 links the research to the business ecosystem domain. Section 6.2.4 links the research to the domain of journal design. 


\subsubsection{Constructive Research}

The research presented here has been conducted from a unique standpoint. It is common for management research to feature research in real-world scenarios, but the typical research team is disconnected from the practical setting. Recommendations may be offered, but the perspective is very much of an "outsider". In other cases, researchers move closer to the research subject as "participant-observers". Here, researchers may be active participants, able to shape the outcome of the research through a hands-on perspective that may even involve a constructive approach. Even so, typical constructivist approaches depict the researcher as a "craftsmen" (see Mir \& Watson, 2000 and references therein), acting in their own interests and on behalf of an owner to create a real-world solution that has a theoretical basis.

In the research presented here, the perspective is novel. As both researcher and owner, the relationship to the subject of study is much closer. I am the researcher in the sense that I must develop and apply a rigorous methodology that is grounded in theory. I am the owner in the sense that the TIM Review is a real-world organization that is "mine to grow and mine to break". Thus, ownership represents unrestricted access and the ability to fundamentally shape the organization through this constructive research.

In constructive research, "the separation of the researcher (subject) and the phenomena under investigation (object) is not feasible" (Mir \& Watson, 2000); this is particularly relevant with the researcher-owner perspective, where this separation is not only not feasible, it is not desirable. Constructive research already faces criticisms about a lack of 
objectivity, which Mir and Watson (2000) counter by pointing out that constructivists openly acknowledge that "researchers are never 'objective' or value-neutral." When the researcher is also an owner, this lack of objectivity can be beneficial. Ownership provides a real-time, subjective perspective on solutions that is difficult to replicate. In particular, the researcher-owner perspective eliminates gaps in understanding, which leads to a more direct reading of the connections between practice and theory, particularly when developing design principles. Also, as a real-time design challenge, the ownership perspective puts beneficial pressure on the need for the design solution to achieve positive results. In closed environments, the failure of constructive research projects provides valuable learning. In real-time, ownership-driven research, the failure of constructive research is destructive, at least to the owner and those that depend on the value the real-world organization delivers.

\subsubsection{Organization Design and Results-Based Management}

By combining organization design with results-based management, the methodology developed in this thesis not only gains the benefits of each of these approaches, it contributes back to both theoretical domains. Below, the benefits and gaps of both approaches are summarized to show how the two approaches are complementary.

The key benefits of the organization design approach are: i) the synthesis of practicebased lessons and research-based lessons into design principles that guide subsequent design steps and ii) a closed-loop framework for making continuous refinements to the design. However, the drawbacks of this approach are: i) the lack of specific guidance on 
how to relate design elements to outcomes on different timescales and ii) the lack of a specific, practical mechanism for closing the feedback loop based on data gathered after the design solution is implemented.

The key benefits of the results-based management approach are: i) a practical framework for demonstrating the causal links between activities, outputs, and outcomes on different timescales and ii) a practical mechanism for indentifying indicators that will track the performance of elements in the logic model. However, the drawbacks of this approach are: i) the lack of theoretical grounding in the logic model and ii) the lack of a specific mechanism to make improvements based on the performance data.

The combination of these two approaches retains the key benefits of each approach, while at the same time closing the gaps contained in both of these complementary approaches. Therefore, the combined approach of results-based organization design should be of interest to scholars in both domains.

\subsubsection{Business Ecosystems}

This research contributes to the literature of business ecosystems by providing a methodology that can be used to design keystone organizations. Although the functions and responsibilities of a keystone organization are described in the literature, there is little practical guidance about how such organizations should be designed. This research provides not only a methodology for others to follow; it is a practical example with insights and lessons that may be beneficial to others. 


\subsubsection{Journal Design}

Most articles relating to journal design focus on the physical design of publications or aspects that are quite specific to strictly academic settings. There is little literature on how to design the organizations that produce journals. Thus, this research makes a contribution to the literature by beginning to address the gap relating to designing and improving an organization that produces and delivers content. 


\section{Conclusions, Limitations, and Future Research}

Chapter 7 provides the conclusions about the research described in this thesis, the limitations of the research, and suggestions for future research. Section 7.1 provides the conclusions. Section 7.2 lists the limitations of the research. Section 7.3 suggests areas for future research.

\subsection{Conclusions}

The "results-based organization design" approach gives designers a means to: i) ground design decisions in theory and practice; ii) build a logical framework that describes how desired outcomes will be achieved at multiple timescales; iii) measure progress toward those outcomes; and iv) effect ongoing change to improve the organization's ability to deliver desired outcomes. This combination of a design cycle from the domain of organization design and a complementary results-based management approach is synergistic; it combines the benefits of each approach while their closing gaps.

Through the construction of the TIM Review, this research demonstrates how the resultsbased organization design approach can bridge the gap between theory and practice by providing a means to inform design with theory and contribute to theory through practice.

The first application of the results-based organization design approach confirmed the potential the methodology holds for providing real-time feedback on the organization's performance and providing a mechanism for acting upon this feedback to improve the organization. Evidence of this potential was seen in the lessons learned from the first six months of operating the TIM Review. These lessons not only feed back into ongoing 
design improvements through the embedded methodology, they can now be shared with other researchers and practitioners, thereby informing future research and the construction of other organizations.

\subsection{Limitations}

The following limitations of this research have been identified:

1. Due to time limitations for completing this thesis, only one full cycle of the results-based organization design approach is discussed. Further cycles would not only provide more data, but would better illustrate how the approach can lead to changes at any point in the design cycle. With the inclusion of a draft of a refined logic model, it can be argued that the thesis reports on more than a full cycle, but further insights would come from re-design processes at every point along the cycle. It would also be informative to see whether multiple cycles deliver on the promise of ongoing improvement, rather than just further change.

2. As constructive research, the design solution's credibility depends on its successful implementation and functioning in a real-world context (Lukka \& Kasanen, 1995); however this research has not yet passed a strong market test. The design solution presented in this research has been successfully implemented and this thesis reports on its initial functioning in the real-world context of the TIM Review over a six-month period. However, this level of implementation means the solution has only passed a weak market test. A semi-strong market test is passed when a solution is adopted widely by other organizations; a strong 
market test is passed when the solution has been demonstrated to deliver systematically better financial results (Kasanen et al., 1993). Opportunities to apply variants of the design solution described here exist even within the TIM program's ecosystem. If others are sufficiently persuaded by the value of this approach, semi-strong and strong market tests may follow.

3. It is difficult to evaluate the ultimate success of the research when the timelines for intermediate and ultimate outcomes for the organization that was constructed are much longer than the research study, at least in terms of time limits for completing a thesis related to the early results of ongoing research. In their guidance about results-based management, CIDA cautions that "the results chain must identify outputs and outcomes that are achievable during the project's lifetime. Impact, however, may only be visible after the project's completion." (CIDA, 2000). Thus, evaluation of the impact of the research must be separate from evaluation of the impact of the organization. Even if the organization fails to meet its outcomes, the research could be deemed successful in academic terms. It will be months or years before the TIM Review's ultimate outcome can be reached; however the early indications about the success of the organization are positive.

\subsection{Future Research}

This research has generated the following suggestions for future areas of study: 
1. The research methodology, including the design principles, can be replicated in the design or re-design of another keystone organization that publishes content.

2. The research methodology, including the design principles, can be applied to the design or re-design of another keystone organization in an adjacent context (e.g., startup technology companies, mentorship programs for entrepreneurs).

3. A study could specifically focus on refining the design principles, especially relating to the design of keystone organizations. The design principles developed here could provide a useful starting point.

4. General tools could be developed through research to support the methodology.

5. Specific tools could be developed through research to support the performance management framework of the TIM Review. A dashboard that automatically tracks the indicators and issues alerts when the data fall outside preset parameters would add considerable value.

6. Finally, the TIM Review organization itself is a source of future research. This thesis reports on the early findings of a research methodology that is embedded within the TIM Review. 


\section{References}

Adner, R. 2006. Match your innovation strategy to your innovation ecosystem. Harvard Business Review, 84(4): 98-107.

Anderson, J. C., Narus, J. A., \& Van Rossum, W. 2006. Customer Value Propositions in Business Markets. Harvard Business Review, (March 2006).

Aslett, M. 2011. The decline of 'open source' as an identifying differentiator. The 451 Group. http://blogs.the451 group.com/opensource/2011/06/27/the-decline-ofopen-source-as-an-identifying-differentiator/, February 10, 2012.

Bailetti, T. 2010a. Keystone Off-The-Shelf. Open Source Business Resource, (September 2010).

Bailetti, T. 2010b. Blueprint and approach to grow revenue in small technology companies. Open Source Business Resource, (June 2010).

Boudreau, K. J., \& Hagiu, A. 2009. Platform Rules: Multi-Sided Platforms as Regulators. Platforms, Markets and Innovation: 163-191. Northampton, MA: Edward Elgar Publishing, Inc.

Brown, P. O., Eisen, M. B., \& Varmus, H. E. 2003. Why PLoS Became a Publisher. PLoS Biol, 1(1).

Van Burg, E., Romme, A. G. L., Gilsing, V. A., \& Reymen, I. M. M. J. 2008. Creating University Spin-Offs: A Science-Based Design Perspective. Journal of Product Innovation Management, 25(2): 114-128.

Carleton University. 2009. Defining Dreams: A Strategic Plan for Carleton University 2009. http://www1.carleton.ca/about/cu/wpcontent/uploads/strategic_plan_final.pdf, December 1, 2011. 
CIDA. 2000. RBM Handbook on Developing Results Chains. Ottawa: Canadian International Development Agency.

CIDA. 2008. Results-based Management Policy Statement 2008. http://acdicida.gc.ca/acdi-cida/acdi-cida.nsf/eng/ANN-102084042-GVJ, November 30, 2011.

CIDA. 2011. Results-Based Management Tools at CIDA: A How-to Guide. http://www.acdi-cida.gc.ca/acdi-cida/ACDI-CIDA.nsf/eng/NAT-92213444-N2H, November 5, 2011.

Clark, I. D., \& Swain, H. 2005. Distinguishing the real from the surreal in management reform: suggestions for beleaguered administrators in the government of Canada. Canadian Public Administration, 48(4): 453-476.

Clarke, R., \& Kingsley, D. 2008. e-Publishing's Impacts on Journals and Journal Articles. Journal of Internet Commerce, 7(1): 120.

Denyer, D., Tranfield, D., \& van Aken, J. E. 2008. Developing Design Propositions through Research Synthesis. Organization Studies, 29(3): 393-413.

Eisenhardt, K. M., \& Sull, D. N. 2001. Strategy as Simple Rules. Harvard Business Review, 79(1): 106-116.

Evans, D. S., Hagiu, A., \& Schmalensee, R. 2006. Invisible Engines: How Software Platforms Drive Innovation and Transform Industries (1st ed.). Cambridge, MA: The MIT Press.

Freeform Solutions. 2011. Get your open source ideas published. Freeform Solutions (@free4orm). http://twitter.com/\#!/free4orm/status/79284329993351168, April $11,2012$. 
Freeman, R. E., Wicks, A. C., \& Parmar, B. 2004. Stakeholder Theory and 'The Corporate Objective Revisited'. Organization Science, 15(3): 364-369.

Gamble, J. A. A. 2008. A Developmental Evaluation Primer. Montreal: The J.W. McConnell Family Foundation.

Iansiti, M., \& Levien, R. 2002. The new operational dynamics of business ecosystems: Implications for policy, operations and technology strategy. Harvard Business School Working Paper, (03-030).

Iansiti, M., \& Levien, R. 2004a. The Keystone Advantage: What the New Dynamics of Business Ecosystems Mean for Strategy, Innovation, and Sustainability. Harvard Business Press.

Iansiti, M., \& Levien, R. 2004b. Strategy as ecology. Harvard Business Review, 82(3): $68-78$.

Iansiti, M., \& Levien, R. 2004c. Keystones and dominators: Framing operating and technology strategy in a business ecosystem. Harvard Business School Working Paper, (03-061).

Jelinek, M., Romme, A. G. L., \& Boland, R. J. 2008. Introduction to the Special Issue: Organization Studies as a Science for Design: Creating Collaborative Artifacts and Research. Organization Studies, 29(3): 317-329.

Jones, T. M., Felps, W., \& Bigley, G. A. 2007. Ethical Theory and Stakeholder-related Decisions: The Role of Stakeholder Culture. Academy of Management Review, 32(1): $137-155$. 
Kasanen, E., Lukka, K., \& Siitonen, A. 1993. The Constructive Approach in Management Accounting Research. Journal of Accounting Management Research, 5(Fall): 343-264.

Kling, R., \& Callahan, E. 2003. Electronic journals, the Internet, and scholarly communication. Annual Review of Information Science and Technology, 37(1): $127-177$.

Lavigne, D. 2007a. Editorial: Introducing the OSBR. Open Source Business Resource, (July 2007).

Lavigne, D. 2007b. OSBR Editorial Policies. Open Source Business Resource. http://osbr.ca/ojs/index.php/osbr/about/editorialPolicies\#focusAndScope, July 5 , 2011.

Lukka, K., \& Kasanen, E. 1995. The problem of generalizability: anecdotes and evidence in accounting research. Accounting, Auditing \& Accountability Journal, 8(5): $71-90$.

Mayne, J. 2007. Challenges and Lessons in Implementing Results-Based Management. Evaluation, 13(1): 87-109.

McPhee, C. 2011 a. Reflecting on Fifty Issues of the OSBR. Open Source Business Resource, (August 2011).

McPhee, C. 201 lb. Home | TIM Review. Technology Innovation Management Review. http://timreview.ca/, February 12, 2012.

McPhee, C. 2011 c. Carleton Grad Student Helps Cities Give People a Voice. Carleton University Faculty of Graduate and Postdoctoral Affairs. 
http://www5.carleton.ca/fgpa/2011/carleton-entrepreneur-helps-cities-give-thepeople-a-voice, April 13, 2012, Ottawa.

McPhee, C. 2011d. Carleton Entrepreneur Makes His Mark on Real and Virtual Worlds. Carleton University Faculty of Graduate and Postdoctoral Affairs. http://www5.carleton.ca/fgpa/2011/carleton-entrepreneur-leaves-his-mark-in-realand-virtual-worlds, April 13, 2012, Ottawa.

McPhee, C., \& Bailetti, T. 201 1a. Editorial: Collectives. Open Source Business Resource, (April 2011).

McPhee, C., \& Bailetti, T. (Eds.). 2011b. Open Source Business Resource - April 2011: Collectives. Ottawa: Talent First Network.

Mir, R., \& Watson, A. 2000. Strategic management and the philosophy of science: the case for a constructivist methodology. Strategic Management Journal, 21(9): 941-953.

Moghaddam, G. G. 2009. Why are scholarly journals costly even with electronic publishing? Interlending \& Document Supply, 37(3): 149-155.

Moody, L. 2011. Carleton Launches Innovative New Online Technology Review. Carleton University Faculty of Graduate and Postdoctoral Affairs. http://wwwl.carleton.ca/graduate/2011/carleton-launches-innovative-new-onlinetechnology-review, April 13, 2012, Ottawa.

Moore, J. F. 1993. Predators and prey: A new ecology of competition. Harvard Business Review, 71(3): 75-86.

Moore, J. F. 2006. Business ecosystems and the view from the firm. Antitrust Bulletin, $51: 31$. 
Moraes, E. 2010. Assessing Trust Between Members of a Marketplace. Open Source Business Resource, (September 2010).

Office of the Auditor General of Canada. 2000, November 30. Implementing ResultsBased Management: Lessons from the Literature. http://www.oagbvg.gc.ca/internet/English/meth_gde_e_10225.html, Apri1 5, 2012.

Olson, M. 1965. The logic of collective action: public goods and the theory of groups. Harvard University Press.

Ortiz, E. F., Kuyama, S., Münch, W., \& Tang, G. 2004. Implementation of ResultsBased Management in the United Nations Organizations. http://www.unjiu.org/data/reports/2004/en2004_6.pdf, April 6, 2012, Geneva: United Nations Joint Inspection Unit.

Paine, R. T. 1969. A note on trophic complexity and community stability. The American Naturalist, 103(929): 91-93.

Power, M. E., Tilman, D., Estes, J. A., Menge, B. A., Bond, W. J., Mills, L. S., et al. 1996. Challenges in the quest for keystones. BioScience, 46(8): 609-620. , June $1,2010$.

PricewaterhouseCoopers LLP, \& Interis Consulting Inc. 2009. Five-Year Evaluation of the Management Accountability Framework. http://www.tbs-sct.gc.ca/mafcrg/implementation-implementation/fye-eq/fye-eq03-eng.asp, May 8, 2012.

Romme, A. G. L., \& Endenburg, G. 2006. Construction Principles and Design Rules in the Case of Circular Design. Organization Science, 17(2): 287-297.

Schacter, M. 2007. In Defence of Results-Based Management. Public Sector Management, 18(1). 
Sherrill, J. 2011. August OSBR open. DragonFly BSD Digest.

http://www.shiningsilence.com/dbsdlog/2011/06/11/7945.html, April 11, 2012.

Suehle, R. 2012. Q\&A. What Is the Secret of Red Hat's Success? Technology

Innovation Management Review, (January 2012): 25-28.

Treasury Board Secretariat. 2001. Guide for the Development of Results-based

Management and Accountability Frameworks. http://www.tbs-

sct.gc.ca/cee/tools-outils/rmaf-cgrr/guide-eng.pdf, April 5, 2012, Ottawa:

Treasury Board Secretariat.

Treasury Board Secretariat. 2011. Management Accountability Framework.

http://www.tbs-sct.gc.ca/maf-crg/index-eng.asp, May 8, 2012.

Weiss, M. 2011. Control and Diversity in Company-led Open Source Projects. Open

Source Business Resource, (April 2011). 